\title{
Get the picture ? A cognitive-psychological approach to systematic health education materials design
}

Citation for published version (APA):

Kools, M. (2006). Get the picture ? A cognitive-psychological approach to systematic health education materials design. [Doctoral Thesis, Maastricht University]. Datawyse / Universitaire Pers Maastricht. https://doi.org/10.26481/dis.20060127mk

Document status and date:

Published: 01/01/2006

DOI:

10.26481/dis.20060127mk

Document Version:

Publisher's PDF, also known as Version of record

\section{Please check the document version of this publication:}

- A submitted manuscript is the version of the article upon submission and before peer-review. There can be important differences between the submitted version and the official published version of record.

People interested in the research are advised to contact the author for the final version of the publication, or visit the DOI to the publisher's website.

- The final author version and the galley proof are versions of the publication after peer review.

- The final published version features the final layout of the paper including the volume, issue and page numbers.

Link to publication

\footnotetext{
General rights rights.

- You may freely distribute the URL identifying the publication in the public portal. please follow below link for the End User Agreement:

www.umlib.nl/taverne-license

Take down policy

If you believe that this document breaches copyright please contact us at:

repository@maastrichtuniversity.nl

providing details and we will investigate your claim.
}

Copyright and moral rights for the publications made accessible in the public portal are retained by the authors and/or other copyright owners and it is a condition of accessing publications that users recognise and abide by the legal requirements associated with these

- Users may download and print one copy of any publication from the public portal for the purpose of private study or research.

- You may not further distribute the material or use it for any profit-making activity or commercial gain

If the publication is distributed under the terms of Article $25 \mathrm{fa}$ of the Dutch Copyright Act, indicated by the "Taverne" license above, 


\section{Get the picture?}

A cognitive-psychological approach to systematic health education materials design 


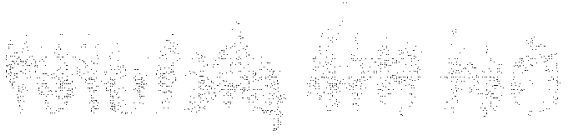

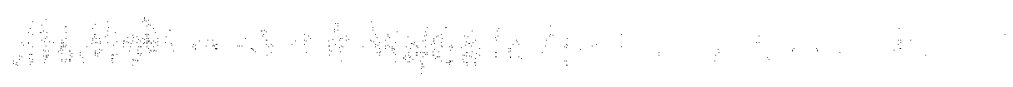

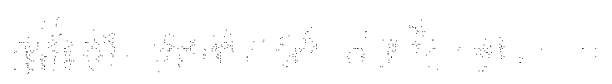




\section{Get the picture?}

\section{A cognitive-psychological approach to systematic health education materials design}

proefschrift

ter verkrijging van de graad van doctor aan de Universiteit Maastricht, op gezag van de Rector Magnificus, prof.mr. G.P.M.F.Mols,

volgens het besluit van het College van Decanen, in het openbaar te verdedigen op vrijdag 27 januari 2006 om 12.00 uur door

Marieke Kools

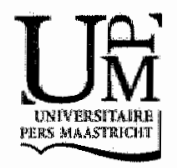


promotor

Prof.dr.G.Kok

co-promotors

Dr.R.A.C. Ruiter

Dr. MW. van de Wiel

beoordelingscommissie

Prof. dr. H.L.GJ, Merckelbach (voorzitter)

Prof, dr. A Hartley (University of Keele, UK)

Dr.l.Mesters

Dr. H. van Oostendorp (Universiteit Utrecht)

Prof.dr. N.K. deVries

colophon

Lay-out/Graphic design: Maarten Schrijvers $\Theta$

Cover and Illustrations: Hanneke Kools (9)

Production: Datawyse | Universitaire Pers Maastricht

C Marieke Kools, Maastricht, 2005

All rights reserved

ISBN 9052784965

The research was funded by a grant from The Netherlands Organisation of Health Research and Development (ZonMw), Grant 2200.0086. 


\section{Contents}

Chapter 1

Chapter 2

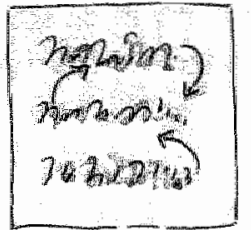

Chapter 3

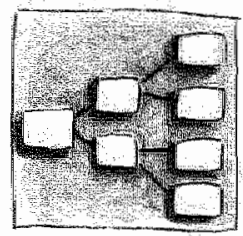

Chapter 4

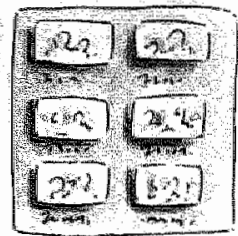

Chapter 5

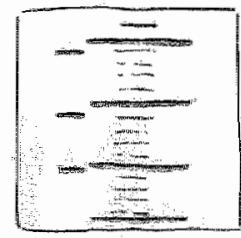

Chapter 6

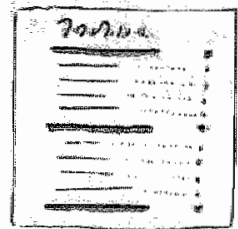

Chapter 7

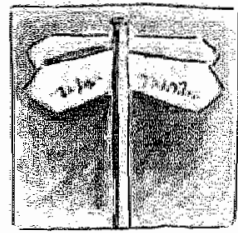

Chapter 8

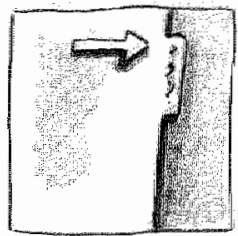

Chapter 9

Summary

Samenvatting

References
General Introduction

Increasing readers' comprehension of

health education brochures: A qualitative study in to how professional writers make texts coherent

1

subjective and objective comprehension of a health education text medical devices: Effects on recall and actual performance

The effects of headings in a brief health education text on locating speed and evaluation

Access structures help readers locate and remember information in a health education brochure

The understandability of pictorials in a health education brochure

Testing the usability of acces 5 structures in health education brochures

General discussion: Implications for health education practice 
With a word of thanks the disadvantage of text is that it is sequential, implying a hierarchy of importance. Everyone I want to thank here has contributed to this thesis equally much, in their own way. Therefore, start reading this page from the center to whichever point you like.

Margje; voor je niet-aflatende Jettie, voor je frisse, praktische blik op de zaken bij onze jaarlijksse gesprekken. grondigheid in je feedback. Door mij steeds stil te laten staan bij de cognitieve kanten van het verhaal was je voor mij een onmisbare steun.

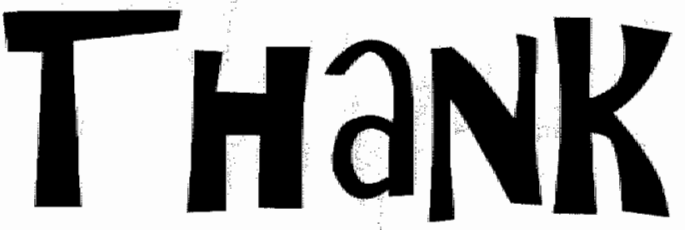

Pat, for your warm welcome at Cardiff University.

Giving me that opportunity means very much to me, as it has been a learning experience both professionally and personally.

Gerjo, voor het mogelijk maken van dit fantastische

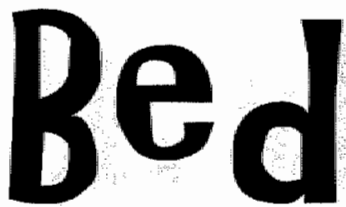
AiO-sichap en een nog fantastischer buitenland-verblijf. Je enthousiasme woor mijn ideeën was erg motiverend.

Hanneke liewe tweelingzus, woor hoe verschillend je bent van mij. En voor de mooie omslag en illustraties van dit proefschrift. En dat je mijn paranimf wilt zijin.

Nicole, een fijnere, lievere kamergenote kan ik me niet voorstellen. Je opmerkzaamheid en goede raad, onze leuke gesprekken, alle plezier. Ik zal dat missen, maar heb er een goede vriendin bij.

Mama en Papa, da's moeilijk te verwoorden, maar bij deze toch een poging : bedankt voor al jullie liefde en steun, en de ontzettend fijne, gezellige thuisbasis die jullie voor ons creeëren. 
Collega's van EP, voor die o-zo-

belangrijke leuke werksfeer op de 2 de en 3 de.

Kim. Mijn beste vriendin en collega wat een leuke combi. Ik ben blij ben dat je mijn paranimf bent.

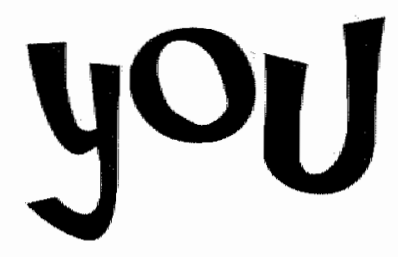
Matt and Steve, for being such brilliant office-mates for 'that silly Dutch girl', with her strange tea- and clothing habits $:$. All your help with setting up my experiments and especially the great fun we had, made each day working at Park Place a joy.

\begin{abstract}
Rob, voor het vertrouwen dat je me gaf in mijn capaciteiten als onderzoeker. Met jouw snelle feedback hield je me steeds op het juiste experimentele spoor.
\end{abstract}

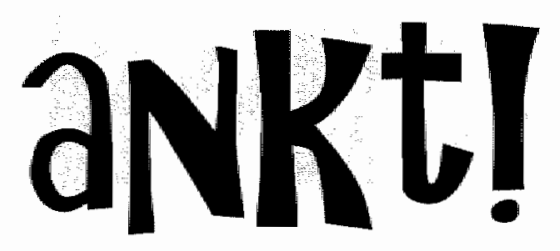

Femke, voor je adviezen bij mijn eerste studie. En in het algemeen voor je fantastische humor en grote-zus-zijn. Erg leuk dat we nu ook collega's zijn.

\title{
Ilse Mesters, Ingrid Steenhuis,
}

Hans Brug, voor het ter beschikking stellen van jullie onderzoeksmaterialen en alle handige advies.

My housemates at 24 Claude Road:

Natalie, Mangit, Matt, and Deri, the way you took me in and shared your

Nicole $\mathrm{N}_{\text {, }}$ woor je hulpvaardigheid, en het regelen van al die belangrijke dingen voor mij. lives with me made my stay in Cardiff an unforgettable one.

Liefste Maarten, voor al je trots en liefde, wat me veel energie geeft. En dat je me zo vrij laat in alles wat ik doe, ook als je me dan lang moet missen. Oh ja, natuurijk ook voor de vormgeving van dit proefschrift. 


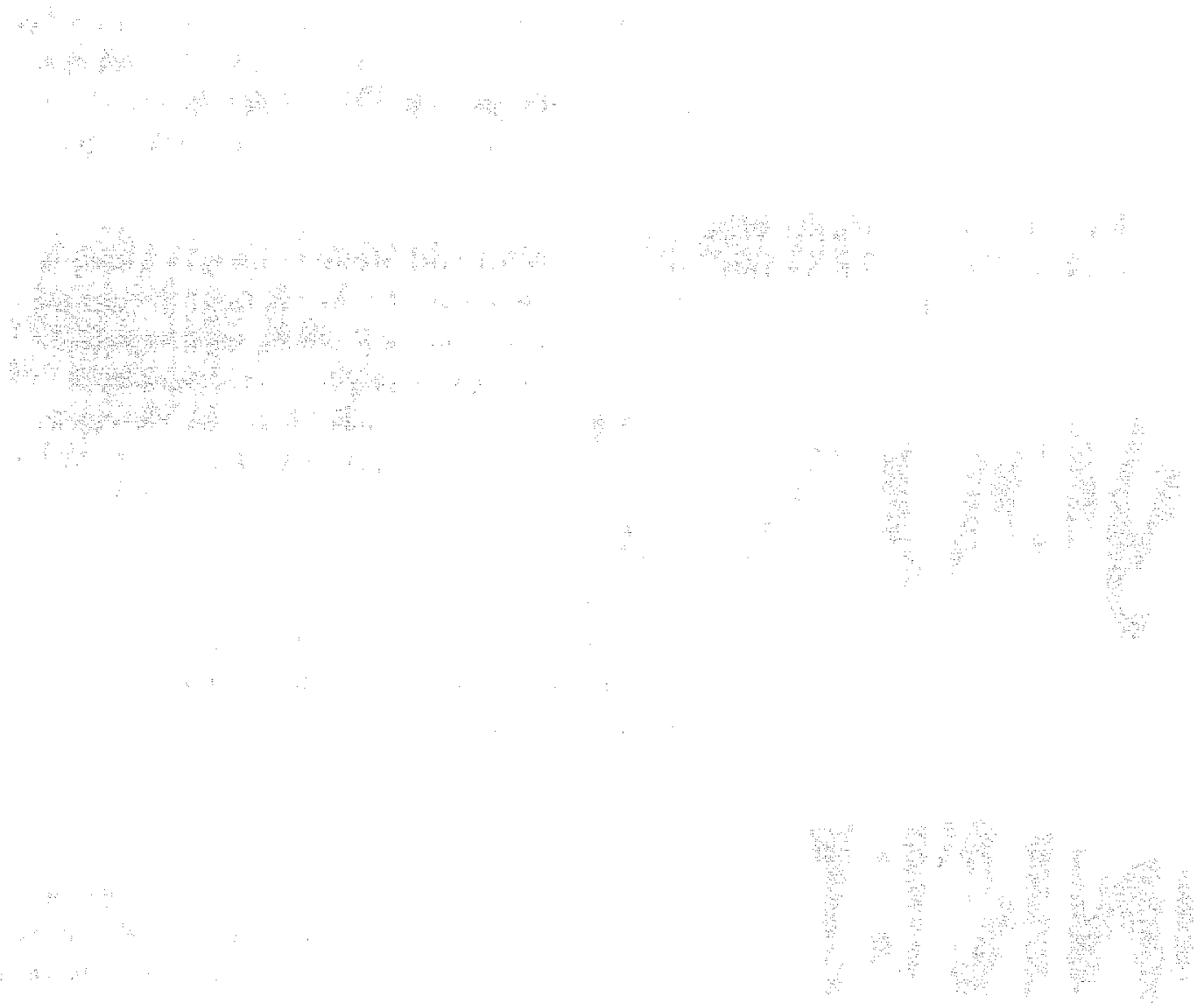


Chapter 1

Chapter?

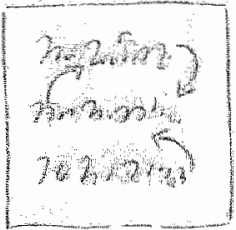

General Introduction

hereasing reader comprehension of

health educatbon broclunes: A qualtative study into how protessional whers make texis coherent

Chapter 3

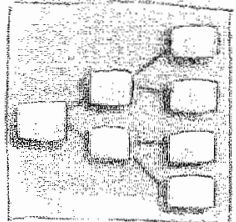

The effect of graphic organizers on

subjective and objective comprehension of a health education text

Chapter 4

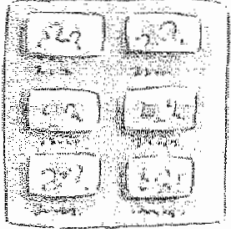

Pichures and text in instructions for medical devices: Effects on recall and actual performance

Chapter 5

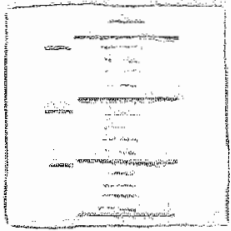

The effects of headings in a brief heath education text on locating speed and evaluation

Chapter 6

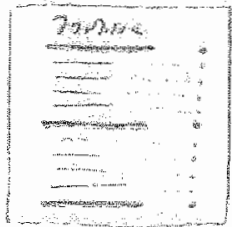

Access structures help readers locate and remember information in a heath education brochure

Chapter 7

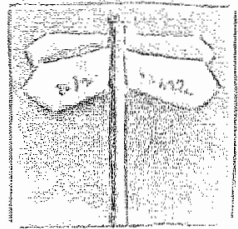

The understandability of pictoriats in a heath education brochure

Chapter 8

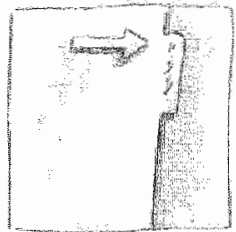

Testing the usability of access structures in heath education brochures

Genaral discussion: Implications for health education practice 
eople who are concerned with their health inevitably come in contact with written health information, as part of a broader health promotion program. Whether it is a general concern to eat healthy and do sports or a specific concern about a medical condition, ample brochures and leaflets are available to help. Such 'active dealing' with a health issue mostly requires behavioral change, a concept that is the major focus of health education research and design. The contents of brochures and leaflets in evidence-based interventions are carefully chosen based on theories and models of behavioral change, such as Social Cognitive Theory (Bandura; 1986), the Transtheoretical Model and Stages of Change (Prochaska \& DiCelemente, 1984), the Theory of Planned Behavior (Ajzen, 1988), or Protection-Motivation Theory (Rogers, 1983). For instance, different kinds of information are intended to help readers who are in different stages of behavioral change: simple filling-out tests may aim at improving awareness of ones own eating habits, explanations of negative effects of fat on ones health may motivate readers to contemplate changle, and practical tips on what readers may do to eat healthily at parties or when eating with others helps them maintain their behavioral changes in difficuit (social) situations (for a more detailled explanation of models of behavioral change, see e.g. Glanz, Rimer, \& Lewis, 2002).

Design characteristics of these written materials, on the other hand, are much less the subject of research. Although there is wide consensus that comprehension of the information is a necessary condition for behavioral change (cf.McGuire, 1985), comprehension of brochure texts is hardly measured. In cases where understanding of materials is measured, this usually entails asking volunteers whether they have understood the text and how much attention they paid to it. However, psychological research has shown that people's introspective capabilities, (being primarily post-hoc rationalizations of one's own behavior) are often flawed (Wilson, 2002) and in self-assessments, they may develop an 'illusion of knowing' (Glenberg, Wilkinson, \& Epstein, 1982). Thus, the value of such reports may be questionable. In addition, the few studies in health education that focus on design issues lack appropriate experimental designs and dependent measures that enable causal conclusions of specific design characteristics on message comprehension. Studies have combined textual and content-oriented changes in an experimental version of a brochure and then compared that to an original brochure without those changes (see e.g., Clark, AbuSabha, von Eye, \& Achterberg, 1999; Paul, Redman, \& Sanson-Fisher, 2003; Michielutte, Bahnson, Dignan, \& Schrieder, 1992), thus blurring the independent effects of separate content- and textual changes. Other studies have assessed the value of design characteristics such as typographical cueing, color use, and illustrations by asking readers'opinions about them (Achterberg \& Bradley, 1991; Michielutte et al., 1992; Shepherd, Sims, Cronin, Shaw, \& Davis, 1989), or by inferring the strength of design changes from measures of behavioral attitudes and intentions after reading the persuasive information (Paul et al, 2003), thus lacking more objective measures of comprehension of the materials.

On the other hand, in cognitive-psychological research regarding education and cognitive ergonomics, the design of information and its effects on learning, comprehension, and attention are widely studied (e.g., Duffy \& Waller, 1985; Guthrie, Weber, \& Kimmerly, 
1993; Hartley, 1985; Hartley, 2004; Kintsch, 1994; Kintsch, 1998; Lorch, 1989, Larkin \& Simon, 1987, Mayer, 1989; Mayer \& Sims, 1994; Moore \& Readance, 1989; Reynolds, Trathen, Sawyer, \& Shepard, 1993; Rouet, Vidal-Abarca, Erboul, \& Millogo, 2001; Wogalter, 1997; Wright, 1999). Central to cognitive ergonomics research is the question of how to design information so that it maximally fits human information processing characteristics (for an overview of definitions of cognitive ergonomics, see Wilson, 1995). Next to consumer products, technical devices (Kragt, 1992), and human-computer interaction (Helander, Landauer, \& Prahbu, 1997), written information carriers such as technical texts (Mayer, Steinhoff, Bower, \& Mars, 1995), user-manuals, instructions (Carroll, 1990; Ganier 2004; Van der Meij \& Caroll, 1995), and wamings (Wogalter, 1999) are being studied to see how such materials can be made more effective for users. Objective measures are mainly used to gain insight into cognitive processes and knowledge acquisition involved. For instance, participants' memory for information is asked with recall-items, understanding is assessed with comprehension questions, and the use of computer-interfaces is observed while having participants think-aloud to gather data on their behavior. To complement such performance measures; subjective assessments are used to evaluate user-satisfaction (see Wilson \& Corlett, 1995, for a complete account of ergonomics research methods).

\section{The current perspective on health education design}

This thesis aims to explore whether applying insights from cognitive psychology to the design of written health education materials could make these materials more effective for directing readers' attention and promoting their comprehension. The role of these processes in behavioral change is illustrated in McGuire's information processing model of behavioral change (1985). Where health education researchers mainly focus on the last three steps of yielding, retention and behavior, the present thesis focuses on two important prior stages in the behavioral change process, namely attention and comprehension of the information. Being prerequisites for behavioral change (McGuire, 1985), our reasoning was that more effective processing of the information in terms of distribution of attention over the matterials and better comprehension would facilitate the transfer of knowledge, which may be necessary for related attitude- and behavioral change. It should be noted here, that attention, a multi-facetted concept in research, was approached from a cognitiveergonomics point of view, in terms of guiding readers to relevant information parts there referred to as attention-allocation over the materials). That is, when people use health education materials, effectively guiding readers' attention-allocation may be crucial for them to gain an overview of and thus understand the general contents and find answers to questions easily.

In the present series of studies, existing health education materials (mostly brochures) were changed according to cognitive-psychollogical theory and empirical data, and in controlled experiments compared to the original to see whether readlers" dealing with and comprehension of the materials could be improved. Starting point was that members of the materials target group allready had the materials in question and wished to use it: The basis of all studies was the notion that the understanding of written information is the result 
of 'top-down ("conceptually-driven") processes and "bottom-up" (data-driven") processes (Neisser, 1967). Top-down processing of information implies that mental processing is guided by means of a reader's knowledge stored in memory (Kintsch, 1988). For instance, when people already have quite some knowledge and understanding of healthy dieting, they may wish to look up or read only specific information in a brochure. Thus, readers may not read the booklet from start to finish (Wright, 1988). Bottom-up processes, on the other hand, refer to the effects of features and clues in information on readers'attention-allocation and comprehensilon of the information. Such features of the materials may meet readers" (top-down) expectations about what they will encounter in the brochure and thus help them look for specific information, and at the same time guide reader $s^{\prime}$ comprehension (bottom-up) of main concepts in a brochure. The studies described in this thesis try to pinpoint aspects of design characteristics that in a 'bottom-up' fashion help readers' active use and understanding of the contents. In doing this, relevant top-down characteristics of participants were kept constant as much as possible either by controlling for relevant prior knowledge in selecting the participants or by giving them explicit goals (i.e., search tasks) for using the materials. in addition, participants were always randomly assigned to conditions in the experiments, to ensure comparable variation in (top-down) characteristics of participants between experimental conditions. Before introducing the experimental studies described in this thesis, general cognitive theory on information processing and the role of attention and comprehension in this are described.

\section{Top-down and bottom-up processes when using written information}

Readers who have some prior knowledge about a health-related subject may want to search for specific kinds of information in a brochure. For instance, readers who know that a diet can be healthy or unhealthy, and are wondering what healthy eating habits entail, will find general information about healthy living interesting to read. Readers, who have already pinpointed their specific problem-areas concerning fatty foods, may want to find answers to practical issues about how to counter the problem. Such people will thus selectively attend to, or search for that (kind of) information.

Top-down processes in information processing (Greasser, Millis, \& Zwaan, 1997; Kintsch, 1988) are essentially caused by prior experiences of the reader with a brochure's subject and with health education brochures in general. Based on this prior knowledge, readers may form expectations about what they are going to encounter in an unfamiliar brochure. Such general knowledge may help readers locate information. Thus, regarding the form of $a$ brochure, readers may expect to encounter a table of contents on the first page, for instance, and headings in the main text that signal the texts' subjects on different levels of generality. The design of such features determines the overall structure, and thus the overview readers can attain when initially skimming through a brochure (Hartley, 2004). In other words, visually distinguishing different kinds of information on a page or throughout a brochure may exert bottom-up influences on what relations readers perceive among those pieces of text (Winn, 1994). For instance, giving headings of similar importance and with similar kinds of information the same type-size and color may help readers perceive and understand the 
subjects they irtroduce as similar in nature (Medin, Goldstone, \& Gentner, 1993). As readers expect such features to help them gain an overview (i.e., understand the materials) and find specific information, their presence in 'new' materials encountered may improve accessibility. Unconventional design of such features may not easily fit with the prior knowledge of readers and therefore result in sub-optimal processing of the information. Especially when choosing an uncommon design-format, an effort should be made to flag informational structure and proper use for readers, to prevent not reaching their goals with the materials, causing readers not to read the information at all (Wright, 1988).

Different elements of a clear and explicit brochure structure may guide readers" attention as well as help them search for specific information. For having novice readers perceive links among related subjects or similar kinds of information, this information could be presented in similar design (in line with Gestalt principles of perception (cf. Wallace, West, Ware, \& Dansereau, 1998)). For example, readers attention may be drawn with a color and all related information may be presented in the same color:In addition, searching information in a brochure may be supported by a visual distinctiveness of different kinds of information, Improving its surveyability and thus accessibility (Guthrie, Britten, \& Barker, 1991; Waller, 1982; Waller \& Whalley, 1987).

\section{Understanding information in written documents}

In cognitive psychology, knowledge that a person has is viewed as an associative knowledge network (Kintsch, 1988). Nodes in this network represent concepts that a person has encountered and stored in his/her long-term memory. The relations between these concepts are represented by the connections between the nodes in the network. These connections indicate the kinds and strengths of associations among concepts (Kintsch 1988; Kintsch 1998). Thus, the meaning of a concept is given by its position in the network, specified by the strength of its connections to neighboring concepts and concepts that lie at greater distances from it.

When encountering written information, text that is read and design characteristics that are attended to enter the reader's short-term memory, also called working memory (Baddeley, 1986). This is a system in which the information is held for further mental processing. Thus, working memory can be seen as a memory buffer or register that holds current and recently attended information. Further processing of information in working memory may consist of retrieving information from long-term memory to which the new information is then linked in a meaningful way. When information is transferred from working memory to long-term memory, it is integrated into the knowledge network just described: new nodes are added or existing links among nodes change. In short, comprehension takes place.

When reading to understand text, the mechanism of 'attention' is assumed to transfer information from sensory to short-term or working memory almost instantly and automatically. In addition, attention is seen as a critical mental resource necessary for the operation of any conscious or partly conscious process. That is, attention provides the 
resources for the transfer of information among a reader's sensory memories, working memory, and long-term memory (Baddeley, 1986).

The limits in readers' attention span (i.e., attention resources) determine the amount of information that can be held active in working memory at the same time. This influences readers' comprehension of a text: information and concepts that are read enter working memory sequentially, where they may be linked in some way. Information that is widely separated over pages and is thus sequentially encountered over a relatively long period of time may not be meaningfully linked with each other during reading. For instance, an explanation of how an asthma attack builds up may not be in working memory anymore when five pages later a relevant environmental factor causing this attack, is presented. To ensure that different pieces of information are associated with each other in the comprehension process, textual or visual 'links' should be made that ensure the concurrent activation of these units in working memory. Thus, readers' focus of attention (i.e., what they attend to on a page and thus enters their working memory) may be guided by these links to enable the subsequent comprehension of the contents.

Thus, the level of understanding can be influenced by the coherence of a text. A text has two different levels at which it can be coherent: the global and the local level, also called the macro and micro level, respectively (Van Dijk \& Kintsch, 1983). Coherence at the macro level implies that the order of topics is logical as opposed to random and that the smaller and larger sections of text are clearly related to each other and to the overall topic. This kind of coherence can be established in a text with headings above sections and paragraphs, and 'macro signals': sentences at the end and start of each section, that explain the link with previous and upcoming text (McNamara, Kintsch, Songer, \& Kintsch, 1996). Such textual devices enable the reader to maintain a coherent overall 'picture' of the text, thus creating an understanding of how main text elements are related to each other.Coherence at the micro level implies that each sentence is explicitly related to the next. This overlap in textual arguments enables two or more sequentially encountered concepts being simultaneously active in readers" working memory, which in turn results in text comprehension (Kintsich \& van Dijk, 1978).

Ideally the reader forms a coherent mental representation of the text's content as reading proceeds. However, at instances where the overlap between concepts during reading is not sufficient and text coherence is thus low, a long-term memory (or knowledge network) search has to be initiated. Such "inference processes' are assumed to make relatively

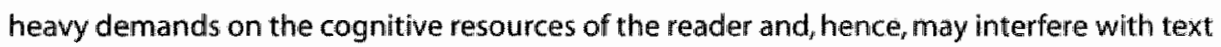
comprehension (van Dijk \& Kintsch, 1983).

To ensure that a target group with considerable variety in cognitive recourses (regarding attention span and prior knowledge enabling them to connect incoming information in a meaningful way) understands the information, the design of health education information should require minimal inferences by readers. Research has suggested that for readers with minimal prior knowledge about an instructional text subject, information and coherence should be very explicit to ensure comprehension (Mc Namara et al., 1996). With health education materials and especially with brochures that are aimed 
at informing people about health subjects they are generally unfamiliar with, this may be crucial to reach as many members of the target group as possible.

Thus, a clear macro structure (with headings and spacing) of health education brochure may serve as a steppingstone for understanding the information that readers encounter on the micro level of the text. This way, a brochure by itself may provide a'schema' to readers, which they may readily cognitively encode. Such an overview of the information in a brochure ensures that the reader does not lose track of the links among (main) concepts. Taken together, for attention-allocation and subsequent comprehension, clear brochure design may play an important role in how readers use the brochure and cognitively process the information in it.

\section{This thesis}

With the goal of exploring possible improvements regarding readers' attention-allocation and comprehension of written health education materials, seven studies were conducted and are reported in this thesis. First, to assess what health education text writers do to make their texts coherent and thus understandable on the micro- and macro level, a qualitative study was performed in which the findings from 17 interviews and think-aloud protocols were compared with cognitive-psychological guidelines for textual coherence (chapter 2).

In the applied experiments that were subsequently performed, three existing intervention materials served as a basis for the stimulus material: a brochure aboutt asthma, a brochure about healthy dieting, and a personal letter about healthier eating habits. All materials had been developed as part of evidence-based health education interventions (Brug, Steenhuis, van Assema, \& de Vries, 1996; Mesters, Meertens, Kok, \& Parcel, 1994; Steenhuis, van Assema, \& Reubsaet, 2000) and as such, their contents were based on theories of behavioral change. Therefore, the informational contents of the materials were taken as a starting point in the studies, to see how design characteristics could influence readers' processing of those contents. Based on an initial analysis of potential problems readers could encounter with each of the materials, possibilities for improvement were assessed, implemented, and tested in individual experiments.

The experiments were all designed based on four criteria for research on meaningful instructional methods (Mayer, 1989). That is, positive evidence that comprehension is enhanced in the reader can be expected when (1) the to-be-learned materials are potentially meaningful, (2) readers are unfamiliar with them, (3) the instructional manipulation directs readers' attention to crucial elements for understanding, and (4) understanding is measured in an appropriate way in relation to the materials.

Here, the materials used were potentially meaningful in that they contained healthrelated information and instructions, from which readers could form a coherent mental model. With regard to their usability, the materials were meaningful in the sense that the text's subjects followed each other in a meaningful way and the coherence on the macro level was potentially understandable for readers. Secondly, as the usefulness of design adjustments has been found to be greatest when readers have little prior knowledge of the text subject (Mayer, 1997; Mayer \& Sims, 1994; MCNamara et al, 1996), the present 
experiments accounted for that. That is, with the brochure about asthma participants were selected on their low prior knowledge on the text subject. The original brochure from which the instructions were extracted was also aimed at readers without prior knowledge of asthma, so this seemed a valid component in this study. Because health subjects such as fat in foods and fruit and vegetables consumption are relatively common subjects people encounter in daily life, with the healthy diet brochure and the personal letter, participants" prior knowledge was difficult to control for by participants-selection. Therefore, random appointment of participants to experimental conditions was used to make the groups comparable with regard to their prior knowledge.

Regarding the third prerequisite for meaningful instructional design research, the effects of various design elements were the primary aim of the studies. All design characteristics were inserted to direct readers' attention towards crucial content- and design elements of the materials, so that understanding of both kinds of elements could improve. The design features tested were either aimed at improving readers" comprehension of the informational content (graphic organizers, illustrations, pictorials) or of the informational arrangements within the materials (headings, contents list, pictorials, colors, and tabs). Finally, in line with the fourth criterion the dependent measures comprised meaningful, ecologically valid learning outcomes. That is, comprehension of contents was measured with open comprehension questions on text base and situation model level (graphic organizer study), comprehension of pictorials by asking with open questions to explain their meaning (pictorials), and comprehension of instructions and of access structures was assessed by observing participants while using the instructions (asthma devices with illustrations) and finding information within the materials themselves (headings, tabs), respectively. Altogether, an attempt was made to make a practically valuable contribution to the design of effective health education materials. In total, six experiments were conducted: two with the brochure about asthma, one with the personal letter, and three with the brochure on healthy dieting.

Studies with asthma brochure.

The brachure 'Asthma in Children', aimed at parents of children with asthma, was an A4-size booklet with in total 65 pages. It informed its readers extensively about what asthma is and what causes it, what to do about it, and how to use various medications. Two features stood out with regard to the understandability of the information in this brochure. First, the main text contained many different kinds of information spread out over many pages. Keeping in minid the limited attention span in which related information should optimally be encountered to be linked with each other, it was expected that readers with little prior knowledge about asthma to compensate this, could experience comprehension difficulties. Especially regarding the text's macro structure, this was expected to result in problems for readers in keeping track of the information, thus interfering with the formation of a situation model and possibly even a proper text base understanding. To reduce necessity for making inferences by the reader and provide them with an advance insight into the brochure's subject and relations among the various concepts, graphic representations were systematically inserted in the text. The effect of these graphic organizers on readers' text 
base and situation model comprehension of the micro-and macro level text elements were assessed with comprehension questions on these levels (chapter 3).

Another potential problem for users of the asthma-brochure pertained to the instructions of two medical aids it comprised. These instructions for the use of the inhaller chamber' and the peak flow meter" were text-only, with minimal explanation on relevant visible features to attend to when using the device Based on findings related to enhancing effects of illustrations on recall and understanding, it was hypothesized that spatial information needs less inference-making by the reader and is thus easier to understand when presented visually as well. Thus, illustrations accompanied each instructional action in both instructions and effects on different levels of understanding were assessed with open recall and performance with the device and its instruction (chapter 4 ).

Situdy with personal letter.

A computer-tailored nutrition letter was tested on accessibility, so the ease with which information could be located. The stimulus material was a five-page informative letter that was tailored to the receiver's eating habits and information needs. As such, it was a relatively short text, containing descriptive information about that person's current eating habits, what should be changed, and some practical tips on how to do so. With little explanatory information regarding processes that needed to be understood, the understandability of the content was expected to be high to begin with. However, the text contained various enumerations of different foods and a strong hierarchy in the text's macro structure, which was signaled with various levels of headings. This raised the question whether different degrees of explicitness in signaling text structure could enhance the accessibility of the text. Four text versions with various numbers of headings were compared on how quickly participants could find specific information and their subjective experience with their text version (chapter 5).

Studies with healthy diet brochure.

The self-help guide about healthy dieting was a 33-page, A4-size booklet, which contained

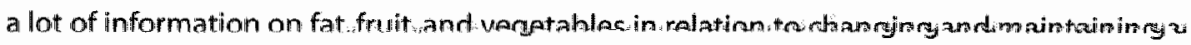
healthy diet. The information was highly segmented into separate paragraphs and did not comprise common access structures such as main section headlings $s_{i}$ a table of content, or an index. Instead, throughout the brochure, readers were signposted, or referenced towards other related sections of potential interest. In addition, these referencing paragraphs were flagged with pictorials of an arrow. As the amount of information, together with the uncommon referencing system in the brochure and the pictorial's design could lead to difficulties for readers in understanding the informational contents and using the brochure, these features were the main focus in three studies. First, the additive value of the presence of a contents list and main section headings on the ease with which readers could find information and understood (recalled) the lay-out of sections, was assessed (chapter 6). Also, the understandability of the arrow-pictorial was assessed and compared to a signpostpictorial used in the same context (chapter 7). Finally, the usability of the original access structures was compared with systematically adding regular arrows, tabs, and colorcoding to the referencing-5ystem (chapter $\mathbf{8}$ ). In this way, four versions of the brochure 
were compared regarding four usability-measures with regard to effectiveness, efficiency, satisfaction, and learnability.

Finally, because the main aim of the current research project was to see how cognitive. psychology could aid contribute to the design of written health education materials, the general discussion in chapter 9 is aimed at health education practitioners. That is, in light of the theoretical bases that might be of interest to this field, the findings of all experimental studies are discussed and emanating guidelines for health education design are stated. Furthermore, in light of Intervention Mapping (Bartholomew, Parcel, Kok, \& Gottlieb, 20011, a protocol is described for using these guidelines in practice. Finally, suggestions for further research are done.

It should be noted that this thesis is primarily a collection of published articles and manuscripts submitted for publication. Because most chapters were written to stand alone, some discontinuity and repetition is present throughout the thesis. 
Chapter

Chapter 2

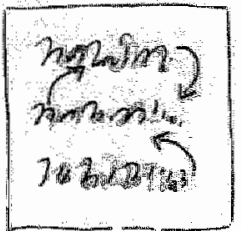

Chapter 3

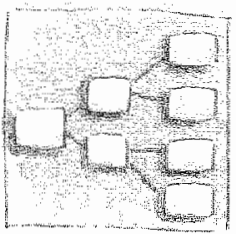

The effect of graphic organizers on

37

subjective and objective comprehension

of a health education text

Chapter 4

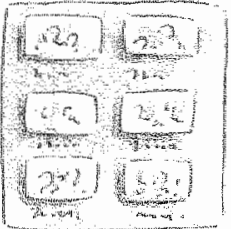

Chapter 5

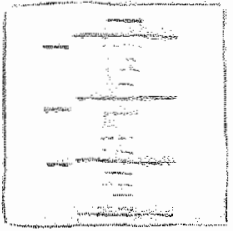

Chapter 6

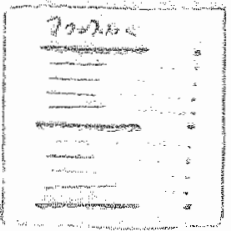

Chapter 7

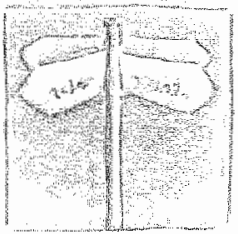

Access structures help readers locate and remember information in a health education brochure

The understandability of pictorials in a health education brochure

Chapter 8

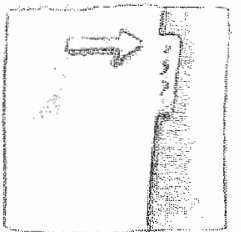

Testing the usability of access structures in health education brochures

General discussion: Implications for health education practice education text on locating speed and evaluation 


\section{COHERENCE PRANCLLS IE TEXTWATES}


$\mathrm{H}$

ealth education information takes many forms. Its diversity wanges from mass media TV messages, to written texts in materials such as advertisements, information leaflets and more comprehensive brochures, to strictly interpersonal counseling activities. One of the key conditions for effective health education, according to information processing theories, is the comprehension of the arguments that are made (McGuire, 1972). Information in a brochure, for instance about the causes and consequences of a disease, should be well understood by the readers in order to motivate them to perform suitable preventive actions (see, e.g., Roger, 1983).

In this paper we focus on the use of written texts with the typical length and content of a brochure. In the Netherlands, health education brochures are usually written by professional text writers who are hired on a part-time basis. These text writers often write for diverse organizations with various target groups. Mostly they have a background in journalism or the national language. The present study aimed to gain insight into the ideas that text writers of health education materials have about text comprehension by means of a think-aloud procedure and interviews. Its findings may be helpful in developing guidelines for increasing readers' understanding of a text, regardless its contents.

To the best of our knowledge; the study presented here is the first that examines the ideas health education text writers have about text comprehension and the methods they apply to elicit understanding in the reader. Most cognitive psychological studies exploring writing that have been carried out so far focused on the cognitive processes involved in writing (Flower \& Hayes, 1980; Hayes \& Flower, 1987). That is, these studies examined the cognitive processes that describe how writers coordinate the expression of ideas with the constraints of language and rhetorical structure. However ${ }_{s}$ the present study focused primarily on the writing process, i.e., the techniques text writers use to increase text comprehension in their readers. Specifically, it focused on techniques (writing principles) text writers use to increase text coherence, which has been identified as the main variable of text comprehension (Kintsch, 1988).

This article describes in detail how purely textual aspects of written materials can enhance cognitive processing of texts and as a result the comprehension in the reader, regardless of a text's content. The present study thus contributes to health education research that has endorsed the need for readable materials for readers of all literacy levels (Doak \& Doak, 1980; Davis, Michielutte, Askov, Williams, \& Weiss, 1998), and has resulted in guidelines for writing effective materials (see e.g., Doak, Doak, \& Meadie, 1996). However, those guidelines aim to enhance not only text comprehension, which is the focus of the present study, but also motivation to read, feelings of involvement, and behavioral change. No clear distinction is made between purely textual and more content-related guidelines for effective health education. Moreover, many of these guidelines are based on logical reasoning (sometimes in line with related experimental findings) and on the experience of the authors instead of on experimental research. As a basis for this study, theoretical accounts of text comprehension have been used from the field of cognitive psychology and all writing principles that are described are grounded in findings from experimental 
research. Before describing and discussing the methods and results of our study, we will briefly desicribe cognitive mechanisms of text comprehension, followed by an overview of specific writing principles that are thought to enhance readers' understanding of a text.

\section{Text comprehension and knowledge representation}

When a reader comprehends a text, its content becomes part of the reader's overall knowledge. In cognitive psychology, knowledge that a person has is viewed as an associative knowledge network (Kintsch, 1988). Nodes in this network represent concepts that a person has encountered and stored in his/her long-term memory. The relations between these concepts are represented by the coninections between nodes in the network. These connections may vary in label and strength values, indicating the kinds and strengths of associations among concepts (Kintsch, 1988; Kintsch; 1998). The meaning of a concept is given by its position in the network, specified by the strength of its connections to neighboring concepts and concepts that lie at greater distances from it. Such mental networks that contain and generate the meaning of concepts are generally referred to as 'knowledge networks' (Kintsch, 1998). Every time a concept is encountered, its meaning is 'activated' in working memory by activating a certain subset of concept nodes. In working memory "incoming" or new information is processed together with the activated prior knowledge from the knowledge network. The context in which the concept is encountered determines which specific subset of nodes becomes activated in working memory. In this way, models of knowledge networks account for the flexibility and changeability of meaning at any point in time.

When a person reads a text, its content is processed in working memory by activating concepts that are sequentially encountered. The representation of the text-content is formed by continually connecting incoming text information with prior knowledge. The reader must identify each new piece of text information and relate it to information already given (e.g., Clark \& Haviland, 1977). Specifically, while reading, the reader continuously grasps what is given and what is new information. Memory is searched for an antecedent of the given information and then the new information is added to this antecedent in memory. For a smooth association process between concepts it is imperative that these concepts are active in working memory at the same time. Because only a limited number of concepts can be held active in working memory at any point in time, it is important that concepts recur within a comparable (limited) scope of the text. In that way, related concepts are properly processed into at text representation and stored in the knowledge network in long-term memory (see also Figure 1).

Idealiy the reader forms a coherent mental representation of the text s content as reading proceeds. However, at instances where the overlap between concepts during reading is not sufficient, and text coherence is thus low, a long-term memory (or knowledge network / search has to be initiated. Such 'inference processes' are assumed to make relatively heavy demands on the cognitive resources of the reader and, hence, interfere with text comprehension (Van Dijk \& Kintsch, 1983). 


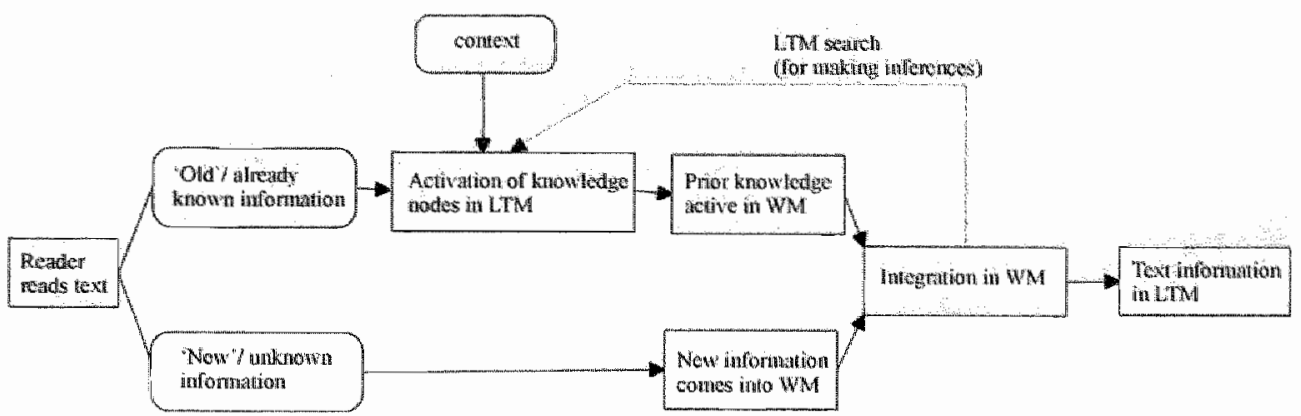

Figure 1.

Processes in text comprehension

Note: Squares with sharp angles represent steps in the process; squares with obtuse angles indicate influences, the dotted line indicates a possible process. LTM=long-term memory, WM= working memory; both are part of the reader's knowledge network.

\section{Writing principles to increase text coherence}

In cognitive psychology, ample research has been done into text comprehension (for an overview, see Goldman, 1997). The coherence of text, i.e., the logical and consistent structure of a text, is considered to be the major factor that influences text comprehension (Van Dijk \& Kintsch, 1983). Increases in text coherence reduce the amount of inferencing a reader has to make and thus reduce the chance that the reader infers incorrect relations between concepts or misses those relations altogether. Text coherence thus positively contributes to text comprehension (Kintsch, 1988; Van Dijk \& Kintsch, 1983).

A text has two different levels at which it can be coherent: the global and the local levell, also called the macro level and micro level, respectively. At both levels readers maintain coherence in their mental representation of a text's content (Albrecht \& O'Brien; 1993; Lorch, Lorch, \& Mathews, 1985). A text is coherent at the macro level when the order of topics is logical as opposed to random, and if the smaller and larger sections of text are clearly related to each other and to the overall topic. At the micro level a text is coherent if each sentence is explicitly related to the next. Consequently, inference reduction takes place, meaning that readers do not have to infer relations among sections and sentences by themselves. At both levels, coherence can be increased by applying specific writing principles to the text, which will be discussed next.

\section{Increasing coherence at the macro level}

Global structure is the major determinant of coherence. To make a text coherent at the macro level, there are no specific restrictions or rulles for the order of various (kinds of) information, as long as that order 'makes sense' to the reader. The eventual macro structure depends on the message the writer wants to convey to the readers. In deciding upon information ordering, the writer can keep in mind that when the textual structure is in agreement with the reader's expectations, text processing and comprehension are facilitated (Lorch, 1985; Duffy, 1986). When information units are encountered at the moment the reader expects to encounter them, related concept nodes in the knowledge network 
are already activated. The subsequent integration of the newly encountered information with those activated nodes will continue smoothly, resulting in an adequate mental representation of the text in the reader.

More specifically, two types of text coherence improvements have been found effective at the macro level (McNamara, Kintsch, Songer, \& Kintsch, 1996). First, the adding of relevant (sub)headings improves text comprehension in readers. Headings and sub-headings clarify overall text structure and can serve as anchor's for the reader in the sense that they specify a relevant context for integrating subsequent, subordinate content (Lorch, 1989). In general, it may be assumed that headings influence cognitive processing by (a) acting as cues for activating related prior knowledge, (b) accentuating the relationship among important concepts in a text, and (c) providing retrieval cues for subsequent recall of a text (Brooks, Dansereau, spurlin, \& Holley, 1983; Wilhite, 1988). Thus, (sub)headings can activate relevant concepts in working memory to which the content of the subsequent section should be added. Especially when headings are assigned to short sections of text, as opposed to longer sections of text, they can facilitate recall, and thus comprehension (Lorch \& Lorch, 1996).

A second way of improving coherence at the macro level is by adding 'macrosignals' in the text that refer to the overall topic and identify how the information should be interpreted in light of the general theme (McNamara et al., 1996). Macrosignals are usually applied at the beginning or end of each section in the form of one or two sentences. Those sentences provide information that explains why the section follows the previous one(s) and how it fits in the whole text. At the same time, it helps to build a framework in which upcoming information can be interpreted and understood. Cognitively, macro signals cam serve to guide attention during reading, and they may activate memory representations of previous content, thereby enhancing integrative pracessing (Glover, Dinnel, Halpain, \& Mckee, 1988; Dixon \& Glover, 1990). The use of topic sentences and relational sentences in sections has been found to enhance text recall (Lorch \& Lorch, 1985) and reduce the required cognitive capacity in the reader (Britton, Glynn, Meyer, \& Penland, 1982). In general, headers and macrosignals together provide a framework that explicates and improves understanding of the information that a text is meant to convey.

\section{Increasing coherence at the micro level}

Seven writing principles have been identified that increase textual coherence at the micro level (McNamara et al. 1996; Britton \& Gülgöz, 1991). First, sentences can be written so that they repeat the linking word from the prewious sentence to which they should be linked. According to Kintsch and Van Dijk (1978), this principle of 'argument overlap' is the most important criterion for textual coherence. Cognitively, argument overlap ensures that important concepts recur within the limited scope of working memory, so that the reader does not have to make inferences to understand the conceptual relations. A corollary of the principle of argument overlap is that whenever the same concept appears in the text, the same term should be used for describing it (e.g., replace someone and patients with child and children) (Britton \& Gülgöz, 1991). 
A second writing principlle that increases text coherence, which is strongly related to the principle of argument overlap, states that pronouns that are potentially ambiguous should be replaced by noun phrases. For example, in a sentence such as The oxygen is given to the blood and that transports it through the body; a naive reader could interpret 'it' wrongly as referring to 'the blood' instead of to 'the oxygen'. By replacing it" with 'the oxygen' such misunderstandings can be prevented and thus the text is made more coherent. In a knowledge network, only the node representing 'oxygen' will be activated, instead of an initial activation of both possible referents of "it" and the subsequent elimination of the wrong one.

A third way to enhance the micro coherence of text is by adding descriptive elaborations that link unfamiliar concepts with familiar ones (e.g. The blood transports the residue to the lungs. This residue is called carban dioxide). In terms of knowledge networks, these descriptive elaborations activate concepts (i.e., prior knowledge) from the network to which the information in the text can be linked.

Fourthly, sentence connectives can be added to specify the relationships between sentences or between ideas (e.g, however, therefore, because). These sentence connectives help specifying the kinds and strengths of the connections between newly introduced concepts and those that are already present in the reader's knowledge network. These linguistic markers guide the selection of the correct relation (Sanders, 5pooren, \& Noordman, 1992) and thus facilitate text comprehension, as can be seen in enhanced recall of text content (see Lorch, 1989, for an overview).

A fifth principle of inference reduction at the micro level implies the arrangement of sentences into a 'given-new'order, which means that information that is familiar to the reader precedes information that is new to the reader. This writing principle is based on the 'given-new contract; introduced by Clark and Haviland (1977), which states that the distinction between 'given' and 'new' information should always be clear to the recipient. Cognitively, with a 'given-new' order, the text with familiar or 'given' information is activated in working memory in the form of one unit of information. The subsequent literal "new" sentence-part fits in easily with that unit in working memory and can be related to that 'old' information. With a 'given-new' sentence order, the new information does not have to be kept active in working memory until the knowledge with which it should be associated is encountered and activated. Thus, mental effort for comprehension is reduced, which contributes positively to understanding.

A sixth principle is that whenever the actor of a highly relevant verb is not explicitly mentioned, and thus could be missed, the actor should be added to the sentence. For example, compare the sentences "The oxygen is transmitted to the blood which is then transported through the body' and 'The oxygen is transmitted to the blood by the alveoli and is then transported through the body'. This principle was deduced from a more general principle that Britton and Gülgöz (1991) applied to experimental texts, namely'making explicit any important implicit references; that is, when a concept that is needed later is referred to implicitly, refer to it explicitly if the reader may otherwise miss it. In this way, 
important concepts for comprehension are activated along with the "new" information, thus contributing to text comprehension.

Finally, aseventh principle states that causal relations should be made explicit Loman \& Mayer, 1983, Linderholm, Everson, van den Broek, Mischinski, Crittenden, \& Samuels, 2000). Although this principle is partly implied by the above-mentioned principle of using sentence connectives like because' and'therefore', it is mentioned separately here because of its fundamental nature. Any way in which causality in texts can be explicated may be beneficial to text comprehension, as causality is thought of as a basic principle in organizing human knowledge (Noordman \& Vonk, 1998; Sanders \& Noordman, 1998). Compare the sentences "Dust enters the airways, the slime swells and narrows the airways" and "Dust that enters the airways causes the slime to swell, which results in a narrowing of the airways: Explicating causal relations helps the reader to construct the exact nature and strengths of links among relevant concepts in mentally representing the text. For an overview of all the principles mentioned, see Table 1.

Table 1. Cognitive writing principles to maximize text coherence.

\begin{tabular}{|c|c|c|}
\hline Text level & Principle & Application \\
\hline \multirow[t]{2}{*}{ Maicro } & 1. Headingis & $\begin{array}{l}\text { Insert a heading above every subject change in the text. Make sure that } \\
\text { the level of each section created in this way is clear. }\end{array}$ \\
\hline & 2. Macro-signals & $\begin{array}{l}\text { Start every section that is preceded by a heading with a brilef explanation } \\
\text { of the relation between that section and the prewious text content. }\end{array}$ \\
\hline \multirow[t]{7}{*}{ Micro } & $\begin{array}{l}\text { 1. Argument } \\
\text { overlap }\end{array}$ & $\begin{array}{l}\text { In a new sentence, repeat from the preceding sentence the word to } \\
\text { which the reader should relate the information in the current sentence. } \\
\text { For important concepts in a text, consistently use the same words, that is, } \\
\text { awoid synonyms. }\end{array}$ \\
\hline & $\begin{array}{l}\text { 2. Ambiguous } \\
\text { pronounis }\end{array}$ & $\begin{array}{l}\text { Only choose a demonstrative pronoun if there is only one possible referent } \\
\text { in the previous sentence. When a demonstrative pronoun could refer to } \\
\text { two concepts in the previous text, repeat the referent word or phrase itself. }\end{array}$ \\
\hline & $\begin{array}{l}\text { 3. Descriptive } \\
\text { elaborations }\end{array}$ & $\begin{array}{l}\text { Allong with unavoidable jargon or unusual words, add descriptive } \\
\text { elaborations of generally known concepts. }\end{array}$ \\
\hline & $\begin{array}{l}\text { 4. Sentence } \\
\text { commectives }\end{array}$ & $\begin{array}{l}\text { Usei sentence connectives where possible to clarify the relations between } \\
\text { sentences, Especially causal rellations among concepts should be made } \\
\text { explicit this way. }\end{array}$ \\
\hline & $\begin{array}{l}\text { 5. Givenumew } \\
\text { order }\end{array}$ & $\begin{array}{l}\text { Within sentences, mantain an information order of given-new'start a } \\
\text { sentence with information that has been mentioned earller in the text and } \\
\text { insert after that the "new" (i.e., to the reader unknown information, which } \\
\text { the reader has to relate to the previous information. }\end{array}$ \\
\hline & 6. Explicit actor & $\begin{array}{l}\text { State the actor of every important verb explicitly in the text, Similarly, every } \\
\text { concept that is important to a proper comprehension by the reader should } \\
\text { be named explicitly in the text. }\end{array}$ \\
\hline & $\begin{array}{l}\text { 7. Explicit } \\
\text { Causality }\end{array}$ & $\begin{array}{l}\text { Make causality explicit within and between sentences by imeans of explicit } \\
\text { descriptions of causal processes and an appropriate word-ordering of } \\
\text { cause followed by effect. }\end{array}$ \\
\hline
\end{tabular}




\section{Focus of this study}

In the present study we investigated the extent to which the above-mentioned writing principles to improve text coherence at the macro and micro level are applied by text writers of health education materials. Inherent to this issue was the objective to identify the ideas text writers have about how to increase text understanding in readers, and whether additional techniques could be identified that could not be classified as one of the writing principles described above.

Since professional text writers usually write from experience, and in general do not have a background in cognitive psychology, it was expected that most of them would not be aware of the above-mentioned principles. Nevertheless, it is possible that they apply those principles to their texts because they have learned them through the reactions of readers and others.

In order to get a clear picture of the kind of principles that health education text writers employ, respondents revised a health education text in the presence of the interviewer and subsequently were asked questions about their revisions. While revising the text; respondents were asked to think aloud to get reliable insights into the process of writing (Ericsson \& Simon, 1984). The task of text revision served two purposes, namely as a frame of reference for the subsequent interview about text coherence and comprehension, and as a trigger for respondents with respect to their thoughts and ideas in writing a health education brochure.

\section{Method}

\section{Respondent demographics}

Seventeen professional writers of health education materials, nine men and eight women, were interviewed over a period of two months. Writing experience ranged from three to 32 years, with an average of 11 years. Fifteen respondents were recruited via prominent national health promotion organizations in the Netherlands (the National Institute for Health Promotion and Illness Prevention, the Dutch Heart Foundation, the Foundation against STD: 'Stichting soa-bestrijding'). They all reported they had written health education brochures and/or leaflets for these organizations. Two respondents worked at the Department of Health Education at Maastricht University and had ample experience with writing texts for health education purposes Seven respondents worked as freelance writers on assignments for various sorts of clients, among which health education organizations. They were interviewed at their homes. The remaining ten persons were or had been engaged as editors of thealth education materials.

Respondents had a wide variety of educational and professional backgrounds, such as law school, management school, dietetics and medical sociology. The commonest background among respondents was in journalism, which seven respondents had. All respondents indicated that they have always had a great affinity for texts and text writing. 


\section{Materilials}

Testirig materials consisted of a tape reconder that recorded all interviews, a paper copy of a text, and a pen with which respondents had to work. The text was part of a draft that had served as a basis for the development of an actual health education brochure in the past. The aim of this brochure was to educate parents of children with asthma about various aspects of the disorder. For practical reasons, only part of this brochure was taken as the experimental text. lit consisted of almost five full pages (1362 words) with line-spacing 1.5; font size 12, and letter type Times New Roman.

The text started with a one-page description of the lungs, followed by thiree pages describing causes of asthma and asthma symptoms, and ended with a brief general description of medicines. The middle section about various causal factors was divided into two main sections, named 'exogenous factors' and 'endogenous factors", referring to the environment and the body, respectively, as general sources of asthmatic symptoms. Under the exogenous factors two sub-headings were given, named 'Allergy' and 'Hyper-reactivity' and each, in turn, contained one sub-heading with descriptions of four concrete factors that cause allergy and hyper-reactivity, respectively. In the part about endogenous factors; there were three sections with the headers "genetic factors, "hormonal factors' and 'emotions: For the purposes of this study, the text had been degraded somewhat on the micro-and macro level. For instance, based on the coherence principles described, some macro signals were removed, some sentence-orders were changed so that causality became less explicit and 'given-new' sentence orders were reversed, so that we were sure that the text could be improved with regard to all principles described.

\section{Procedure}

Each session consisted of two components, namely rewriting the health education text and a semi-structured interview. A complete session took two hours. First, respondents were given a text and were told that it was taken from an existing brochure for parents of children with asthma. No additional information about the target group was given. Then, they were asked to read the text silently at their own pace. After they had read it once, they were asked about their general impressions of the text, i.e., how well written and understandable they found it. Subsequently, respondents were instructed to make changes on the hard copy of the text as they thought were necessary to improve readers understanding of the text. When making these changes, they were asked to verbalize their thoughts. This thinking-aloud procedure was used to reveal motivations that writers had for the textual changes, and to determine whether they applied any of the cognitive coherence principles in revising the health education text.

In the subsequent semi-structured interwiew we elaborated the changes respondents had made. Initially, the interview focused on why and how they thought their textual changes contributed to a better understanding of the text. Furthermore, to find principles that might not have been applied during the revising session itself, respondents were asked what additional changes they would make if they had more time. This led to issues of text writing, e.g. features of a text that they thought contributed to text understanding and what 
they believed readers would and would not understand. Special attention was given to text coherence and how to create it. If respondents themselves did not mention it, they were asked what principles they used to increase coherence in texts and where in this specific text they thought coherence was already good. Also, we asked respondents to rank order textual features that they thought would best promote understanding. Finally, the demographic questions were asked. The whole procedure was pilot tested with two writers, but no changes were deemed necessary.

\section{Data analysis}

All tapes of the two-hour sessions were transcribed. The transcribed interviews were divided into meaningful components and subsequently analyzed in detall. Changes in the text were categorized according to the levels of text they pertained to li.e., surface, micro- of macro level), and when possible coded as one of the coherence principles described in the introduction section of this article. The reasons for the changes that respondents mentioned were also coded. Furthermore, respondents' ideas about text writing and comprehension in the reader and other comments about the text were codled in relevant (sub) categories. The analysis was done using the qualitative analysis package QSR Nud ist 4,0. For a detailed explanation of this program, see Buston (1997).

\section{Results}

\section{General evaluation of the text}

Overall, respondents found the text about asthma on the micro-level sufficiently coherent at first sight. Apart from some mental jumps in the content, on a purely textual level it was initially considered as well written as sentences seemed to follow each other fluently. On a second reading, however, during the task of improwing the text while thinking aloud, many comments were made with regard to shortcomings in the text that respondents thought needed to be improved. All respondents explicitly and often repeatedly said that they wished to adjust the text to the target group. Accordingly, most textual changes were done in light of what information parents of children with asthma would expect, need or want, and how they would (or would not) understand certain textual elements. The changes made will be elaborated in the following sections. First, coherence changes that respondents made in correspondence with the macro and micro level principles in the introduction, are described. Subsequently, additional changes that respondents made are described, which did not completely match the pre-specified principles, but which may increase text coherence just as well. The types of changes will be illustrated by excerpts from think aaloud protocols. Table 2 illustrates the results as explained below.

\section{Changes made at the macro level}

At the macro level of the text, all respondents had ample suggestions how to change the text to increase understanding in the reader. In many interviews, the overall structure of a text's content was considered to be the most important feature for textual coherence. At the macro level, considerable agreement was found among respondents on the types of 
Table 2. Number of respondents (N) that made changes according to the writing principles, and number of respondents that made explanative remark(s) (during rewriting or in the interview) in line with the writing principles.

Note that athough there is generally great overlap, respondents who changed the text are not necessarily the same respondents as the ones who made a remark about it.

\begin{tabular}{|c|c|c|c|}
\hline Text level & Principle & $\begin{array}{l}\text { NApplied writing } \\
\text { principle to the } \\
\text { existing text }\end{array}$ & $\begin{array}{l}\text { N Made explanatory } \\
\text { remark in line with } \\
\text { writing principle }\end{array}$ \\
\hline \multirow[t]{2}{*}{ Matro } & 1. Headings & 13 & 17 \\
\hline & 2. Macro-signals & 13 & 17 \\
\hline \multirow[t]{7}{*}{ Micro } & 1. Argument overlap & 13 & 8 \\
\hline & 2. Ambiguous pronouns & 8 & 7 \\
\hline & 3, Descriptive elaborations & 8 & 7 \\
\hline & 4. Sentence conruectives & 10 & 2 \\
\hline & 5. Given-new order & 5 & 0 \\
\hline & 6. Explicit actor & 4 & 2 \\
\hline & 7. Explicit causality & 5 & 1 \\
\hline \multirow[t]{5}{*}{ Additional } & 1. Sentence length & 15 & 8 \\
\hline & $\begin{array}{l}\text { 2. Passive }>\text { active sentence } \\
\text { structure }\end{array}$ & 7 & 3 \\
\hline & 3. Main verb to front & 2 & 2 \\
\hline & 4. Replace difficult words & 17 & 17 \\
\hline & 5. Add/delete content & 17 & 17 \\
\hline
\end{tabular}

changes they suggested. Most respondents commented an the various kinds of macro level changes as explained in the introduction. However, there was considerable variation in the amounts of changes that individuals made within the various categories, ranging from only one to ten.

More specifically, macro level changes included adding and changing headings and subheadings, adding extra information to clarify the relations among paragraphs, and changing the order of certain pieces of information. Frequent comments were especially made about the order of information and paragraphs, concerning either features that respondents found good about the text or things that they would do differently. For example, some respondents found the existing information order good in the sense that it started to explain what asthma is, followed by all rellevant causes and ended with information on the use of medication. This was in accordance with what respondents thought the reader would expect. However, a considerable number of respondents preferred to integrate causes of asthma symptoms with appropriate actions so that right after every cause the recommended action would be stated. Another frequent change in the information order was separating "background information' more from the main theme by putting it to the back of the brochure or in a separate text box, for instance the paragraph about the mechanisms of the lungs. Sometimes such changes also served to address the reader's need for information. 
In the following two sections, changes that respondents made in accordance with the two cognitive macro-level principles of adding headings and macro signals to the text will be discussed.

\section{Headings}

Mast respondents added headings to the text. Respondents preferred to separate sections with those headings at points in the text where the topic changed and where this transition was not regarded as very obvious at first glance.

Respondent: It seems as if this piece of text links up with this piece of text, but nevertheless this is a new narrative. Because this is all about function and how the lungs wark.. And now it suddenly is about how someone gets asthma, and how you can recagnize it. So this is an entirely new subject, therefore a new heading must be added in between."

Also, at points in the text where the subject change was already indicated by a white line, many respondents chose to add a heading above the paragraph. For instance, where white lines separated enumerations of factors concerning asthma, one-word headings were often placed above these very short sections. Headings that were aliready in the text were changed if respondents thought that the vocabulary was too difficult or did not cover the section adequately. Some respondents changed headings to attract the reader's attention, or to address the reader more directly. This was done by adding words like 'you' and 'your child' into the headings.

\section{Macro signals}

Most respondents who added macro signals did this in the form of short introductions at the beginning of paragraphs, introducing the theme and explaining how it related to the previous information:

Respondent: Then the fourth section is about treatment and then you should actually refer to the causes of asthma, so to the content of prewous pages, that is, to the body and the envirommental influences. Well, then / could say in the section on treatment "Hereditary causes cannot be influenced by ourselves. But environmental factors can."

Macro signals were sometimes also placed in the middle of a section, specifically to add explanatory information. Relevant concepts that had been mentioned in other sections were repeated in the explanation of the new concept if this was thought to contribute to a proper understanding of a new concept. 
Bespondent: Here, in the paragraph about medication, you could also say something about how important it is that the bronchi stay open as widely as possible. And some explanations should be provided about the mechanisms of the muscles, so how the medicine works an those muscles. For that purpose, the information from previous paragraphs can be used:

\section{Changes made at the micro level}

All respondents made changes in the text in order to increase coherence at the microlevel. However, there was great variation in how many respondents applied each of the seven cognitive coherence principles as described in the introduction, and how often they applied it. For instance, argument overlap was improved by 13 respondents while only five respondents made causality explicit. Within these two groups, respondents varied in the amount of specific changes made from one to ten changes for argument overlap and from one to two changes for causality. $\mathrm{Als}$, none of the respondents mentioned or used all coherence principles on the micro level. In the analysis, micro-coherence changes were labeled as one of the seven categories mentioned in the introduction, and will be discussed in that same order.

\section{Argument averlap}

The experimental text already had considerable argument overlap in the sense that nouns were regularly repeated in succeeding sentences, but often rather implicitly in the form of demonstrative pronouns. All respondents were meticulous about the fact that there should not be ary doubt in the (poor) reader what the text is about. That is, the meaning of a specific statement should be clear. Consequently, nouns were often repeated in sentences that succeeded each other. This striving for explicitness in the use of nouns was especially notable when it concerned the use of synonyms in the text: in most revisions respondents. used the same words again, mostly without further comments. Also, when adding information, they seemingly automatically repeated the noun or the subject about which they added text.

Original text: (at the beginning of the section about the lungs:) When we breathe we provide our bodies with oxygen. The inhaled air flows via the nose and mouth....' Bespondent" (add's two sentences in the front) " would start with "Our bodies need oxygen. Oxygen is the fuel with which we walk and move;

In such instances; none of the respondents came up with synonyms for important inouns, but used the same words instead. While rewriting, some respondents consciously commented on this issue:

Original text: "When we breathe we supply our body with oxygen. The breathed air flows wia the nose or mouth past the throat and the vocal cords through the windpipe to the left and right lung." 
Respondent: And what happens very often is that people don't like to use the same word twice, then they use other words. Here it says "When we breathe we supply our body with axygen, and in the next sentence it says breathed air: Then / start thinking "where did the oxygen go here? And is oxygen the same as air?'Most people don't recognize that. So, usually / choose the same word so that people consistently get the same understanding."

\section{Ambiguous pronouns}

Pronouns that ambiguously refer to a noun or concept are detrimental to a straightforward understanding of text. Pronouns in the text that are potentially ambiguous for the reader were recognized as such by almost half of the respondents and replaced by the nouns that the ambiguous pronoun referred to.

Original text: 'A narrowing of the airways occurs because of the contraction. On the inside of the airways extra slime is formed to remove the stimulus. This blocks the airwaypassage even more.'

Respondent: Here is again a reference about which / wonder where it refers to. To the slime or to the contraction? This way, the process is explained less exactly the information is hidden to some extent. I would repeat the exact word that "this" refers to; so "The slime blocks.. 'etc'.

Typically, as respondents read the text, they sometimes paused, indicating that they were confused, and asked aloud what certain words referred to exactly. In such instances, respondents always replaced the ambiguity with the noun itself. Related to the first principle, the existing argument overlap was made more explicit by replacing the pronoun with the noum it stood for. Even when respondents understood pronouns without hesitation, they replaced them with nouns if they thought that there was a chance of misunderstanding in the reader.

Sometimes respondents replaced ambiguous pronouns seemingly automatically, while actually tackling another problem. Specifically, in rewriting sentences that they considered too long into two separate sentences, they replaced the pronoun by the noun-subject of the second sentence:

Original text: The oxygen is delivered to the blood and this transports it through the body: Respondent: " think that for a brochure a sentence is already too long when it contains more than one statement. Here for instance. [... II would make this "Oxygen is delivered to the blood. The blood transports the oxygen through the body."

Since splitting a sentence unto two does not necessarily require that demonstrative pronouns are replaced by nouns, the fact that it was done here suggests that it was not just an outcorne of the splitting procedure, but an improvement in itself. 


\title{
Descriptive elaborations
}

When descriptive well known terms are added to difficult new concepts, text coherence and thus text comprehension is improved. Respondents added only a few of these descriptive elaborations when they found a concept too difficult or uncommon for the reader. In such instances, respondents mainly chose to add examples to provide a more concrete explanation for the concept To a lesser extent they chose to add a more common synonym to the concept.

\begin{abstract}
Original text: Children whose symptoms can every time be related to repeated contact with certain organic substances, are probably allergic to those."

Bespondent: "Certain organic substances, that's an unknown term. I don't know an alternative for that, but in any case I would write that totally differentiy. With an example or so, adding one or two examples of organic substances."
\end{abstract}

Adding explanations to difficult concepts, however, was generally not regarded as the best remedy to repair breakdowns in comprehensibility of concepts in the text. Whenever respondents did not regard a difficult concept as crucial for the reader, they preferred to delete it altogether. Important concepts that were rated as too difficult preferably were described in another way, usually with some more words than in the original sentence.

\begin{abstract}
Original text" (header:) "Various stimuli that can cause hyper reactivity."
Respondent:" wonder if I find the term "hyper reactivity" suitable. L... H think for a lot of people that don't read very much, such a word does not mean anything to them. Therefore I would throw out such terms that / don't find very accessible. And almost always you can describe in plain language what's going on."
\end{abstract}

\section{Sentence connectives}

At points in the text where respondents thought sentences could be related more explicitly, they added words to connect those sentences with each other, resulting in one longer sentence. Words like 'but,'like,' for instance,"except,' 'moreover" and 'conversely' were added to the existing text to clarify relations.

Original text: The oxygen is given to the blood and subsequently this transports it through the whole body. Our body also produces waste:

Respondent: " would not want to see these things separate from each other. I would link them more, [... by using a wora like 'conversely": "Conversely, our body also produces waste."

Whereas some connectives were inserted really deliberately, others seemed to be inserted rather automatically, meaning that respondents used explicit connective words in pieces of text that they wanted to add in. For instance, along with every factor concerning asthma 
attacks, many respondents added practical advice on how to act upon them. In those cases, they used words like "therefore' or 'thus' to make the connection clear.

\section{Given-new order}

At hardly any instance did some respondents change the order of the information in a sentence from the sub-optimal'new-given' order to the more optimal 'given-new' order. In the few cases in which respondents did improve sentence-order into 'given-new' they did this either without further remarks or it was the result of another, strongly related problem that they tackled. For instance, some respondents found that the subject of a sentence should be placed in the beginning of a sentence, from which an unintended 'given-new' order arose.

Original text: 'An important part of the airways are the smallest branches; the bronchi.' (Where the bronchi had been mentioned in the previous paragraph). Respondent: "What I see here (...) is that the subject is placed far to the back of the sentence. "The bronchi, the smallest branches of the lungs, are an important part of the airways." It is actually very simple, it all sounds very boring. [... ] But it reads so much easier when you immediately encoumter the subject, the verb and then the information. In Dutch it is increasingly often turned around. Then you first encounter a lot of text and after that the subject."

Although respondents made no remarks about changing sentences to a 'given-new' order, it should be noted that when they added sentences, in many instances they employed a 'given-new' order, seemingly without conscious deliberation.

\section{Explicit actor}

Some respondents applied the cognitive coherence principle of the "explicit actor', i, $e_{\text {, }}$ they added the actor in sentences in which it was not explicitly mentioned Typically, however, most respondents made the actor of a verb more explicit by rewriting passive sentences into active ones (see 'additional changes'). Furthermore, some respondents repeated the actor when they thought the text was unclear in who did what.

Original text: The finest branches end up in many little alveoli. Around those there are veims. The oxygen is given to the blood and this transports it through the entire body." Respondent: 'In any case I would want to make clear who does what and here it is "what does what?'But "the axygen is given", then it suddenly is much less concrete and then I would say, "Those alveoli give the oxygen to the blood".

In addition, many respondents commented on the distance that is created between the text and the reader by using general sentences without actors such as 'you' and 'your child'. Consequently, many respondents put these terms in as the actors of sentences. 
Original text "The slime is then swallowed or spitted out:"

Bespondent: "If it's possible I would make it active You should address the reader directily. It makes the text really awkward if you write a lot in the passive vaice Because it almost seems as if it is not related to yourself... When / read this brachure / think it is me, or a person who swallows. The reader might not get that So: Then you swallow the slime or you spit it out:

\section{Causality}

In general, only some changes, and hardly any remarks were made with regard to making causal relations more explicit. Even though the sentences themselves contained very few explicit markers of causality, words or phrases such as "because," as a consequence,' 'if...then' and therefore' were only infrequently added in the text for reasons of explicating causal relations between concepts.

Original text: People with an allergy react differently to certain substances than people without an allergy. Tussocks of plants for instance: these harmiess substances do not bother most people, but do harm people with an aliergic predisposition."

Respondent" "would say here "If you come in contact with tussocks of plants, then you will get complaints in your airways. That is a consequence of an allergy, so in that case there is achance that you have an allergy"

As already mentioned in the section on sentence connectives, in cases where respondents wanted to add text on practical actions that could be taken to deal with asthma, they did use causality indicators in the form of connective words. However, respondents only rarely explicitly mentioned causality as a coherence improvement.

Causality was more often made explicit with regard to the macrostructure of the text. Specifically, some respondents changed the order of sentences into one fitting a cause and effect-sequence; starting with a situation and subsequently elaborating the effect(s). Respondents mentioned 'plain logic' or 'taking the reader by the hand'as a basis for such information order-changes.

\section{Other textual coherence changes}

Not all the changes that respondents made could be classified under one of the cognitive coherence principles described in the introduction. However, some changes that respondents made may contribute to text coherence and text comprehension. In this section, those additional text coherence changes are briefiy described.

First, changes were made in surface characteristics of the text, which in the minds of the respondents specifically concerned the length of sentences. In this vein "many respondents shortened or split up sentences they considered too long. Respondents said they wished to restrict sentence length to a maximum of approximately welve words. As a result, sentences contained only a limited amount of different concepts, which the reader should keep active 
in working memory. Thus, the information quantity is kept well within the limits of the working memory span, so that no breaks occur in information processing.

Second, a considerable number of respondents explicitly preferred sentences constructed in the active voice instead of the passive. As a side effect, a subject is put into the sentence, which in turn increases textual coherence. Third, a small minority of respondents put the main verb in the beginning of sentences, so that the reader would not have to keep too much information in working memory before encountering the verb to which it should be'related:

Fourth, all respondents frequently replaced difficult or unusual words and terms with more commonly known synonyms. When they found a word or term superfluous or confusing, they deleted it altogether. This change improves text coherence in the sense that the incoming information matches well with the existing knowledge networks of the readers, and so their working memory is not overloaded with unnecessary information.

A fifth kind of textual change was used by all respondents, namely, they intended to increase text comprehension by adding or deleting whole pieces of information in order to explain more and reduce redundant information. For instance, respondents frequently proposed to insert practical advice on feasible counter-measures against causes of asthma attacks throughout the brochure. By adding this information, the writers wanted to meet readers" wishes and expectations about the health education material. In a similar velin, detailed information that was not thought of as necessary to trigger correct behavior was deleted to prevent confusion.

\section{Discussion}

Health education messages should be understood optimally so that there remains no uncertainty in the audience of how and why to comply with it behaviorally. The current study examined how professional text writers of health education materials think about and apply the concepts of text coherence and text comprehension in writing informative and persuasive messages. The major goal of this study was to gain insight into the extent to which health education text writers know and use coherence principles from cognitive psychollogy. Another goal of this study was to find out if text writers apply additional kinds of textual changes that can be grounded in psychological theory. Answers to these questions may indicate a need for more systematic attention to the formulation of understandable messages, by providing clear guidelines of textual principles that have proven effective in increasing text comprehension.

The results indicate much variation among writers in the nature and the extent of the writing principles they apply, especially in two respects. First, all writers had their own preferences in the kind of textual aspects that they improved in the text. Some mainly focused on the macro level and made very few kinds of changes on the micro level, whereas others made many different kinds of changes especially on the micro level and left the macro level mostly as it was. Second, there was great variation in the extent to which individuals made textual changes within the various categories. 
In general, text writers were quite aware of their readers: they write a health brochure for a clear target group with specific wishes and possibly limited capabilities in mind, to which they try to maximally fit their texts. Typically, writers nead through the text and paused at places where they judged it to be unclear or when they thought the (simple) readler could not understand, and subsequently changed the text. Past experience with their readers seems to play a major nole in this awareness.

There also appeared to be a general consensus about what constitutes an overall coherent text. Respondents especially emphasized structure on the macro level of the text in the sense that texts and content order should correspiond with the reader's need for information. This idea is supported by cognitive psychological research: when a textual structure is in agreement with the reader's expectations, text processing and comprehension is facilltated (e.g, Lorch; 1985; Duffy, 1986). In addition, the overall macro structure of the text was considered to be the most important textual feature to promote understanding in the reader. Indeed, this is partly supported by cognitive psychological research, which showed that a logical structure with an introduction enhances text comprehension (Vidal Abarca; 1992) as revealed in better text recall (Lorch \& Lorch, 1985). Despite this general agreement, however, there was much variation in how writers put macro structure into practice Some thought the order should be from general to more specific explanations, whereas others preferred to place background or general information in separate appendices and the more specific and practical information to the very front of a brochure text. The former strategy corresponds more to the writers' interpretations of readers" expectations, and the latter more to the writers'view of readers' immediate needs. From a cognitive point of view, in so far as the text is consistent with what the reader expects of the content and finds logical in the ordering of subjects, both strategies could benefit comprehension in the reader (Lorch, 1985; Duffy, 1986). To come to a definite ordering of information, research should be done into the expectations of the target group of a brochure.

Respondents had corresponding ideas about the benefits of introducing headings and macro signals. That is, they all emphasized clear headings as promoters of text comprehension, as well as short explanations of how paragraphs fit in the overall theme. Their main motive behind this corresponds with current ideas in cognitive psychology, that headers and macro-signals indicate how specific information relates to the overall theme and helps people to build a coherent semantic representation that fosters comprehension (e.g., Brooks et al., 1983; Hartley \& Trueman, 1985; Wilhite, 1988; Lorch \& Lorch, 1996).

At the micro level of the text, most changes that the writers made were not explained explicitity in terms of text coherence. Indeed, the way they rewrote sentences implied an implicit rather than an explicit awareness of coherence on the sentence level of the text. Again, there was remarkable variation among text writers in whether they made certain changes, and if so, how many and where they placed them in the text Of the seven coherence principles that served as a basis for this study, only the principles of argument overlap, the use of unambiguous pronouns, and the use of descriptive elaborations seemed to be present explicitly in the minds of text writers, as almost half of them mentioned those during the session. Most writers did not comment at all on the principles of sentence 
coninectives, given-new order, explicit actors, and causality. With regard to the last three principles mentioned, mosit changes that were beneficial to coherence were the result of a change made with a different purpose. The finding that text writers used those principles without commenting on their actual nature could imply an implicit awareness of the effects of such principles on the reader: However, whether and where in a text such principles were applied appeared to be very unpredictable. A more explicit understanding of these principles in writers could better ensure their consistent and effective use throughout health education texts.

Five additional kinds of textual changes were mentioned by many respondents and were frequently applied to the text, but could not be categorized as one of the writing principles with which this study started out. Those additional 'principles' mostly fit with what is generally proposed in health education articles (Doak, Doak \& Meade, 1996), and are consistent with the cognitive psychological view on text comprehension. First, the shortening of long sentences indeed facilitates comprehension, because of the limited working memory span in which the meaning of a sentence should be processed to maintain coherence (Baddeley, 1997).

A second noticeable preference of respondents was the use of active over passive. sentences, which can also be supported in light of text comprehension theory. Namely, in active sentences the order of information generally conforms to the order in which meaning should be inferred from information, starting with the actor to which subsequent actions have to be ascribed. Moreover, in active sentences, as opposed to passive ones, there mostly is an actor present to which information should be associated, whereas in passive sentences the actor has to be mentally inferred by the reader, bringing about needless cognitive load or even a break in the comprehension process (Britton \& Gülgozz, 1991). Thirdly and strongly related to this, moving the main verb to the front of the sentence helps readers in the sense that they quickly encounter the meaning that connects two concepts. Hence, the exact sentence structure does not have to be kept active in working memory untill one knows how to relate the information.

A fourth frequently applied principle is the use of simple wordings and if possible words that are well known to the reader population. It is quite obvious how this contributes to comprehension in the reader: from the reader's existing knowledge network words are: activated in his or her working memory, which facilitate integration of the new context and new information into prior knowledge, fostering comprehension (Kintch, 1998).

Lastly, related to content, respondents frequently added information in the form of practical advice to make rather abstract information more concrete and imaginable for the reader. Cognitive findings indeed confirm that concreteness, or the ease of imagery of information contributes to comprehensibility and recall (Sadoski, Goetz, \& Fritz, 1993). In addition, addressing and using the reader's prior knowledge (already in the knowledge networks) this way in a text enables the readers to append to their existing knowledge the information they newly encounter in the text, thus fostering comprehension. Similarly, all respondents actually did delete or wanted to delete irrelevant information, and indeed, in psychological research the inclusion of irrelevant information in texts has been found to be 
detrimerital to making conceptual connections (Trabasso, Siecco, \& van den Broek, 1984). In addition, the unfamiliarity of text content could hinder the construction and validation of inferences (Goldman, 1997).

So, alfhough professional text writers showed great variation in the nature, the extent, and the explicitness of their use of coherence principles as generated by cognitive psychological research, motives behind other principles that many of them use and mention explicitly can be supported by research in cognitive psychology.

\section{Limitations of the study}

Some limitations of the method used in this study should be noted. Because of the restricted time respondents had to improve the text, the revisions made cannot be seen as conclusive. Since the process of writing and rewriting is uterative, there is no guarantee that the revised version as determined in this study is the ultimate version of the text that writers would produce to optimize coherence. Related to this, the fact that writers were faced with one specific text might foster some kinds of coherence changes more strongly than others.

Despite this, we believe that inferences can be made about the prominence of coherence principles that text writers have in mind when they write or rewrite texts in general. Even when writers did not make the expected changes to the experimental text, coherence and text comprehension were discussed thoroughly in the subsequent interview. Respondents had scope to express all kinds of textual features they usually apply to their texts to optimize text coherence and comprehension in the reader. Thus, coherence principles that were not applied nor mentioned in the interview may be regarded as not used explicitly by the text writers. This is even more true given the fact that in advance the text was manipulated somewhat to be sure that it offered opportunities for improvements in all cognitive coherence principles described in the introduction.

Another limitation that might be raised is the total number of seventeen text writers that were interviewed in this study. Although seventeen seems a rather small sample, it consisted of almost all the writers that were mentioned by prominent national health education institutes on our request for the names of text writers they employ or have employed. This adds considerably to the representativeness of the sample: In addition, as the number of interviews accumulated, hardly any new insights were acquired from text writers and earlier findlings were only reinforced. However, to be able to draw any firm conclusions concerning this issue with regard to health education practice in other (smaller) organizations and in other countries, more similar research on text writing practices is necessary.

\section{Implications for practice}

Findings from this study suggest that many health education text writers working for prominent Dutch health promotion organizations are not aware of coherence principles that have proven effective in fostering text comprehension in their readers. In light of text coherence principles from cognitive psychology, the results indicate little consistency in the way that text writers view and establish text coherence in health education materials. 
Given that text writers have their own ideas about how to foster comprehension, and do not necessarily know about or use all coherence principlles, optimal writing of health education materials cannot be guaranteed. A contributing factor to this is the fact that in the process of writing, text writers project themselves into the (often less capable) reader and judge and improve text comprehension accordingly. Hence, the end result depends heavily on the imagination capabilities of the writer, which adds up to the subjectivity of the end result.

By consistently checking and adjusting a text in accordance with an objective set of coherence principles, as described in this article, an important part of that intuitive and subjective writing of understandable texts is overcome. Keeping in mind the cognitive insights in knowledge representation can help the writer to focus solely on improving textual comprehension, independently from the content of the information. Thus, the diffusion of knowledge of cognitive text processing views and various coherence principles among text writers in health education can foster more consistent use of such knowledge and principles. Therefore, text writers in health education, and in fact writers of any other kind of texts, are urged to check their texts on the guidelines discussed in this paper to enhance coherence (as summarized in Table 1). Also, to increase comprehension, they should take into account the additional guidelines that emanated from this study, e.g. make sure sentences are not too long (an average sentence length of 15 to 20 words is advised), use simple or generally well-known words or expressions (when using jargon is inevitable, descriptive elaborations should contain such simple words), and place the actor and the main verb in the beginning of a sentence so that additional concepts can be related to them smoothly (using the active instead of the passive voice has a similar result). Finally; to come to an optimal order of information on the macro level of a health education brochure so that text comprehension is maximized, research should be done with the target group as to what information order they expect in the brochure.

Using these guidelines while writing a text, and possibly as a checklist while rereading a written text, contributes to the promotion of comprehension. Especially for novice writers of health education texts, such knowledge and guidelines may give an effective head start in their ability to write texts that foster comprehension in the reader. 
Chapter

Chapter 2

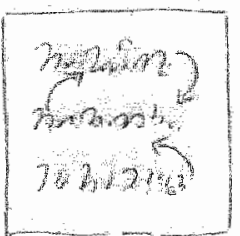

Chapter 3

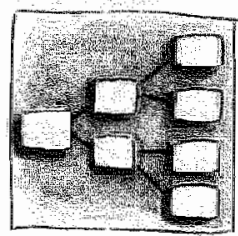

Chapter 4

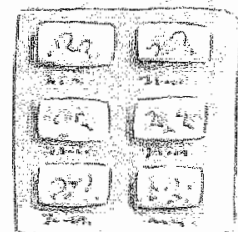

Chapter 5

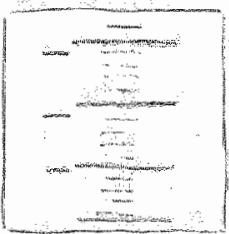

Chapter 6

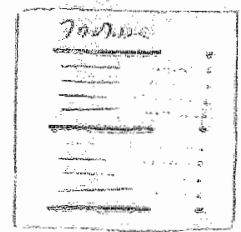

Chapter 7

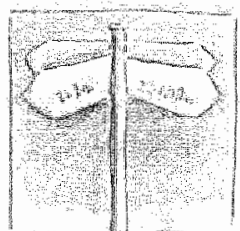

Chapter 8

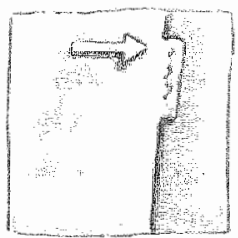

Chapter 9

Summary

Samenvatting

References
Generall introduction

1

frceasing readers comprehension of

heath education brochures: A qualtative

study into how professional writers make texts coherent

The effect of graphic organizers on subjective and objective comprehension of a health education text

Pictures and text in instructions for medical devices: Effects on recall and actual performance

The effects of headings in a brief health education text on locating speed and evaluation

Access structures help readers locate and remember information in a health education brochure

The understandability of pictorials in a 99 health education brochure

Testing the usability of access structures 109 in health education brochures

General discussion: Implications for health education practice 
GRAPHIC OAGANHEAS 
he goal of any instructional text and thus also of health education texts should be that the reader comprehends and remembers its content. In health ieducation theory and practice it is widely acknowledged that comprehension is a necessary condition for communication to occur, next to exposure to and attention for the message (McGuire, 1972). The reasoning behind this is that when there is an insufficient or inadequate understanding of the information, the probability of behavioral change in accordance with the information objectives diminishes. So, information in health education should be properly comprehended to be effective in terms of knowledge transfer and related attitudeand behavior change.

In this study into text comprehension, it was attempted to bridge a gap between two general areas of research, namely that of the persuasion domain and then specifically health education, and cognitive psychology. This is in line with current health promotion approaches such as Intervention Mapping (Bartholomew, Parcel, Kok, \& Gottlieb, 2001), which try to incorporate theoretical methods from different domains into health education development and practice.

The main dependent variables in the health education domain usually are attitude and behavior. Where comprehension is taken into account, measures have been restricted to Likert-scale items that checked for perceived difficulty and understandlability, with the aim of deciding whether certain paragraphs in the text should be simplified. In cognitive psychology on the other hand, ample research has been done into comprehension of information (Kintsch, 1994; Kintsch; 1998), as well as into text characteristics and design principles that can improve text comprehension in the reader (Britton \& Gülgöz, 1991; McNamara, Kintsch, Songer, \& Kintsch, 1996; Moore \& Readance, 1984). In addition, in this research area it is well-known that readers are not allways capable of estimating their own text comprehension correctly. That is, when readers have to judge their own comprehension of a text, inaccurate evaluations can be made (Glenberg, Wilkinson, \& Epstein, 1982). A wellknown phenomenon in cognitive psychology is called 'illusion of knowing; which refers to the effect that readers rate their comprehension as high, while at the same time failing to show textual comprehension on objective questions about the text. To prevent such adverse effects and because in cognitive psychology, the general aim is to ascertain what exactly is understood and what not, it is more common to measure actual comprehension with various kinds of open questions about the text content (see, e.g., Kintsch, 1998; McNamara et al., 1996; Mayer, 1989).

The aim of the present study was twofold. First, we wanted to explore the contributing value of a specific design characteristic developed in the field of cognitive psychology, namely the 'graphic organizer', to comprehension of a health education brochure. Typically, in research so far, graphic organizers were implemented in relatively short and complicated scientific study texts (Bernard, 1990; Hofman \& wan Oostendorp, 1999; Kiewra, Dubois, Christian, \& MCShane, 1988; Waller \& Whalley, 1987). The present study aimed at extending these findings to a longer and generally simple informational text. Second, because instructional design research has shown that readers' subjective comprehension monitoring 
is generally low (Commander \& Stanwyck, 1997; Glenberg, Wilkinson, \&pstein, 1982), another aim was to assess whether health education could benefit from objective measures. Therefore, subjective and objective measures of text comprehension were compared here. Before describing and discussing the methods and results of the present study, we will briefly elaborate on the concepts of text comprehension, text coherence and graphic organizer.

\section{Levels of cognitive text comprehension}

In order to comprehend a text, the text information should become part of the reader's personal knowledge base (Kintsch, 1988; Kintsch, 1994). When readers try to understand a: text, they need to cognitively 'encode' the incoming information by maintaining coherence in their mental representation of the text's content (Albrecht \& O'Brien, 1993; Lorch, Lorch $\&$ Matthews, 1985, van Dijk \& Kintsch, 1983). That is, while reading, concepts from the text enter the readlers' working memory, and if understanding takes place, they are linked to each other and to the knowledge base that is already there. Thus, incoming information is constantly connected to information that already has been learned.

Cogritively, the encoding of a text by the reader can take place on a text base level and on a situation model level (van Dijk \& Kintsch, 1983). The distinction between the two is related to the richness of the connections that readers make between text information and their prior knowledge base. Text base comprehension refers to a relatively superficial form of understanding. When readers have mentally formed a complete text base representation of a text the semantic and rhetorical structures of the text are in long-term memory. Based on this mental text base representation, readers will be able to irecall portions of the text rather literally, without necessarily having a thorough understanding of its content.

In contrast, reaclers who have formed a situation model representation of a text have elaborated on the text information by actively integrating this with their prior knowledge (Kintsch, 1993). This results in multiple connections (hence:'deep' understanding) between text-concepts and already existing concepts in their knowledge base: Based on this more extensive representation of the information in the text, readers will be able to generalize the acquired knowledge to other situations and thus answer questions of which the answers are not stated literally in the text. To learn something from a text and to make high-level inferences such relatively deep understanding is requiled, whereas for mere reproduction of the text, a more shallow text base understanding suffices (Kintsch, 1993).

While reading and understanding a text, readers monitor their comprehension (e:9. Otero, 1998). Instructional research into this 'comprehension monitoring" consists of measuring the relation between readers' predictions of understanding text and their actual performance on questions about the text content (Glenbergl \& Epstein, 1985). Several studies have found evaluation problems in readers, that is, failures of participants in answering questions about the text while showing high confidence in their own comprehension (Commander \& 5tämwyck, 1997; Glenberg et al, 1982; Otero \& Kintsch, 1992; Schommer \& Surber, 1986). This confidence may occur because readers fail to monitor or control comprehension, or because they mentally construct a text that conforms with their meta- 
cognitive models of the text (i.e, their understanding of what is believed to be in the text) rather than the actual text (Hacker, 1998). Either way, such an illusion of knowing" (Glenberg et all, 1982) may mask a text's effects on readers' actual, objective understanding.

\section{Levels of textual coherence}

Readers" actual levels of undierstanding can be influenced by the coherence of a text: A text; in turn, has two different levels at which it can be coherent: the global and the locallevel, also called the macro and micro level, respectively (van Dijk \& Kintsch, 1983). Coherence at the macro level implies that the order of topics is logical as opposed to random and that the smaller and larger sections of text are clearly related to each other and to the overall topic. This kind of coherence can be established in a text with headings above sections and paragraphs and 'macro signals': sentences at the end and start of each section, that explain the link with previous and upcoming text (McNamara et al., 1996). Such textual devices enable the reader to maintain a coherent overall 'picture' of the text, and thus an understanding of how main text elements are related to each other. Coherence at the micro llevel implies that each sentence is explicitly rellated to the next. In addition to abvious relations among sentences based on their content, this coherence can also be achieved with writing itself. With various writing principles (see, e.g., McNamara et al., 1996) it can be made sure that there is 'argument overlap' (Kintsch, 1998; Kintsch \& van Dijk, 1978) on the micro level. This overlap in textual arguments enables that two or more concepts that are sequentially encountered by readers, are simultaneously active in their working memory, which in turn enables text comprehension in the reader.

Based on the distinction between the levels of understanding and the text levels, Hofman and van Oostendorp (1999) developed four kinds of comprehension questions: text base macro, text base micro, situation model macro, and situation model micro questions. In the present study, questions were constructed in accordance with these levels. Specifically, text base questions could be answered with only a text base understanding of the text, so the answers to these questions were stated literally in the text, either on the micro or on the macro level. Situation model questions, however, were designed to tap into a deeper situation model understanding of the text. In order to answer these latter questions, the reader had to be able to make inferences on the micro-and macro level.

\section{Graphic organizers}

A graphic organizer (Barron, 1969) is a graphical depiction that conveys important relations between concepts in the text (Guri-Rozenblit, 1989; Robinson \& Kiewra, 1995). It is a graphic form of the advance organizer developed by Ausubel (1968). Graphic organizers can be given before the goal text with the purpose of cognitively activating and clarifying relations among text-concepts, thereby fostering deep comprehension (i.e., construction of a situation model) of the text content. As the most important concepts in a text are usually put in the macro structure of the text, graphic orglanizers mostly are aimed at clarifying relations among the macro level concepts in the text. 
Graphic organizers can take various forms, such as matrices (Robinson \& Schaw, 1994)" network maps (Robinson \& Skinner, 1996) and hierarchical tree dlagrams (Guri-Rozenblit, 1989). Tree diagrams have most consistently been found effective for learning compared to plain texts (Dee-Lucas \& Larkin, 1995; Guri-Rozenblit, 1989; Robinson \& Kiewra, 1995) and even compared to network maps (Shapiro, 1999). The diefining feature of a hierarchy is that it represents multiple levels of subordinate concepts with the main purpose of communicating superordinate-subordinate concept relations. Research into knowledge representation has shown that people represent knowledge partly in a hierarchical way (Chi, Hutchinson, \& Robin, 1989; Kintsch \& van Dijk, 1978; Mannes \& Kintsch, 1987) and are better in using and understanding hierarchical relationships among concepts than linear ones (5hapiro, 1999). Thus, hierarehical overviews seem to facilitate comprehension of the thematic structure of a text and the organization of information in the reader's memory (see, e.g. Lorch, Lorch, \& Inman, 1993).

In the present experiment, the graphic organizers reflected information on the macro level of the text. Therefore, we hypothesized that especially on that level "comprehension would increase compared to the plain text condition: Furthermore, we predicted that the scores between the graphic organizer group and the text-only group would differ more on the objective measure than on the subjective measure, as the former is a more precise measure of text comprehension than the latter.

\section{Method}

\section{Participants}

Forty-six first-year undergraduates from the Department of Psychology at Maastricht University participated in this study for course-credits. Students had expressed a general willingness to participate in some behavioral science studies, by leaving their names and telephone numbers on sign-up forms. From this list; participants were selected and invited to the laboratory based on their low prior knowledge about the text-subject "asthma', which had been established with a knowledge questionnaire about asthma among the whole sample of first-year undergraduates two months earlier. They were randomly assigned to one of two conditions: 23 participants ( 4 males and 19 females, mean age 19) received a text with graphic organizers, and the other 23 (5 males and 18 females, mean age 18.83) received the same text without graphic organizers.

\section{Materials}

A 12-page text (A4-paper size, average sentence length 12.33 words, average word length 1.75 syllables) was extracted from an existing brochure about asthma, which has proven effective in changing the behavior of parents of children with asthma (Mesters et al., 1994). It started with an explanation of what asthma is and what happens in the lungs during an asthma-attack. This was followed by an extensive enumeration and explanation of physical and environmental factors that can trigger or contribute to asthma-symptoms. Then, actions were described to clean the house from asthmatic stimuli such as dust and moisture and finally, warious kinds of medication were explained. 
Multiple graphic organizers were devised in line with suggestions made by Robinson and Kiewra (1995). Specifically, four graphic organizers were developed that corresponded with the four main themes of the text as described above (see Figure 1). The organizers were informationally equivalent to the text content in that the relations that were expressed in the organizers were also mentioned in the text. The organizers were hierarchical in nature, in the sense that concepts were interconnected from left to right to communicate
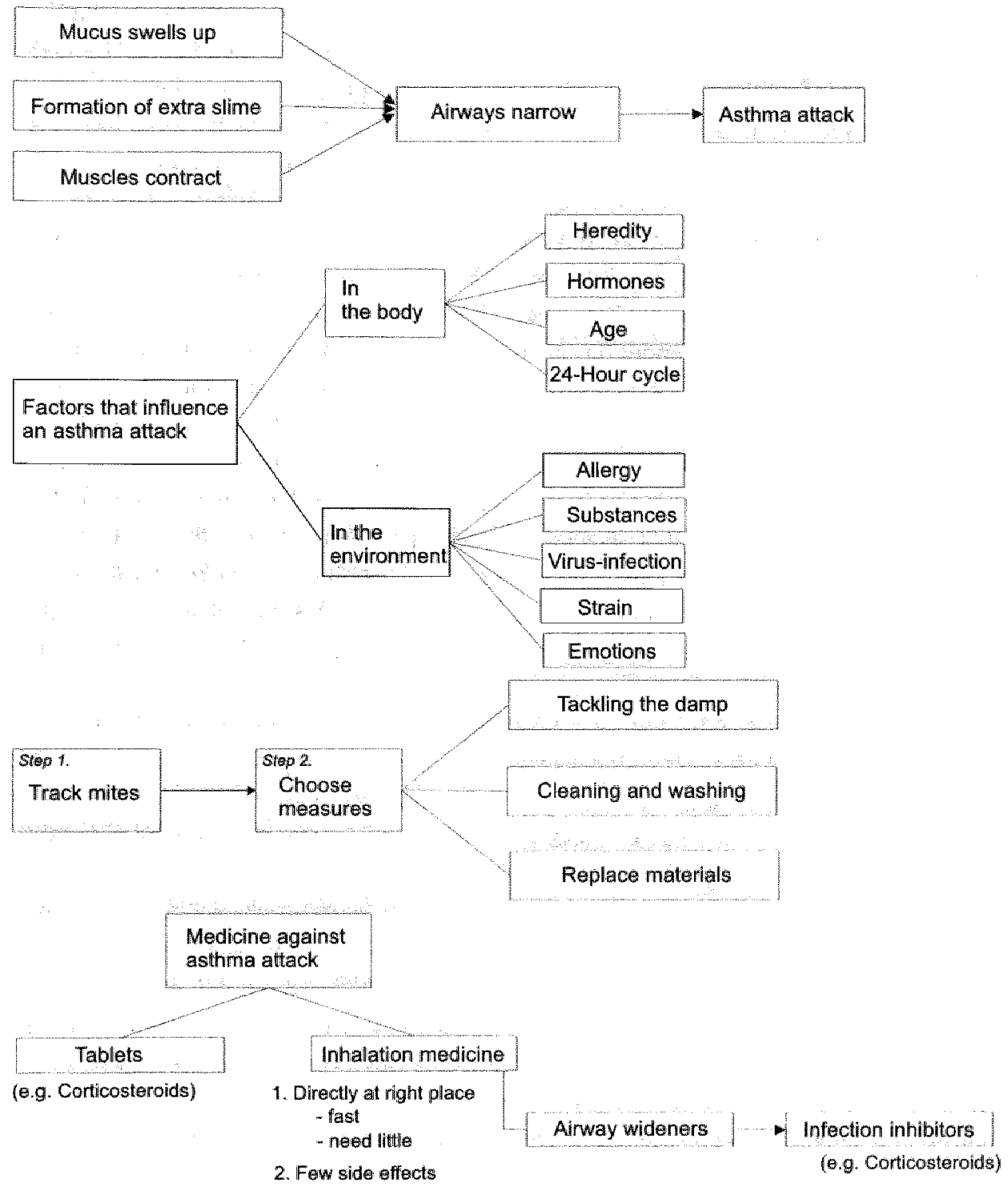

Figure 1. Examples of the four different graphic organizers used in the asthma brochure, for each main subject of the text. Note that arrows indicate some temporal sequence, whereas for mere linkage of concepts, normal lines are used. Each figure was presented on the top of the page, with its relevant section. 
superordinate-subordinate relations (Wallace, West, Ware, \& Dansereau, 1998). Except for the first page of the text, on every page an organizer was placed on the top, with the relevant concepts addressed on that page highlighted in the organizer by means of thick lines and shadings (Waller \& Whalley, 1987).

\section{Measures}

Participants were asked to rate several general aspects of the text and their reading process on a questionnaire containing 15 seven-point Likert-scale items ( $1=l_{\text {low }} 7=\mathrm{high}$ ). Specifically, five questions concerned estimations of one's own comprehension and formed a reliable index of subjective comprehension (Cronbach's alpha $=.72$ ). Three questions concerned effort that they had put in trying to understand the text (Cronbach's alpha $=.71$ ). Three questions concerned the reading process itself, such as how many times they had reread pieces of text. Inter-item correlations of these items was low, therefore they were analyzed separately. Also, two control questions were inserted to make certain that the two groups were comparable with regard to interest in the text and experience of 'fit' of the text's information with the reader's prior knowledge about the subject. Finally, one manipulationcheck item specifically asked about the amount of attention participants had paid to the structure of the text, since the graphic organizers point to the overall structure of the text.

A questioninaire with 43 open-ended questions was developed to measure actual or objective text comprehension on four different levels, as explained in the introduction. The questionnaires were pretested in two iterative cycles with four and then two second-and third year students to ensure that questions elicited a generality of specificity in answers as was intended by the researchers. Fifteen of 43 question formulations were adjusted to assure unambiguous wordings and answer levels. There were 9 text base macro, 12 text base micro, 8 situation model macro, and 14 situation model micro questions, which were put in a random order in the final questionnaire (see Table 1).

To score objective comprehension, a coding scheme was developed specifying the correct answers to all the open-ended questions. For every correct proposition or concept in an answer, one point was given. In this way, scores on questions ranged from one point up to ten points. Two raters scored the answers independlently and blindly to condition. Scores were ascribed to the answers based on the coding scheme and subsequently compared their scores on each question for each participant. The inter-rater agreement was $75.6 \%$. In cases where the ratings differed, this turned out to be the result of consistent differences in interpretations of the instructions by the two raters. Wherever the raters differed the relevant answer was re-evaluated and the final score was determined with consensus. The maximum scores that could be gained for each question category was 34 on the text base macro, 29 on the text base micro, 27 on the situation model macro, and 45 on the situation model micro level. Individual scores were transformed into percentages of these maximum possible scores. 
Table 1. Two examples of open-ended questions at each comprehension level. Note that answers to both kinds of text base questions were stated literally in the text, whereas both kinds of situation model questions required participants to apply their knowledge acquired from the text to situations not elaborated in the text itself.

\begin{tabular}{|l|l|}
\hline Kind of question & Examples \\
\hline Text base macro & $\begin{array}{r}\text { Asthma-symptoms can be caused or influenced in two different ways. } \\
\text { Which two ways are that? } \\
\text { Name five substances to which asthma-patients are often allergic. }\end{array}$ \\
\hline Text base micro & $\begin{array}{l}\text { What are the branches of the airways called? } \\
\text { Which three events take place in the airways when a child gets an } \\
\text { asthma-attack? }\end{array}$ \\
\hline Situation model macro & $\begin{array}{r}\text { There are children playing in a pool. One of the children gets an } \\
\text { asthma-attack. What are four possible causes of this attack } \\
\text { occurring at that moment? }\end{array}$ \\
\hline Situation model imicro & $\begin{array}{r}\text { Describe an ideal bedroom for an asthma-patient. Name four } \\
\text { characteristics. }\end{array}$ \\
\hline $\begin{array}{r}\text { Suppo in a house there are unusually many mites and also much } \\
\text { mildew. How can you explain that? }\end{array}$ \\
Why are no airway-wideners necessary with the intake of pills?
\end{tabular}

\section{Procedure}

Participants completed the experiment individually while seated in a classroom, with six to eight persons present at a time that were individually assigned to the organizer or noorganizer group. Before starting, participants read and signed a consent form, stating that they participated voluntarily and that they were free to cease participation at any time if they wished. At the start of the session, participants were instructed to read the text carefully and try to understand its content. To increase performance motivation they were told that the best performer on the open questions would get a bonus of 50 euros. Then, the texts were handed out and participants could start reading. Participants were given 35 minutes to read the text, which in pretest had proven to be ample time to read it at a normal pace. So, the time-on-task was 35 minutes, as participants who finished a bit earlier, typically had another glance through the text until the time finished. After 35 minutes, the texts were taken away and the questionnaires were administered, first the closed-ended questionnailre, then the open-ended comprehension questionnaire. All sessions took two hours.

\section{Results}

\section{Control Questions}

In analyses of variance (ANOVA), the two groups showed to be comparable in the extent to which the text was evaluated as interesting $\left(M_{\text {with arg }}=4.78 ; 5 D=1.31\right.$ versus $M_{\text {without org. }}$ $=4.87 ; S D=1.42), F(1,44)=0.05, p=.83$, and the extent to which the text fitted well with participants' prior knowledge about asthma $\left(M_{\text {with org. }}=5.30 ; 5 D=1.40\right.$ versus $M_{\text {wathoul ory }}=5.04$; $S D=1.66), F(1,44)=0.33, p=.56$. The two groups did also not differ in the effort they put into 
reading the text, $F(1,44)=0.20, p=66$. Overall, participarits had high indications of effort $\left(M_{\text {wititiong }}=5.97 ; 5 D=64\right.$ versus $\left.M_{\text {werthoum org }}=5.88 ; 5 D=.69\right)$. Furthermore, the two groups did not differ in their scores on all three items measuring the reading process. Both groups did not often reread earlier parts of the text $\left(M_{\text {surit arg. }}=3.35 ; S D=1.47\right.$ versus $M_{\text {without org. }}=3.04 ; 5 D$ $=1.43), F(1,44)=0.51, p=.48$. Also, they did not seem to thumb back in the text to see what the text was about again' $\left(M_{\text {wath org }}=1.65 ; S D=.83\right.$ versus $\left.M_{\text {withoun org }}=1.87 ; S D=.92\right), F(1,44)=$ $0.71, p=41$. Finally, both groups did not evaluate the text as hard to read $\left(M_{\text {with org }}=1.91 ; 50\right.$ $=1.24$ versus $\left.M_{\text {without org. }}=2,35 ; 50=1.47\right), F(1,44)=1.18, p=.28$.

\section{Attention for text structure}

An ANOVA on the manipulation-check item revealed a significant difference in the amount of attention that was paid to the text structure: the graphic organizer group scored higher $\left(M_{\text {with ong }}=5.00, S D=1.13\right)$ than the text-only group $\left(M_{\text {without org. }}=4.22,50=1.41\right), F(1,44)=$ $4.31, p<.05$.

\section{Subjective Comprehension}

The graphic organizer and the text-only group did not differ in perceived text comprehension $\left(M_{\text {with org }}=5.66 ; 50=.52\right.$ versus $\left.M_{\text {without org }}=5.49 ; 50=.97\right)$, as measured with an ANOVA, $F(1,44)=0.59, p=.44$. 5o, participants generally rated their comprehension as high on the 7-point Likert scale.

\section{Objective Comprehension}

A repeated measures ANOVA showed a main effect of group on text comprehension as measured by the open questions, $F(1,44)=20.56, p<.01$. Overall, the graphic organizer group performed better $\left(M_{\text {with org }}=57.23 \%, S D=11.03\right)$ than the text-only group $\left(M_{\text {without ong. }}\right.$. $=43.79 \%, S D=10.2)$ A repeated measures ANOVA with group (with and without graphic organizers) as between subjects factor and level of comprehension (text base macro, text base micro, situation model macro, situation model micro) as within subjects factor showed a main effect of question type (see Figure 2 for means). However, there was an interaction effect between group and the level of text comprehension, $F(3,132)=10.96, p$ $<01$. Separate analyses showed that the graphic organizer group scored better than the tex"-only group on all four comprehension levels (see Figure 2). Text base macro questions were answered significantly better by the graphic organizer group than the text-only group $F(1,4.4)=50.81, p<.01$, as was the case with text base micro questions, $F(1,44)=4.60, p<$ .05 , situation model macro questions, $F(1,44)=10.59, p<.01$, and situation madell micro questions, $F(1,44)=6.08, p<.05$. As clearly depicted in Figure 2 , the difference between the graphic organizer and text-only group was especially large on the text base macro level. 


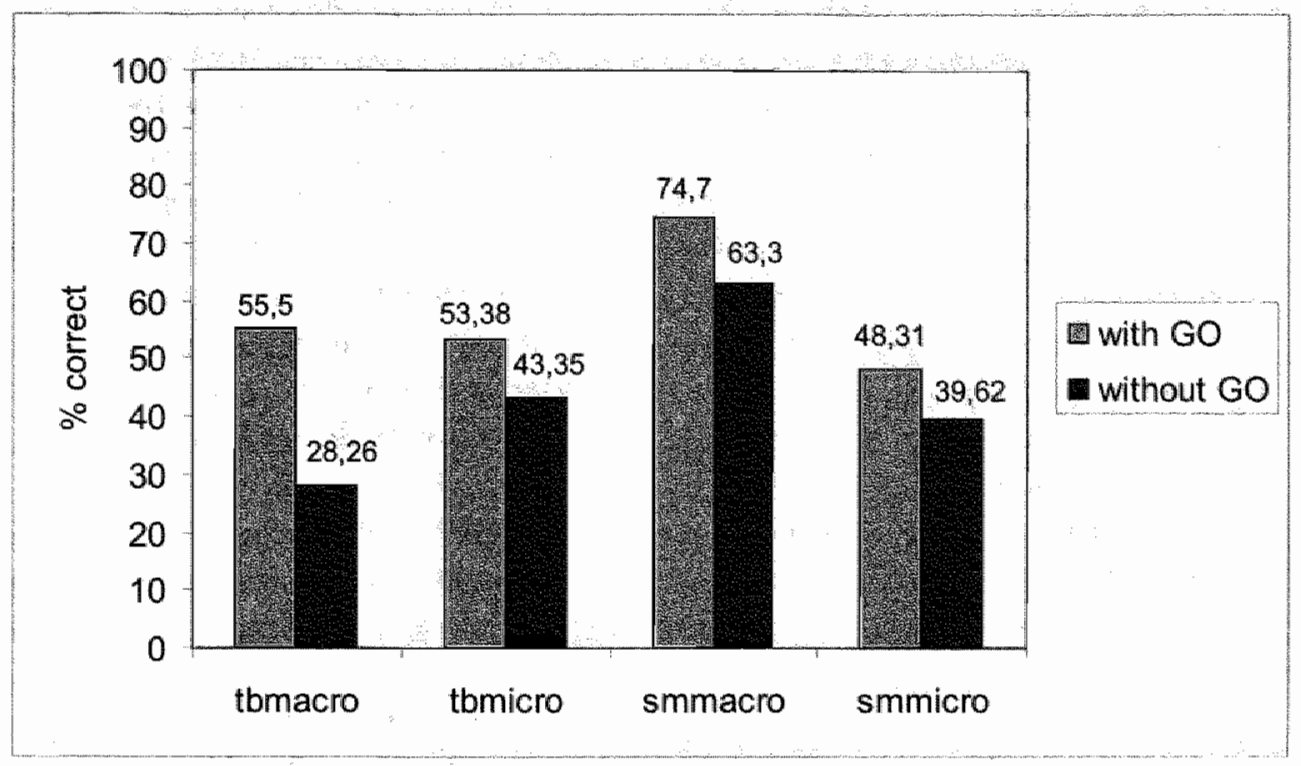

Figure 2. Performance in percentage scores of the two groups on text base macro, text base micro, situation model macro and situation model micro questions, respectively. As can be seen, the graphic organizer group outperformed the control group on all four measures, this difference being especially large on the text base macro level.

\section{Discussion}

The primary aim of this study was to examine the value of the systematic implementation of graphic organizers in a long health education brochure text on subjective and objective text comprehension. It was expected that in such a long text, graphic organizers would enhance objective text comprehension in the reader, particularly on the text base macro level. This was indeed what was found. The findings suggest that systematic placement of hierarchical macro-level graphic organizers encourages readers to learn the big picture rather than only facts, as has also been suggested in other research (Robinson, Katayama, Dubois, \& Devaney, 1998). Thus, graphic organizers also improve comprehension of relatively long and simple texts, and not only of short and complicated texts, as has been found so far (Robinson \& Kiewra, 1995).

The results not only show a strong effect of the graphic organizers on text comprehension at the text base macro level, but also on the other three text comprehension levels: the text base micro level, the situation model micro level ${ }_{n}$ and the situation model macrollevel. These effects could not be explained by other comprehension-related variables, such as the readers' reading effort, prior knowledge, or interest in the text. Evidently, the hierarchical graphic organizers helped the readers not only to grasp the macro structure. of the text on text base level, but they also helped the reader remember details on the text base micro level and build a situation model of the global and local text content, fostering deeper understanding on both levels. 
Two explanations could be given for the results. First, it is possible that the organizers helped the processing of the macro level text structure to such an extent that more cognitive capacity was left for the processing of information on the other levels. This reasoning is in line with the visual argument hypothesis (Vekiri, 2002). According to this hypothesis, the visuo-spatial properties of graphic organizers may facilitate the processing of information so that the limited working memory capacity is not exceeded. This perceptual enhancement' of graphic organizers may provide the reader with a computational advantage' (Larkin \& Simon, 1987), leaving enough capacity and thus opportunities to integrate micro level information with the macro level information in the organizers and build a situation model A second possible explanation is that the prominent role of the organizers may have made them effective recall prompts for information on the micro level, resulting in a better memory and comprehension of micro level information (DeeLucas \& Larkin, 1995, However, the data of this study cannot give a definite answer to the exact mechanisms involved; in fact both mechanisms may have exerted some effect simultaneously.

In contrast to the strong effects of the graphic organizers on objective text comprehension there was no difference between the two groups on the subjective measures of comprehension. Even when readers indicated they have comprehended a text reasonably well, when asked to show this on open-ended comprehension questions, shortcomings in their comprehension could be revealed. This is in line with findings reported in the American National Adult Literacy Survey (Kirsch, Jungeblut, Jenkins, \& Kolstad, 1993), that people think they read and understand better than they actually do as verified by objective testing. Thus, open-ended questions clearly have a higher sensitivity than subjective closed-ended questions in measuring comprehension.

The fact that this study was conducted with first year students gives an extra dimension to the interpretation of the results. That is, in general, university students have relatively good meta-cognitive skills (Garner, 1987), which means that they are good in sustaining, monitoring, and taking actions when necessary during reading. Therefore, one would expect that participants in this study would be very well able to learn and comprehend a coherent text without any graphical aids. Especially with a relatively simple text, this would create a ceiling effect, leaving no difference to be found between readers that read a text with and without graphic organizers. However, this did not occur. So, even for yeaders with high metacognitive skills, graphic organizers can facilitate comprehension of simple, coherent and relatively long instructional texts as shown in the present study.

However, to be able to generalize the results of this study fully over various target groups (with various literacy skills, for example) and other instructional and health education materials, further research in this line should be done. In addition to the generalizability over various reading levels and materials, this research could also address other limitations of this study, such as the motivation and the prior knowledge with which readers approach health education materials. It is highly likely that parents of children with asthma for instance, are very involved and thus motivated to learn from a brochure about asthma. Together with some prior knowledge that they may already have acquired through experience with their 
asthmatic child, this may diminish the additive explanative value of comprehension aids such as graphic organizers. Future research with the target group may clarify just how such factors influence the comprehension process.

\section{Implications for practice}

In conclusion, even in relatively simple and coherent health education brochure texts. which the readers say they understand well, implementing graphic organizers in the form of hierarchical tree-structures may facilitate comprehension greatly. Especially where explamations about processes involved in a disease need to be understood, or if recall of important aspects is crucial, such graphic representations could aid readers in the understanding that is required for this. The specific design of graphic organizers depends entirely on the subject of the health education text and the goals of the health practitioner. However, some practical recommendations could guide the design process. Based on the literature review in the introduction of this study, thierarchical tree-diagrams such as tested here, may be preferred over tabular or network overviews. These diagrams, should not be too extensive, i.e., not have more than three levels and preferably only two. Also, the organizer should be placed in close proximity of the text section that it is about, as otherwise readers may miss the relationship between the visual and textual information. If the organizer covers text on several pages it should appear above every page with relevant concepts of that page highlighted in the organizer with thicker lines and shadings.

Furthermore, testing an initial brochure design with readers is highly recommended to establish that comprehension as it was meant from the outset, is achieved. In doing this, it should be kept in mind that using subjective ratings of comprehension in the evaluation of health education materials may not give sufficient insights into actual comprehension by readers. Connections among important concepts may not have been made at all, while the reader is unaware of this gap. Therefore, the use of objective comprehension measures as used in this study, is strongly recommended in developing health education materials.

As constraints in time and resources from a practitioner's point of view are acknowledged, it should be mentioned that this testing does not have to take place on an extensive scale. Answers to open comprehension questions of only a few individuals may already give insights into which aspects of the text or arganizer are not understood, which in turn provides information on possible improvements. To practitioners, closed multiple choíce questions may seem attractive in gathering a lot of data in a relatively easy way. However, next to issues of guessing behavior by participants and the labor-intensive job of coming up with plausible answering-alternatives, an even more important drawback of closed questions is that they hardly give any insight into what exactly is and is not understood by the reader. As this is especially valuable information in designing effective health education information, the use of open and objective comprehension questions is recommended. 
Chapter 1

Chapter 2

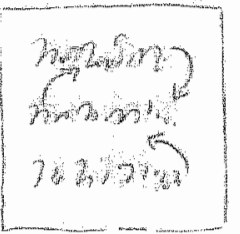

Chapter 3

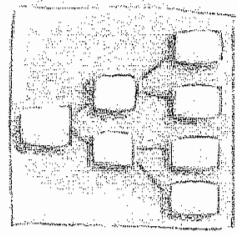

\section{Chapter 4}

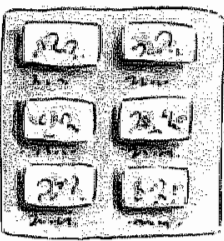

Chapter 5

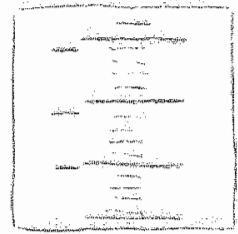

Chapter 6

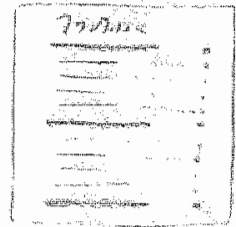

Chapter 7

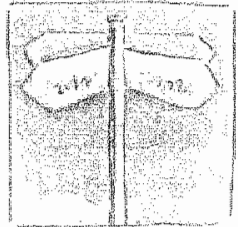

Chapter 8

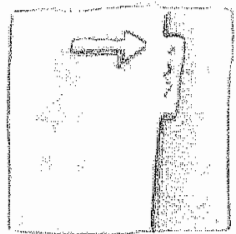

Chapter 9

Summary

Samenvating

References
General introduction

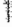

mereasing readers comprehension of

13

health education brochures: $A$ qualitatve study into how professional writers make texts coherent

The effect of graphic organizers on subjective and objectwe comprehension of a health education text

Pictures and text in instructions for medical devices: Effects on recall and actual performance education text on locating speed and evaluation

Access structures help readers locate and remember information in a health education brochure

The understandabilty of pictorials in a heath education brochure

Testing the usability of access stuctures 109 in health education brochures

General discussion: Implications for health education practice 
PiCtuAES IN INSTAUCTIONS 
$n$ $n$ the development of health education materials, very little research is done into how graphical design affects comprehension of information. At most; with a basic notion that pictorial information can aid readability of a brochure text, studies have simultaneously changed text and added pictures to concretize or make the information more interesting to readers (Clark, AbuSabha, von Eye, \& Achterberg, 1999; Michielutte; Bahnson, Dignan, \& Schreider, 1992). However, from instructional design research we know that the presence of pictorial information allows readers to visualize relations in the text (Kosslyn, 1994), enabling the formation of a mental model of the situation, which may enhance understanding of text (e.g., Johnsson-Laird, 1983; Mayer, 1997; Schnotz \& Bannert, 1999).

The present study aimed at testing the additive value of illustrations in medical instructions that were originally part of a health education brochure. Based on research in instructional design (e.g. Levie \& Lentz, 1982; Mayer, Steinhoff, Bower, \& Mars, 1995), it was predicted that when more thought is put into including pictures in such information, this could aid text comprehension. Especially with unfamiliar devices or ambiguous instructions, such effects may be strong. To test these assumptions, we added simple line drawings in two text-only instructions from an existing asthma brochure (Mesters, Meertens, Kok, \& Parcel, 1994) for using two devices, the 'inhaler chamber' and 'peak flow meter." Based on a usabilityanalysis regarding the inherent clarity of features of both devices, illustrations were expected to have a stronger effect with the inhaler chamber than with the peak flow meter. Objective measures were used to assess comprehension.

\section{Text-Picture Understanding}

In the field of instructional design, pictures have been found to improve learning (see e.g. Levie \& Lentz, 1982; Filippatou, 1996), which is explained in terms of a 'mental model theory' (Johnsson-Laird, 1983; Mayer, 1997; Schnotz \& Bannert, 1999). Mental model theory states that through different processing routes, text and pictures enable construction of both verbally ("propositional')- and visually-based mental models. These are integrated by the reader in their working memory to foster comprehension (Mayer, 1997). When presented alone, text has been found to need more cognitive resources than pictures, because it has to be mentally transformed into a propositional representation and then into a mental model of the situation. Pictures, on the other hand, are considered to be external models (i.e. analogical visual representations) that directly allow the construction of a mental model of the situation (Ganier, 2001).

Readers are best able to build connections between these two representations when the corresponding text and picture are in working memory at the same time (Baddeley, 1986). As working memory is limited in time and processing capacity, this concurrent activation is most likely to happen with contiguous presentation of text and illustrations (Mayer, 1997; Mayer et al., 1995), illustrating a 'spatial-contiguity effect' (Moreno \& Mayer, 1999). One possibility is adding textual captions (Bernard, 1990) to illustrations explaining the important aspects of the picture's content. 
Pictures may contain 'depicting-" and 'directing codes.' Depicting codes' simulate characteristics as they are perceived in the real world (Weidenmann, 1994), for instance, photographs depicting the text-subject. Such pictures may serve a representational or a decorative function: text content is merely repeated or the text is madle more esthetical to increase the readers' interest, respectively (Gyselinck \& Tardieu, 1999). "Directing codes, on the other hand, deviate from reall world appearance and typically aim to convey a visual argument: Arrows and exaggerations of specific elements, for example, can prompt the reader's attention to relevant picture details ('visual cueling' (Beck, 1984)) and can direct such cognitive processes as comparing, generating inferences, and imagining motion (Weidenmann, 1994). When inferring movement in procedural pictorial instructions, people have been found not to make inferences unless such movement is expressed explicitly with text or arrows in pictures (Hegarty, 1992).

\section{Procedural instructions}

With procedural instructions such as in the present study' when users have formed an understanding (mental model) of the information, this information should be acted upon. In doing this, several cognitive activities are performed by readers in their working memory, ranging from setting a goal and integrating information from the instructional document; the to-be-used device, and prior knowledge, to action planning, execution, and monitoring the actions (Ganier, 2004). To avoid cognitive overload, readers can reduce the amount of information to process by switching regularly between the instruction and the actions to perform. The design of procedural instructions which supports such step-by-step strategies has indeed been found to shorten execution time and reduce errors in performance (Duggan \& Payne, 2001; Glover, Harvey, \& Corkill, 1988):

With procedural instructions also, a combination of text and pictures generally leads to superior performance compared to text alone (Ganier, Gombert, \& Foyal, 2000). With text-only procedural instructions, readers perform 'macro-switches' between the text and the device to match textual and visual information before planning the actions described. However, when pictures accompany the text, the reader can perform 'micro-switches' between the text and relevant visual elements inside the document. This could take up less working memory resources, because more precise information is given about what to do (in the text) and where to do it (in the picture) (Ganier 2004 ) before switching to the device to perform the actions.

Research of pictures in procedural instructions mainly focuses on relatively technicall devices (Ganier et al., 2000) and complicated compilations of parts (Ganier, 2001; Glover et al., 1988 ; Stone \& Glock, 1981), of which the actions to perform are not obvious to novice users. However, with devices that have a higher inherent clarity the contributing value of pictures may be lower. In cognitive ergonomics, a research area aimed at studying and improving the usability of devices, such inherent clarity is described in terms of 'affordances' and 'constraints' (Norman, 1988). Affordances refer to characteristics of objects that are perceived by their users regarding their potential use: objects permit and even provoke certain useractions because of their form, weight or materials. For instance, a smooth round red button 
Wifted a centimeter from a surface, affords pushing it. Constraints, on the other hand, refer to an object's characteristics that limit possible actions. Sicissors, for instance, have two holes with different sizes, limiting the number of fingers you can put through each of them, and the scissors onlly move in one direction. These constraints help the user identify the proper use. Thus, a device may be inherently clear, or require minimal explanations. Pictures may add very little in such circumstances.

\section{The Present Study}

The aim of the present study was to test the predictions that illustrations would promote understanding of the information more than text-only instructions and that this effect may be stronger with an inherently ambiguous rather than clear device. Understanding of the information was tested with open recall and several performance measures when following the instructions, in line with the general need for performance-based evaluation of (health education) instructions (Wright 1 1999).

Two different instructions were tested, namely for the "inhaler chamber" and "peak flow meter'. The first is a device for using an asthma pump when people have difficulties inhaling from the pump itself and the second is a device to measure the passageway of the airways (see also Figures 1 and 2). The peak flow meter is a tube with one round pointy opening at the front, which was expected to afford blowing in it. The presence of a scale with a pointer that only moves when blowing in the tube contributes to this affordance. Being a non-transparent object with a closed end constraining the possibility for blowing on the wrong end, it would be a challenge to use it differently. The only information that may not be communicated by the device itself pertains to bodily positions when using it; relatively simple actions' that people perform daily to some extent and thus may not be entirely unfamiliar.

The inhaller chamber has a small round extended opening on one side of the tube which affords putting it in one's mouth. A curved holder on the other side of the tube is the only place where the asthma pump fits, constraining the placement of the pump on the chamber. However, the inhaler chamber has some features (valves) that should not be used but may afford using them and several actions are not afforded or constrained by the chamber of the pump. Thus, the inhaler chamber was expected to benefit more from pictures than the peak flow meter. To test this, the present study comprised two separate but identical tests, each comparing a text-only with an illustrated version of the instruction.

\section{Method}

\section{Participants}

Ninety-nine participants of the general public that had responded on leaflets posted in local supermarkets had been selected on low prior knowledge of both asthma devices. They were randomly assigned to one of four groups in two separate between-participants designs. There were 26 participants in the inhaler chamber text-only (11 men, 15 women, mean age 39.88) and 24 in the inhaler chamber text-pictures condition ( 7 men, 17 women, mean age 36.29). Furthermore, there were 24 participants in the peak flow meter text (6 men, 18 
women, mean age 37.38 ) and 25 in the peak flow meter text-pictures condition ( 8 men, 17 women, mean age 33.68 ).

\section{Materials}

For each condition an A4-size one-page instruction was developed, based on original instructions taken from an asthma brochure (Mesters, Meertens, Kok, \& Parcel, 1994). Both original text-only versions of the instructions were lists of bullet points with the steps to follow. The explanation of the peak flow meter contained a total of 26 propositions (i.e. meaningful text elements) and the inhaler chamber 11.ln the text-picture versions of both instructions, seven parts that contained concrete actions were accompanied by $3.5 \times 2.5$ inch line drawings visualizing those actions (see Figure 1 and 2). Each textual instructional step was presented as captions directly below its accompanying illustration, which contained directing codes (arrows and enlarged details) to pinpoint relevant features that readers should attend to and movements they should visualize.

\section{Procedure}

Participants were tested individually. They were told that the aim was to test the quality of various instructions for asthma-devices: One device was put on the table for the participant to look at and one of the four instructions was handed over. They were told to read the instruction carefully until they felt they understood it. In doing this, they were allowed to look at the device on the table. When they signaled they had understood, the instruction and the device were put out of sight and the participant was given an unrelated task - a maze task - to reduce the effects of residual short-term memory for the information (Bernard, 1990; Gambrell \& Jawitz, 1993). Then, participants were asked to verbally recall what they could remember from the instruction they had read. Finally, the instruction and the device were handed over with the request to perform the actions as described in the instructions. Everything was recorded on video to enable transcription and analysis of the data afterwards.

\section{Variables and Data Analysis}

Three general measures were extracted from the video-recordings, some comprising several sub-measures as described below. T-tests were performed on all measures unless otherwise indicated.

First, the time (in seconds) participants took to understand the instructions was measured. Second, the quality of participants' recall was assessed with four sub-measures, extracted from the typed-out transcripts of their verbal recall. First, one point was given for every correctly recalled proposition. In total, the inhaler chamber contained 11 propositions and the peak flow meter contained 26 propositions. Paraphrases in the recall data that conveyed a proposition's meaning were also counted as correct. Second, mistakes in recall, so when participants described an action in a way it should actually not be performed, were counted. Third, the number of steps that participants commented on in their recall (either through literal recall of propositions, or via correct inferences made) was counted (with 


\section{Use of the inhaler chamber}

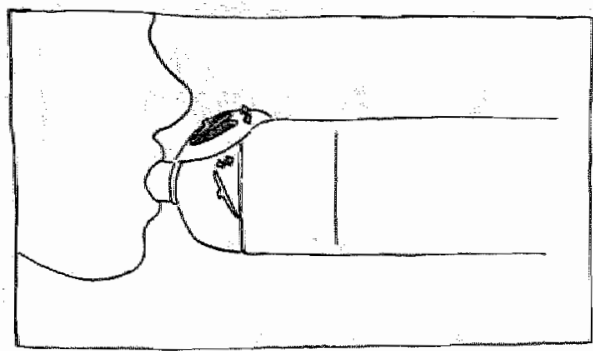

Check whether both valves (ventiles) can move. You can do this by breathing in and out of the inhaler.

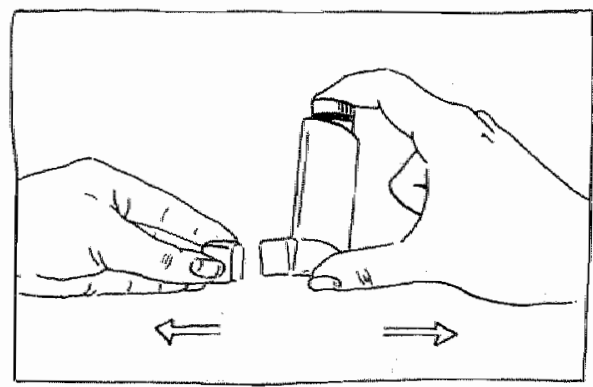

Take the closing cap from the pump.

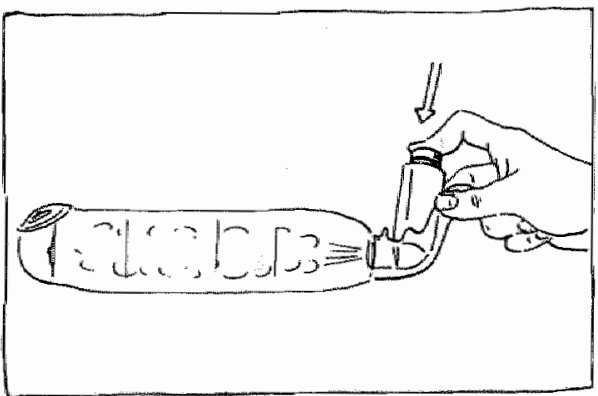

Bring one spray into the inhaller chamber.

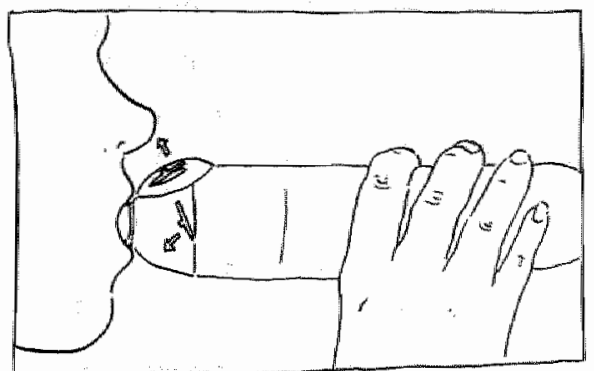

Breath calmly in and out through the inhale chamber, making the valves move.

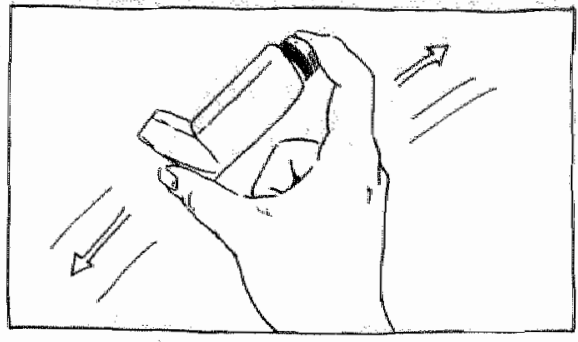

Shake the pump well.

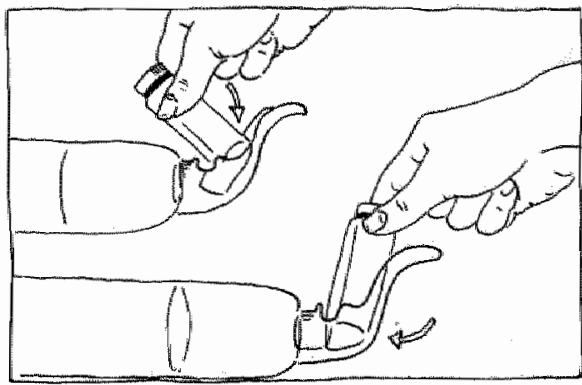

Put the pump into the inhaler chamber

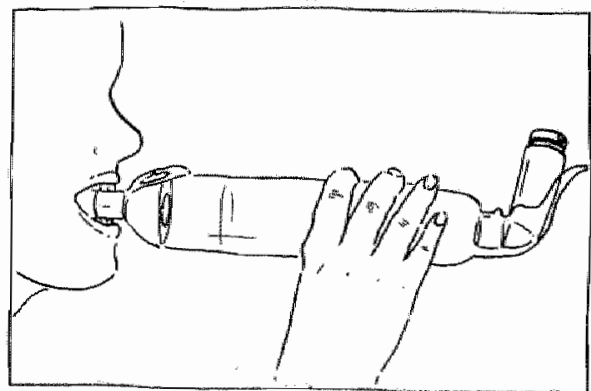

Put the mouthpliece of the inthaller chamber between your teeth. You should close your lips around the mouth plece.

Breathing in and out approximately 5-10 times suffices

Figure1. 
Use of the peak flow meter

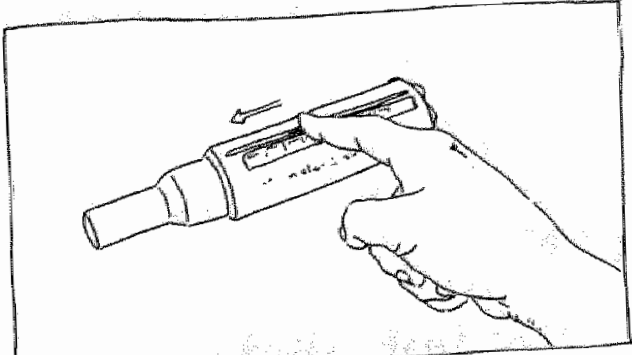

Before blowing, move the indicator back to the bottom of the scale. The indicator is as close to the mouth as possible.

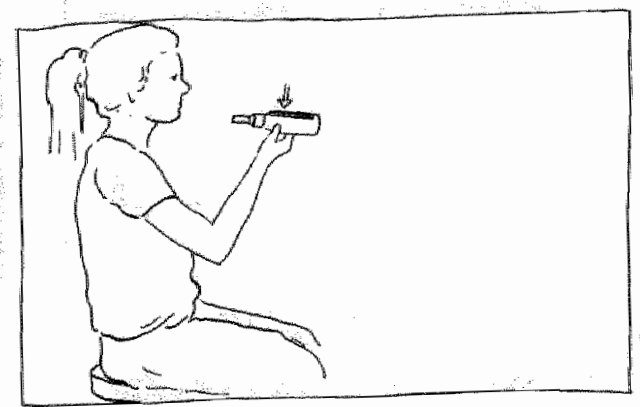

You should take an upright posture e.g. standing or sitting up straight.

When blowing, the scale should be an top.

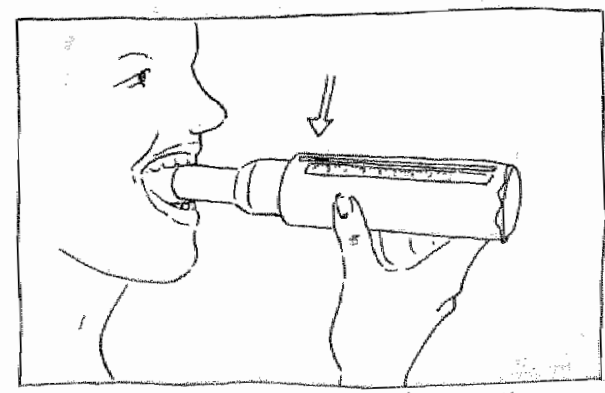

Then put the mouth piece in the mouth, on the tongue; close the teeth and lips around the mouth piece.

The point of the indicator shows the proper reading.

In total do three attempts according to the method described above. Take a short break ( 10 seconds) between each attempt and move back the indicator.

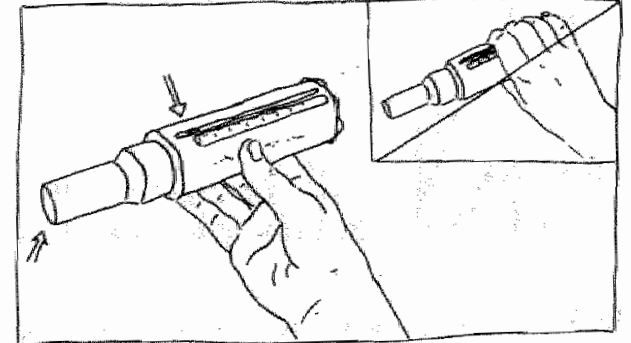

Take care to leave the opening for blowing free and that the indicator can move freely.

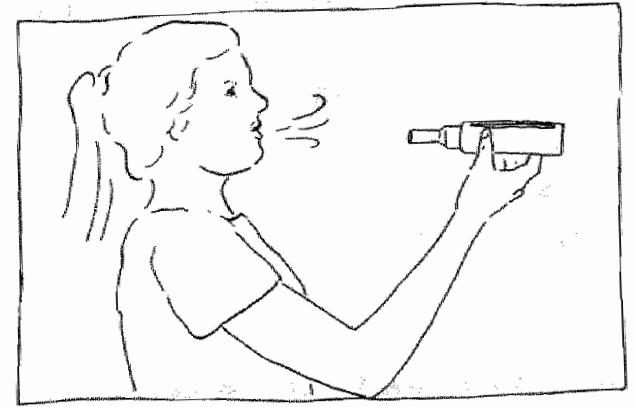

Then breathe in slowly and deeply.

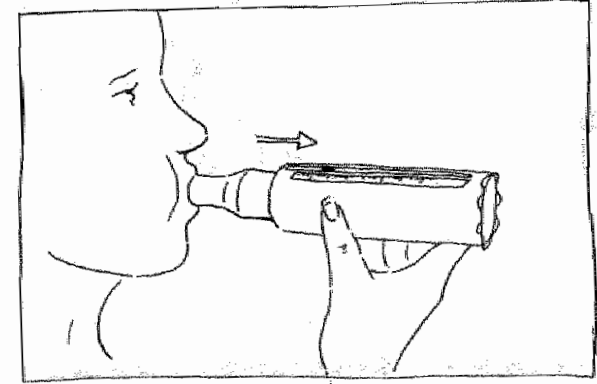

Blow as fast and hard as possible - a short, powerful boost (as if blowing out a candle).

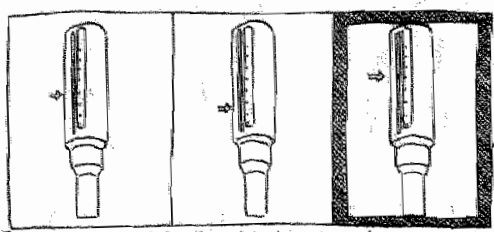

The attempt with the highest valute counts. This value is noted (so don't calculate the average value from the three attempts!).

Figure 1 and 2: The text-picture version of the inhaler chamber and peak flow meter instructions used in this study. Note that the text-only version of this instruction was textually identical to this version, only presented with consecutive bullet-points. 
maximally 8 steps in both instructions). Finally, the order of steps mentioned was compared to the instruction (indicated dichotomously as 'correct/incorrect') and analyzed with chi-square analyses. Two independent ratings of ten participants' recall-transcripts resulted in a mean inter-rater reliability score of .99 .

The third general measure was the quality of participants actions upon the

instructions, assessed from the video data with five observational sub-measures. First, the time participants took to follow the instructions from start to finish was measured. Also the number of instructional steps performed correctly right away was counted. Finally, it was counted how many times participants expressed verbal or behavioral doubts, made a mistake, and corrected that mistake. Mistakes were qualitatively reviewed and reported when providing additional insight to the quantitative data. Two independent ratings of ten participants' performance data on video resulted in a satisfactory mean inter-rater reliability score of .91 .

\section{Results}

Table 1. Mean scores with standard deviations (between brackets) of all continuous data in each group. Significant differences between text-only and text-picture groups are printed in bold.

\begin{tabular}{|c|c|c|c|c|}
\hline \multirow{2}{*}{ (2) } & \multicolumn{2}{|c|}{ Inhaler Chamber } & \multicolumn{2}{|c|}{ Peak Flow Meter } \\
\hline & Text-only & Text-Picture & Text-only & Text-Picture \\
\hline Reading time (in seconds) & $\begin{array}{l}59.85 \\
(37.90)\end{array}$ & $\begin{array}{l}48.29 \\
(18.95)\end{array}$ & $\begin{array}{l}66.316 \\
(32.85)\end{array}$ & $\begin{array}{l}57.92 \\
(20.70)\end{array}$ \\
\hline $\begin{array}{l}\text { Recall: } \\
\text { n Correct Propositions }\end{array}$ & $\begin{array}{l}4.81 \\
(2.06)\end{array}$ & $\begin{array}{l}6.04 \\
(1.71)\end{array}$ & $\begin{array}{l}12.29 \\
(3.29)\end{array}$ & $\begin{array}{l}13.04 \\
(4.59)\end{array}$ \\
\hline n Mistakes & $\begin{array}{l}0.19 \\
(0.40)\end{array}$ & $\begin{array}{l}0.29 \\
(0.55)\end{array}$ & $\begin{array}{l}0.13 \\
(0.45)\end{array}$ & $\begin{array}{l}0.16 \\
(0.47)\end{array}$ \\
\hline$n$ Instructional Steps & $\begin{array}{l}4.69 \\
(1.74)\end{array}$ & $\begin{array}{l}5.96 \\
(0.86)\end{array}$ & $\begin{array}{l}6.63 \\
(1.31)\end{array}$ & $\begin{array}{l}6.68 \\
(1.46)\end{array}$ \\
\hline $\begin{array}{l}\text { Use of device: } \\
\text { Time Taken }\end{array}$ & $\begin{array}{l}110.46 \\
(52.88)\end{array}$ & $\begin{array}{l}56.23 \\
(16.63)\end{array}$ & $\begin{array}{l}78.71 \\
(18.71)\end{array}$ & $\begin{array}{l}70.67 \\
(26.83)\end{array}$ \\
\hline n Correct Right-away & $\begin{array}{l}6.31 \\
(1.54)\end{array}$ & $\begin{array}{l}7.71 \\
(0.86)\end{array}$ & $\begin{array}{l}6.67 \\
(1.01)\end{array}$ & $\begin{array}{l}6.79 \\
(1.64)\end{array}$ \\
\hline n Doubts & $\begin{array}{l}2.46 \\
(1.75)\end{array}$ & $\begin{array}{l}0.21 \\
\quad(0.51)\end{array}$ & $\begin{array}{l}0.25 \\
\quad(0.53)\end{array}$ & $\begin{array}{l}0.00 \\
(0.00)\end{array}$ \\
\hline n Mistakes & $\begin{array}{l}2.27 \\
(2.38)\end{array}$ & $\begin{array}{l}0.00 \\
(0.00)\end{array}$ & $\begin{array}{l}1.46 \\
(0.93)\end{array}$ & $\begin{array}{l}0.96 \\
(1.55)\end{array}$ \\
\hline n Corrected Mistakes & $\begin{array}{l}0.69 \\
(0.88)\end{array}$ & $\begin{array}{l}0.00 \\
(0.00)\end{array}$ & $\begin{array}{l}0.33 \\
(0.48)\end{array}$ & $\begin{array}{l}0.17 \\
(0.48)\end{array}$ \\
\hline
\end{tabular}


In Table 1, mean scores and standard deviations of each group on all continuous measures are presented. Test-results are presented below per variable for both devices.

\section{Reading Time}

No significant differences were found between the text-picture conditions and text-only conditions for both the inhaler chamber, $t(48)=1.35 ; p=.19, d=0.39(95 \% \mathrm{Cl}:-5.71,28.82)$, and the peak flow meter, $f(47)=1.07 ; p=.29, d=0.31(95 \% \mathrm{Cl}-7.42,24.30)$. Although the mean reading times were higher in the text-onily than in the illustrated versions, variations were so high among individuals that the differences were non-significant:

\section{Recall}

Regarding the number of correctly recalled propositions of the inhaler chamber instruction the text-picture group outperformed the text-only group, $t(48)=-2.30 ; p<.05, d=-0.66$ $(95 \% \mathrm{Cl}:-2.31,-0.15)$. With the peak flow meter instruction there was no difference, $t(47)=$ $-0.65 ; p=.52, d=-0.19(95 \% \mathrm{Cl}:-3.05,1.55)$.

With both devices, no difference was found between the text-picture and text-only groups regarding the number of mistakes made in recalled propositions. Specifically, few mistakes were made in recalling the inhaler chamber instruction by both groups, $t(48)=$ $-0.73 ; p=.47 d=-0.21(95 \%, C l:-0.37,0.17)$. This was similar with the peak flow meter, $t(47)=$ $-0.27 ; p=.79, d=-0.08(95 \% \mathrm{Cl}:-0.30,0.23)$.

With the inhaler chamber, participants with the text-picture version recalled significantly more instructional steps than participants with the text-only version, $t(48)=$ $3.22 ; p<.05, d=-0.93\left(95 \% \mathrm{Cl}_{n}-2.06_{n}-0.48\right)$. This difference was not found between both peak flow meter groups, $t(47)=-0.14, p=.89, d=-0.04\left(95 \%, \mathrm{Cl}_{n}-0.86,0.75\right)$.

Finally, regarding the order in which the instructional steps were recalled with the inhaler chamber instruction, 20 out of $26(76.9 \%)$ participants with the text-only version and 19 out of the $24(79.2 \%)$ text-picture group reported a correct order of instructional steps, a difference that did not reach significance, $\chi^{2}(1, N=50)=2.06, n s$. On the other hand, with the peak flow meter instruction only 6 out of $24(25 \%)$ text-only participants had their order correct, compared to 12 out of $25(48 \%)$ in the text-picture group, showing a marginally significant effect, $\chi^{2}(1, N=49)=2.79, p<.10$.

\section{Behavioral Observations}

On the total time taken to follow the instructions with the inhaler chamber, a significant advantage of the text-picture group over the text-only group was found, $r(46)=4.61, p<$ $01, d=1.36(95 \% \mathrm{Cl}: 30.58,77.89)$. Although with the peak flow meter the results seemed to follow a similar direction, the difference between both groups did not reach significance, $t$ $(46)=1.20, p=.24, d=0.35(95 \% \mathrm{Cl}:-5.40,21.48)$.

The inhaler chamber instruction was followed correctly right-away more often by the text-picture group than by the text-only group, $t(48)=-3.92, p<.01, d=1.12(95 \% \mathrm{Cl}:-2.12$, $-0.68)$. No difference was found for the peak flow meter instruction, $t(46)=-0.32, p=.75, d=$ $0.01195 \% \mathrm{Cl}:-0.92,0.67)$. 
The added-up continuous data on whether participants had expressed any doubts, made mistakes, and corrected those mistakes with the inhaler chamber instruction showed that on all three measures the text-picture group had an advantage over the text-only group. Participants with the text-picture version of the instruction expressed less verbal or behavioral doubts, $t(48)=6.08 ; p<.01, d=1.76(95 \% \mathrm{Cl}: 1.51,3.00)$. Also, they made fewer mistakes than the text-only group, $t(48)=4.68 ; p<.01 d=1.35(95 \% \mathrm{Cl}: 1.29,3.25)$. From this a significant effect emerged on how many mistakes participants subsequently corrected, being zero in the text-picture group and higher in the text-only group, $t(48)=3.83 ; p<.01, d$ $=1.11(95 \% \mathrm{Cl}: 0.33,1.06)$.

Identical analyses for the peak flow meter showed different results. Although the data on all three scores were in the anticipated direction; only on expressed verbal or behavional doubts this difference reached significance. That is, the text-only group expressed doubts and the text-picture group did not $t(46)=231 ; p<.05, d=0.68(95 \% \mathrm{Cl}: 0.03,0.47)$. The text-only group seemed to make more mistakes and corrected more mistakes tham the textpicture group, but neither measure reached significance $(t(46)=1.36 ; p=.18, d=0.40195 \%$ $\mathrm{Cl}:-0.24,1.24)$ and $t(46)=1.20 ; p=.24, d=0.35(95 \% \mathrm{Cl}: 0.11,0.45)$, respectively).

The observations revealed the kinds of mistakes made by participants, which were especially noticeable with the inhaler chamber text-only group. With the first instructional step where one had to check whether the valves were moving, participants were often confused which valves were meant. As the tube had two places where it could be opened with two flaps, some started squeezing those. Also, many participants were confused as to where and how to put the pump into the chamber. Participants tried it on the mouthpiece, put the wrong end of the pump into the right end of the chamber, even opened the chamber itself halfway and put the whole pump in it. One participant put the whole wrong end of the device in her mouth instead of the much smaller mouth-plece. These kinds of mistakes were not madie by the inhaler chamber text-picture group. With the peak flow meter, mistakes that were made generally seemed to involve careless reading, in that participants neglected to perform some actions altogether. This skipping of actions ranged from not breething in deeply before blowing into the device, to not putting their teeth around the mouthplece or forgetting to move the pointer back to the starting point.

\section{Discussion}

Altogether, the presence of pictures in instructions for medical devices did seem to have an added value over text alone. Also, as expected, this was especially the case for the inhaler chamber and to a lesser extent for the peak flow meter instruction. With the peak flow meter, both text-only and text-picture versions of the instruction brought about comparable recall of the instruction and performance with the device. Here, the presence of the pictures only seemed to contribute slightly to a better recall of the order of the instructional steps and enhanced confidence, i.e., participants expressed fewer doubts while using the device with the illustrated instruction. 
With the inhaler chamber instruction on the other hand, the effects of the pictures with the textual instruction were more straightforward, both on understanding and performance. Specifically, participants that had seen the version with pictures recalled more specific content and more instructional steps, without making more mistakes in their recall of the conterit than participants with the text-only version of the instruction. Recall for the order of steps was relatively high in both groups, with many participants reporting the correct order of steps of the instruction.

The goal of any instruction is to enable people to carry out the actions flawlessly right away. Therefore, the main and most valid measure of understanding the instructions related to participants' performance of the actions described. With the inhaler chamber instruction, participants with the illustrated version were faster and performed more steps correctly right away while expressing less doubts than participants that did not have any pictorial information at their disposal. This is in agreement with other research (Bieger \& Glock, 1986; Ganier, et al, 2000), in which performance times were sthortest with text-and-pictures instructions. In addition, the absence of incorrect actions in the present study when pictures were present compared to performing incorrect actions when no pictures were available provides a strong case for the picture-effect: A similar advantage was reported by Bieger and Glock (1986), who found that pictorials reduced the number of errors in procedural assembly tasks.

Thus, the overall superior recall with the pictorially enhanced inhaller chamber instruction indicates that participants may have formed links between their textual and visual mental model, creating two possible cognitive 'routes' to remembering the overall information (Mayer, 1997; Schnotz \& Bannert, 1999). During recall, both models could have triggered each other's content, thus enhancing memory compared to when reading only text (Mayer \& Sims, 1994). This coincides with findings from other research (Glover et al., 1988), where general memory for directions was enhanced with mnemonic aids. Similarly, to the extent that the pictures and text were linked in participants' mental models, during recall the pictures may have served as mnemonic aids for recalling the textual contents. The finding that adding pictures to the text also resulted in a generally superior performance with this instruction agrees with research done by Stone and Glock (198\%), who found that pictures convey spatial information more effectively than text. These authors present two alternative explanations for this effect that cannot be ruled out in this study. First, the presence of redundant information in another form may provide the reader with opportunities to resolve possible ambiguities in either the text or the pictures. Second, readers may differ in their ability to extract and use information presented verbally or pictorially and providing both enables flexibility of selecting the optimal form for their needs (Stone \& Glock, 1981).

This variation in performance between both the devises'instructions was reflected in the time taken to follow the instruction from start to finish. The average time taken with the inhaler chamber was halved when pictures were present compared to when only text was available. The negligible beneficial effect on performance speed with the peak flow meter instruction can be regarded as a reflection of the weaker effect overall of the pictures on the 
performance with this instruction. In a study done by Morrell and Park (1993), text-only and text-picture instructions also required comparable amounts of time to perform an assembly task, and only a picture-only condition shortened performance time remarkably. Related to this, with the inhaler chamber text-picture instruction participants may sometimes only have looked at the pictures when using the device. With the one-sentence text with each Illustration the one-to-one overlap between them could have triggered such a strategy, resulting in a successful performance. In contrast, with the peak flow meter the amount of information and thus also text per picture was larger, rendering the overlap between both less evident. This may have encouraged participants with the pictorially enhanced instruction of the peak flow meter to read the text as well, resulting in comparable performance times with and without pictures.

\section{Conclusion}

Overall, the expectation that pictures would contribute most to a textual instruction when the to-be-used device itself is relatively ambiguous was confirmed by the findings in this study. First, as the peak flow meter itself afforded and constrained its use almost entirely and the inhaler chamber did not to such an extent, pictures added significantly to the comprehension of the latter instruction and less to the first. In this light $t_{t}$ it is noteworthy that even the anticipated affordance and constraint of the inhaler chamber were not always effective. As illustrated by the mistakes that were made with the text-only instruction, the only possible fit (i.e., constraint) of the asthma pump on the inhaler chamber was not obvious to all users. Thus, even a careful analysis of the device was insufficient in anticipating the range of user's actions when using it.

Secondly, the 'new' information that the instruction added to the proper use of the peak flow meter mainly related to bodily positions. As to some extent people perform them daily, such rellatively simple bodily positions may be easy to visualize mentally by readers, also without visual aids. On the other hand, the inhaler chamber mainly required actions with the device itself, which were new to users and thus may have been relatively difficult to visualize mentally. Thus, even with medical instructions which may be especially suited for visual aids, the additive value of visual information may depend on the inherent clarity of the device with accompanying text.

\section{Practice implications}

For the design of instructions for medical devices two conclusions may be drawn from this study. First, when designing procedural information, simple line-drawings with descriptive captions should be considered for aiding readers' understanding. Also, the necessity of including illustrations for understanding and using the instructions may depend on the inherent clarity of the device in terms of its affordances and constraints, as well as the "newness' of remaining actions to perform. When financial concerns limit the possibilities to add many pictures, these analyses may enable choices which text exactly rieeds pictorial support. Especially for unfamiliar devices with which several actions should be performed, 
text itself may prove insufficient for immediate understanding. The presence of (relatively inexpensive) simple line-drawings illustrating the described situation may take away doubts and contribute to a better understanding in users.

Secondly, despite the best intentions and applications of pictures with text, testing the comprehension of readers is essential for warranting their effect. Observing users while they work with the instruction, as was done here, but early in the design process, may give valuable insights into potential problems, based on which information design may be improved. 

Chapter 1

Chapter 2

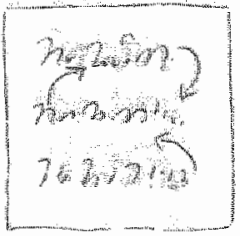

Chapter 3

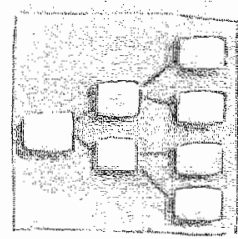

Chapter 4

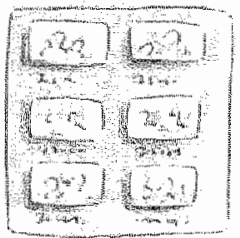

Chapter 5

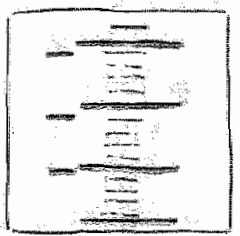

Chapter 6

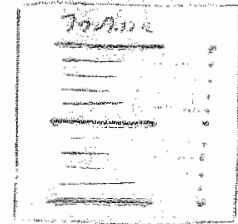

Chapter 7

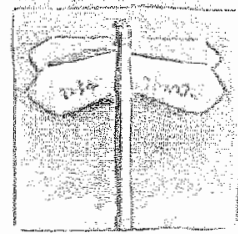

Chapter 8

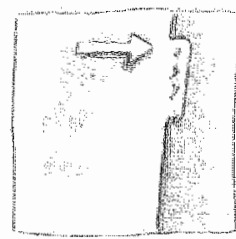

Chapter 9

Summary

Samervatting

References
General introduction

increasing readers comprehension of

health education brochures: Aualtative siudy into how professional writers make texts coherent

The efrect of graphic organizers on

subjective and objective comprehension of a health education text

Pictures and text in instructions for medical devices: Effects on recall and actual performance education text on locating speed and evaluation

Access structures help readers locate and remember information in a health education brochure

The understandability of pictorials in a health education brochure

Testing the usability of access stuctures in heath education brochures

General discussion: Implications for health education practice 
HeADWGS he TeX

trity

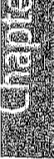


he ability to locate specific information in written documents is an important issue in today"s information-dense society (Dreher, 1993). With so much information at people's disposal, the design of written public documents becomes increasingly important to help readers find what they are looking for. Also for health education materials, which may contain various kinds of information, readers may wish to read specific answers to questions they have, instead of reading it from start to finish. For example, a brochure about healthy living could have three main sections with the titles 'fat,"fruit and vegetables', and 'exercise'. These in turn, could each contain sub-sections that are signaled with lower-level headings, containing a description of the current national situation, general behavioral guidelines, problems people experience in changing their behavior to those guidelines, and tips on how to deal with those problems. Readers who wish to act immediately and are less concerned with reasons for doing so may only want to look up tips throughout the document. Thus, optimizing the accessibility of these individual text subjects may be important for effectively reaching the public. The way that a text is hierarchically structured and how this structure is explicated may be crucial for readers to get an overview of the materials and find information easilly. To this end, signaling devices or 'access structures' (see, e.g., Waller, 1982) such as headings are generally used to identify the subject matter for readers and thus clarify the structure of the text (Hartley, 2004). Such explicit text structure may help focus a readers' attention on particular parts of the text (Jonassen \& Kirschner, 1982) and thus also to locate information that they may look for in the text. In other words, titles and headings that signal a text's overall or'macro' structure (Kintsch, 1994a) effectively may help readers to access the text and find relevant information on the local or 'micro' level.

Professional text writers of health education materials generally seem to be aware that signaling a text's macrostructure helps readers to grasp its contents and main messages (Kools, Ruiter, Van de Wiel, \& Kok, 2004). Health education texts, whether it's leaflets, brochures, or information on the internet, contain titles and headings to explicate the organization of the subjects discussed. However in practice the number of headings that are included in a text varies according to the writers' personal preferences (see Kools et al. 2004 ) and also research is undear about this (see, for instance. Hartley, 2004). To our knowledge, no research has been done into the effect of heading-frequency in a text on locating information in it. Thus, no evidence-based guidelines exist about the specific ordering and explication of a text's macrostructure. The present study is an attempt to shed some light on this issue. Specifically, this study aimed to investigate whether different ways of explicating the macrostructure of an educational text influences the extent to which readers can locate information in it easily. With four versions of a health education text varying in the number of headings, the speed in which participants located specific items in the text-versions and their personal experiences with the materials were compared. Before going into detail about the experiment itself the theoretical background on which the textual manipulations were based will be described. 


\section{The role of an explicit macrostructure}

A text is coherent on the macro level when paragraphs and larger sections are clearly related to each other and to the overall topic (McNamara, Kintsch, Songer, \& Kintsch, 1996). For comprehension and memory of a text, research has shown that its gist (which is formally expressed by the macrostructure) is most important (Kintsch \& van Dijk, 1978). The macrostructure can be made more explicit by structural (macro-) signals such as titles; headings, initial topic sentences, and summary statements (see, e.g, Hartley, 1985; Lorch; 1989, Lorch, Lorch, Ritchey, McGovern, \& Coleman, 2001).

Another important factor in the understanding of a text's macrostructure and the ease with which people can find specific information is the knowledge about text structure, also knowin as 'schemas, which readers already have. Based on these schemas, readers know that particular text types tend to be organized in certain ways. They employ this knowledge to mentally construct schema-based macrostructures of newly encountered texts (Kintsch, 1994). Narratives in our culture are typically put (and thus understood) in a basic expositioncomplication-resolution structure (Kintsch, 1998). Turning the sequence of information around, for instance, would violate the expected organization of cause-and effect, rendering it more difficult for readers to understand the information (Noordman \& Vonki 1998).

The assignment of macro signals such as headings to schematic categories simplifies the readers'task of perceiving the overall organization of a text. Essentially, their (prior knowledge-based) general expectations about the text's macrostructure are explicitly confirmed in the textual signals they encounter. That in turn makes the text easler to follow and its organization easier to grasp. However, from the literature cited above, it is difficult to make unequivocal predictions about the optimal number of headings and thus the extent of categorization that is best for the clarity of a text's structure.

\section{A systematic approach to structuring text}

The only method known to the authors which (among other things) offers very strict and explicit guidelines how information should be segmented and labeled with headings is the Information Mapping (IMAP) method (Horn, 1982, Horn, 1993). This text design method is taught and used world wide, and is applied in many organizations and in various kinds of mainly quite complex technical documents and manuals (Horn, 1993). The effects of this method on learning, understanding, and locating information have been tested to some extent (for an overview, see Table 1 in Hartley, 1982), but as a scientifically founded method it remains controversial (see, e.g. Horn, 1992). That is, many studies that are referred to are not or difficult to trace (including the studies summarized in Hartley; 1982), little details about experimental design are given, and thus the effectiveness remains unclear.

IMAP employs seven different types of information, each represented in a so-called 'map': procedure, structure, classification, process, concept, fact, principle. In addition, seven writing-principles are devised, which are in short: segmenting information into smaller units called blocks, using only one information-type in each block labeling each block with a heading, using the same word for one concept consistency, integrate graphic items where readers need them, keeping the information accessible with growing detail, and segmenting 
Imaps when they cross the boundary of nine information-blocks (see for further explanations of these types and principles Horn, 1993). These information types and principles lead to a consistent and recognizable text-design. That is, all pages of an IMAP text start with a title at the top, followed by highly segmented text into small paragraphs, each indicated with a heading in the left margin of the page. Thus, the explicit text structure (i.e, the structure flagged by headings and titles) essentially consists of two levels of headings. One page of text never contains more than nine paragraphs, which are typically separated by white spacing with horizontal lines. Thus, information is provided in identifable 'chunks' of text.

Although common sense leads researchers to believe that the highly structured IMAP documents strongly facilitate locating information by readers (Hartley, 1982), it remains unclear whether this is the case with all kinds of information and text lengths. An attempt to clarify this matter was done by Jansen and colleagues (Jansen, Korzilius, lePair, \& Roest, 2002) who experimentally compared three wersions of a technical manual text. The original version was three pages long and already contained an explicit macrostructure with headings. This text was compared to an IMAP-and a professionally rewritten version of the text. Participants did not find information faster with the IMAP text than with the other two texts. Using a similar systematic approach, the present experiment further investigated the effects of IMAP design characteristics in the context of health education. Especially the number of headings, the most pervasive feature of IMAP compared to normal text, was evaluated with regard to its effect on readers' search efficiency.

\section{The present study}

This study examined the effect of the number of headings on the accessibility of an instructional health education text. Accessibility' was measured objectively with search speed, and subjectively by asking participants how accessible they had experienced the text. As evidence-based health education texts are typically composed with care, we were interested whether the design of such texts may still be improved. Thus, similar to the study done by Jansen and colleagues (2002), here also special care was taken to create a realistic comparison, so that its results would be potentially useful for health education text writers. That is, an evidence-based health education text (Brug, Steenhuis, Van Assema, \& De Vries, 1996) was used that already contained an explicit macrostructure with headings on several hierarchical levels. To disentangle potential effects of individual macro structure features, three additional versions of this text were created. First, a complete IMAP version of the text was created by the Dutch Information Mapping centre (IMN). This text version had the recognizable design of the IMAP method and thus looked remarkably different from the original text. Because applying IMAP changed the external text structure (lay-out, with headings) of the original as well as the internal text structure (the order of the informationy. another more basic version was made, which mimicked the design of the IMAP text but maintained the information order of the original text. Finally, a control text was created by deleting all headings from the original text leaving only the paragraphs, separated by white lines. So, a text that originally contained headings and thus was expected to have a clear explicit macrostructure (the original text) was compared to a text without explicit access 
structures the control text) and two texts with much more explicit signaling (he, higher numbers of headings) (the IMAP-imn and-control text), one of which also differed in content structure (the IMAP-imn text).

Based on findings in other studies (Hartley \& Trueman, 1985), it was expected that the presence of the headings would help readers to find information more easily than without headings. Thus; participants in this study were expected to take the longest time to find search Items with the implicit, control version of the text. With regard to differential effects on locating information between the other three text versions straightforward hypotheses could not be made. That is, no unequivocall findings in the literature specify the frequencies and levels of headings in a text and the inherent degree of segmentation of text. Regarding the order of information, a logical order as opposed to a random one is expected to be most effective (Jonassen, 1982; McNamara et al., 1996). The IMAP version of the text was the only one with a somewhat different order of information compared to the other three text versions. However, as all of the text versions in this study had a logical ordering of information (i.e., none was random) no differences in search efficiency were expected based on this. To assess different kinds of effects of the four text formats, objective and subjective data were collected.

\section{Method}

\section{Participants}

A total sample of 80 participants was drawn from the student population of Maastricht University. Individualls were randomly assigned to one of four conditions in a betweensubject experimental design, thus creating four groups of 20 participants: the Original text group (Mean age: 20.35 years, $S D=0.57$ ), the IMAP-imn text group (Mean age: 20 years, $S D=$ 0.60 ), the IMAP-control group (Mean age: 20.50 years, $S D=0.61$ ), and the Control text group (Mean age: 21.15 years, $S D=2.72$ ). Estimations of their own reading skills were on average indicated with a score of 5.24 (SD $=1.18)$ on a 7-point scale and did not differ between groups, $F(3,70)=0.17$, ns. Participation was on a voluntary basis and no rewards were given.

\section{Materials}

Text versions. Four versions were created of a health education letter on healthy eating. Specifically, the criginal version of the text was the result of an evidence-based computertailored letter (Brug et al., 1996), aimed at an anonymous person's eating habits concerning the intake of fat, fruit, and vegetables. As such, the text started out with a brief introduction of the topic. Then, for each of the three food types, the intake of the addressee was stated, compared to general guidelines, some explanations concerning that food were provided, and advice was given on how the person could proceed with changing the personal diet to a healthier one. Finally, two low-fat recipes were appended, one for vegetarians and one for non-vegetarians.

The original text was five pages long, of which one page hardly contained any text. Figure 1 shows the macro structure of this original letter, with all the headings that were devised on the various llevels. Based on the contents of the original text, an information 
Mapping version of the text was designed by Information Mapping Netherdands MMAP. imn): This text had the same quantity of information as the original, but the nformation was spread out over eight pages instead of five, each starting with a title and split up into an average of 5.12 subsections (with headings) per page (see Figure 2). Another version of the original text was created according to the Information Mapping principles, with the exception that nothing was changed to the order of the information as compared to the original text. This resulted in a ten-page IMAP-control text version where each page started with a title and an average of 3.90 subsections with headings (see Figure 3 ).

As can be seen when comparing the figures, the macro signaling and order of the information differed between the three versions. First, both IMAP text versions contained notably more headings. The original text contained 23 headings, compared to 44 and 41 headings in the IMAP-imn and IMAP-control text versions, respectively. Also, both IMAP texts

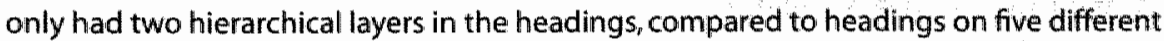
hierarchical layers in the original text. To enable distinction of these five heading-levels from each other and from the running text in the original text, underlining, bold lettering,

Introduction

FAT

HOW FATTY DO YOU EAT?

SUGGESTIONS HOW TO EAT LESS FAT

Important fat-suppliers in your food:

SNACKS

PEANUTS AND SALTY BISCUITS
PASTRY, BIG COOKIES AND CHOCOL
Fatty cookies
Less fatty cookies
DOES EVERYTHING HAVE TO CHANGE?
FRUTT AND VEGETABLES
DO YOU EAT ENOUGH VEGETABLES?
You eat:
The recommendation is:
TIPS ON EASY VEGETABLES
AND THEN FRUIT, HOW MUCH DO YOU EAT?
You eat:
The recommendation is:

page 2

TO CONCLUDE

(bit of text of conclusion)

RECIPES TO EAT LESS FAT

WITH MEAT

page 5

WITHOUT MEAT

Figure 1. Macrostructure original text version 
1. Background and reading guide

Resom

Ain advile lo stoe

Crial

Siniple but teffective

Reading guide

2. Good nutrition for a good health

Introduction

Why good nutrition

Witule fat

Litutle fat: also for slim people

Witte fits also when you sport

Enough regetables:

Enough fruit

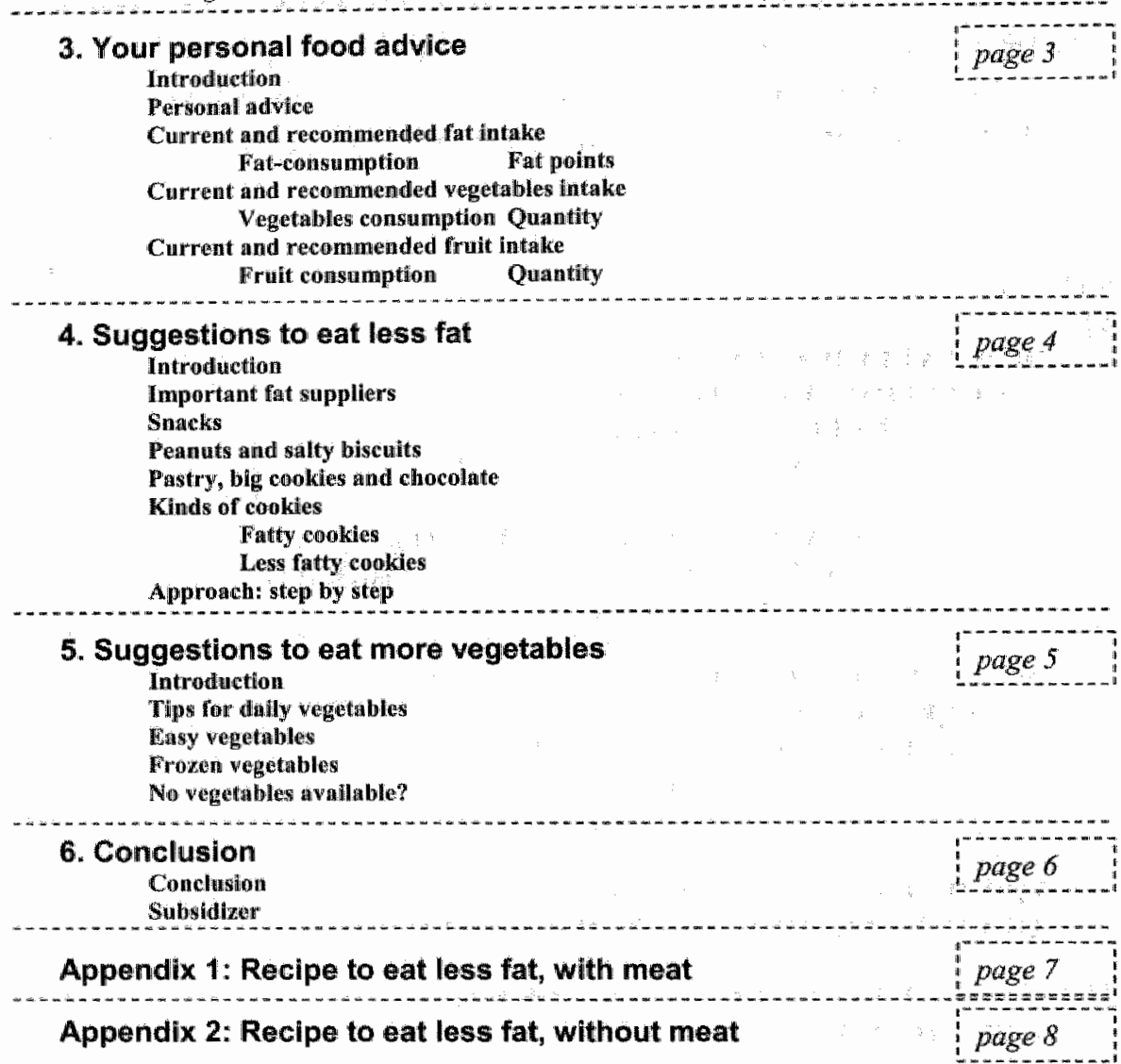

Figure 2. Macrostructure IMAP-imn text version 


\section{Contents}

\section{Introduction}

Reason

page 2

Personal linterest

Goal

Subjects

Change

\section{Your fat consumption}

Danger fat comsumption

Your fat consumption

Carrent and recommended fat consumption

Little fat: also when you are slim

Little fat: also when you sport

\section{Suggestions for eating less fat}

Fat suppliers

Snacks:

Peanuts and salty biscuits

Pastry, big conkies and chocollate

Kinds of cookies

Fatty cookites less fatty cookles

Does everything have to change?

\section{Your vegetables consumption}

Importance of vegetables

Your vegretables corsumption:

Vegetables consumption quantitiy

Advice

6. Suggestions for eating more vegetables

Tips for daily vegetables

Easy vegetables

Frozen vegetables

In case of emergency

7. Your fruit consumption

Importanee of fruit

Vow frutt consiumption

Fruit consumption quantity

Advice

\section{Conclusion}

Conclusiom

Remark

Recipe to eat less fat, with meat

Recipe to eat less fat, without meat

Figure 3. Macrostructure IMAP-control text version 
and upper caising had been used. However, becausie no unequivocal research was known to the authors which points towards differential effects of such features when applied to headings only (see Hartley, 2004; and Wright, 1977, for an early notion of this), here no further steps were undertaken to isolate potential effects on search speed. Another remark should be made regarding inherent differences between the structuring methods, regarding the placement of the headings. That is, in both MAP text versions, each page starts with a big title and all headings are in the left margin of the page, each accompanying paragraph being split from the rest by horizontal thin lines. Conversely, the original text version follows conventional design, with headings placed in the same area as the body text, mostly separated from the text by a white line. However, as research has not pointed towards an advantage of placing headings in the margin versus in the running text (Hartley \& Trueman, 1985), this difference in design was ignored here.

A final comparison of both IMAP text versions revealed two residual differences between theili ordering of information. First, the IMAP-imn text had a first page with text which concluded with a contents overview, whereas the IMAP-control version started with only a contents-overview on the first page. Second; in the IMAP-imn version the current intake of fat, fruit and vegetables was put all together on one 'Personal food advice' page, thereby leaving out a separate fruit page. Conversely, the IMA.P-control text version maintained the same order of information for each food group as in the original text, thus keeping on a separate page about fruit intake.

Finally, a control version of the original text was created in which no headings were present. Instead, white lines separated the sections and paragraphs which had been marked with headings in the original text. Thus, the paragraphing of the original text remained intact in this version. Accordingly, this version of the text was also five pages long.

\section{Measures}

Ten search items were designed that required participants to locate specific information in their text version. The questions were stated in similar wordlings as in the text, to make sure that they would be found by the participants. Pretests ensured that wordings of the items were unambiguous and easy to understand.

A questionnaire with total of 11 questions (ten 7-point Likert scale and one 10point rating scale item) was developed to assess participants' opinions on the text. The plieasantness, understandability (both ranging between $1=$ not at all, and $7=$ very much so), and information quantity of the text were asked with one item each (ranging between $1=$ too little, and $7=$ too much). Also, the ease with which they had been able to locate the search items was asked. Then, three items were combined (Cronbach's alpha $=.86$ ) that asked the participants' opinion on the text's structure, namely 'What did you think of the structure of the text?' (ranging from $1=$ bad to $7=$ good), 'Do you think the text's structure made it easier for you to find the search items? (ranging from $1=$ not at all to $7=$ very much so), and 'Do you think the text's structure contributed to you finding the search items faster?' (ranging from $1=$ not at all to $7=$ very much so). The same three questions, but then related to the lay-out of the text, formed a cluster (Cronbach's alpha $=88$ ). One final question on this 
sheet asked participants to evaluate the text with a grade fanging from 1 (very poor) to 10 (excellent).

\section{Procedure}

Participants were tested individually, while seated at a table with the experimenter In a brief: introduction, they were told that the aim of the study was to assess the effect of various textlayouts on how easily information was found in a text. Then, the text version that they had been assigned to was put in front of them with the request to scan the whole text, to get some idea of its contents. This was done because the unusual Information Mapping lay-out of the texts could potentially take some getting used to by readers who are not familiar with it. Thus, in this respect those versions should not have a disadvantage in advance. They were given one minute to do this, a time that in pretest had shown to be sufficient for scanning the texts once, and were informed when time was running out. To ensure that participants only scanned the pages, they were reminded to do so when they actually seemed to start reading pieces of text. After the minute had past, the participants were asked to close the booklet so that the blank cover sheet was on top and in front of them.

They were then told that that they would be given ten search items, which they were asked to locate in the text as quickly as they could. Questions were asked in a set order, which had previously been arranged in such a way that subsequent search items were not located on the same page. This was to prevent that participants could locate the item without really searching, based on their recollection of the page they had last seen. The search items were printed on cards that were put in front of the participants when the question was asked; and search times were timed with a stopwatch. After they had found an item and the experimenter had noted the search time, they had to close the booklet so that the blank cover was on top again, ready for the next search item. This way, all the search tasks were performed. Finally, participants were asked to fill out the short questionnaire. The entire testing sequence took 7 to 12 minutes.

\section{Analysis of outliers}

Inspection of the search time data revealed that both IMAP-text groups contained three outliers each, so cases which exceeded the $1.5 \times$ Interquartile Range-criterion of suspected outliers. A closer look at the individuals' search times showed that on several items, all these participants had taken exceedingly long times to find the answer. Based on the exclusioncriterion of three times the standard deviation above the mean score within the groups (Tabachnick \& Fidell, 2000), all six cases were excluded from subsequent statistical amalyses.

\section{Results}

A one-way ANOVA on search time showed an overall effect of the different versions $F(3$, $70)=4.94 ; p<.01$. Bonferroni post hoc tests revealed that the control text group $(M=18.86$, $S D=8,67$ ) had taken longer to find the items than the other three groups (all $p^{\prime \prime} s<.05$ ). No significant differences were found among the other three groups (all $p$ 's $>10$ ); the original 
brochure group $(M=13.75, S D=4.95)$ took similarly long as the IMAP-imn $(M=13.69,5 D=$ $3.07)$ and the IMAP control $(M=12.54, S D=2.83)$ group.

Separate one-way ANOVA's were done on the questionnaire data. No significant differences were fourid among the four groups regarding evaluations of the text's pleasantness $(F(3,70)=0.43$, ns), its understandability $(F(3,70)=0.82$, ns), the quantity of inforrnation $(F(3,70)=0.67$, ns), how easy participants had found searching for information $(F(3,70)=2.04, \mathrm{~ns})$, and the structure of the text $(F(3,70)=1.39$, ns). Similar average high scones were found with all four text versions on the pleasantness of the text $(M=5.03,5 D=$ $1.09)$ and its understandability $(M=6,15, S D=0.79)$. The quantity of information was rated with an average of $4.24(5 D=0.70)$, indicating that participants found it neither too low nor too high on the question how easy or difficult they had found it to find the search items in the text, answers ranged from an average score of $3.59(S D=1.37)$ in the IMAP-imn text group to $4.60(S D=1.50)$ in the control text group, indicating that they found it neither very hard nor very easy. With regard to participants'opinion about the structure of the text, the average score ranged from $5.27(S D=1.11)$ in the control text group to $5.82(S D=0.95)$ in the IMAP-control text group, indicating a relatively positive structure-evaluation.

Significant differences were found on two items of the questionnaire, regarding the layout and the general rating of the text. The text's lay-out was evaluated relatively positively, In the following ascending order the control text $(M=4.77,5 D=1.05)$, the original text $(M$ $=5.00,5 D=1.00)$, the IMAP-control text $(M=5.28,5 D=1.03)$, and the IMAP-imn text $(M=$ $5.57,5 D=0.78)$. Here, a marginally significant main effect was found $(F(3,70)=2.31 ; p<.10)$, which was caused by a marginally significant difference $(p<.10)$ between the control text and the IMAP-imn text.

Finally, all groups rated the text relatively positively on the ten-point scale, in an ascending order: the control text $(M=7.10, S D=0.72)$, the original text $(M=7.35, S D=0.75)$, the IMAP-control text $(M=7.62,5 D=0.72)$, and the IMAP-imn text $(M=7.85, S D=0.49)$. An ANOVA showed a main effect of text, $F(3,70)=4.22 ; p<.01$. A Bonferroni-test showed that the difference between the control text and the IMAP-imn text was significant $(p<.01)$.

\section{Discussion}

The primary aim of this study was to find out if different degrees of explicit macrostructure in terms of firequency of headings and the resulting segmentation of text, could improve the accessibility of an evidence-based health education document. For this, three versions of a health education text with an explicit macrostructure and a control text without headings were compared on objective search speed and subjective evaluations of the text. As expected, participants' search times with the texts that containedl headings was faster than with the text that had no headings to signal its macrostructure. Being in line with other research into the effects of headings on search speed (Hartley \& Trueman, 1985), this strengthens the notion of headings as effective 'signals' of textual content.

Among the texts that contained headings, no significant differences in search times emerged. Thus, it seems that the use of many headings (and the corresponding high 
segmentation of text) does not necessarily make a text easier accessible in terms of finding information more quickly compared to conventional use of headings. It seems that as long as there are headings avallable, readers are able to choose the appropriate labeland find information: In addition, no differences were found in search times between the differently ordered IMAP-imn text compared to the original and originally-ordered IMAP-control text. From this, a tentative conclusion may be that as long as the general order of information is meaningful, the exact ordering of information may be of secondary importance to the presence of headings as access structures to find information. In other words $s_{n}$ as long as a text"s order or macro structure fits with readers" prior knowledge or schemas (Kintsch; 1994) of a logical information-sequence, several macro structures may be equally effective for finding information when flagged with headings.

On the subjective measures, only the IMAP-imn version of the text was rated as more positive than the text without any headings, overall and specifically regarding its lay-out. So, all though participants with the IMAP-imn text version were not faster on the objective search tasks than the other two headings groups, on several subjective evaluations the IMAP-imn text was the only text version that was evaluated more positively than the control text. Similar findings were reported by Jansen and his colleagues (2002) who failed to find any advantage in objective performance with an IMAP-version of a text but did find a higher subjective rating of that text. Thus, especially on the experience of readers this specific kind of explicit structuring may have advantageous effects. This may be a reason for health education designers to opt for many headings and relatively high segmentation of text.

However, before any definite conclusions can be drawn regarding the structuring of the health education texts, further research is necessary. First, it should be noted that the present experiment was done with a relatively short text on a health education subject. Being in a testing situation, participants acted on the instruction to locate information as quickly as possible mostly by paging through it while skimming the contents. With a short text this 'exhaustive search' (Klusewitz \& Lorch, 2000) can be regarded as an effective strategy, but with longer texts that contain more pages such a strategy may be inefficient. With longer texts, using access structures such as tables of contents or indexes to locate relevant pages and then scan those pages for the answer (so a 'selective search strategy' according to Klusewitz and Lorch (2000)) may be a more effective strategy to locate information quickly. Whether structuring longer health education texts according to IMAP-principles is beneficial compared to conventional explicit structuring is a question that should be addressed in further research.

An additional suggestion for further research pertains to text comprehension: for instructional (health education) it is important to measure participants' understanding of the information. In this light, ample research has found beneficial effects of headings on text recall and summarization (e.g. Lorch, 1989; Lorch, Lorch, \& Inman, 1993; Lorch \& Lorch, 1996). In addition, Rice and colleagues (Rice, Meyer, \& Miller, 1989) refer to an established levels effect; which states that readers recall information that is high in a text's context hierarchy better than information that is located at the subordinate level. Headings on different hierarchical levels could provide readers with reference points and help them to cognitively 
organize information for better recall and understainding (Jonassen, 1982). Simillarly,

Petterson (2000) stated: "The purposes of headings are to attract the attention of the readiers, make the subject matter readily apparent, and indicate the relative importance of items" (p.120), In this respect it would be interesting to see what happens with IMAP-texts that essentially only contain two hierarchical llevels compared to the conventional text, which typically contain more hierarchical levels. Readers' understanding of different kinds of superand sub-ordinate relationis may differ with different hierarchical relations among headings in a text. Thus only additional research can provide a satisfactory account of when various degrees of explicating macrostructure can contribute to more usable (health education) instructional materials. 
Chapter 1

Chapter 2

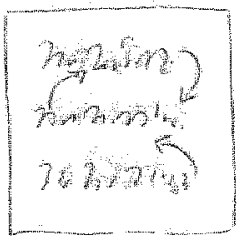

Chapter 3

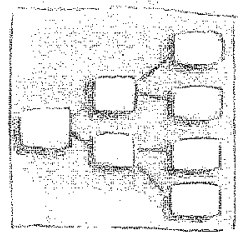

Chapter 4

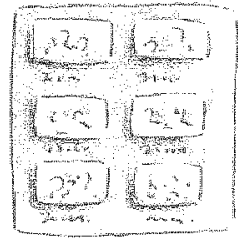

Chapter 5

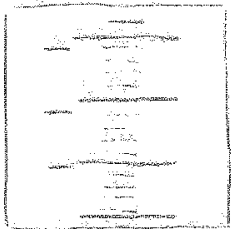

Chapter 6

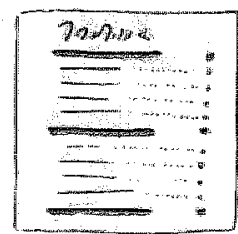

Chapter 7

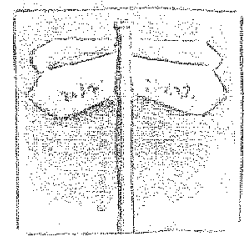

Chapter 8

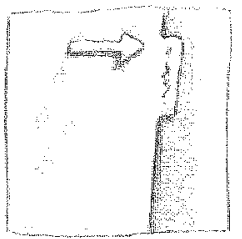

Chapter 9

Summary

Samenvatting

References
General introduction

1

Increasing readers comprehension of

heath education brochures: A qualitative study into how professlonal wrters make texts coherent

The effect of graphic organizers on

subjective and objective comprehension of a health education text medical devices: Effects on recall and actual performance

The effects of headings in a brief health education text on locating speed and evaluation

Access structures help readers locate and remember information in a health education brochure

The under standability of pictorials in a 99 health education brochure

Testing the usability of access structures in health education brochures

General discussion: Implications for heath education practice 
lot of information is provided to users through many channels, among which are brochures within which people have to find those pleces of information that they are interested in and are relevant to them. Thus, the ability to lacate specific information within a brochure text is extremely important. This is especially true for public health education brochures that cover various subjects surrounding a health topic that may be relevant to readers at different times. That is, for a brochure to be an effective help in changing behaviour or handling a disease, it should support selective reading both initially and later on. Therefore, being interested in the general issue of public information, this study examined this in the context of health advice.

In cognitive-psychological literature, looking for information within a document is called 'reading to locate':" a type of strategic reading in which the reader engages in selective reading in order to locate specific, goal-related information" (Dreher, 1993, p. 130). To locate information effectively, some overview of its content and its ordering is necessary, either in the brochure or in the mind of the reader. Taken together, in terms of usability an effective brochure is one in which the content structure is clear when searching for information and in which the content structure is remembered by the reader. The presence of 'access structures" sucth as main section headings and the presence of a clear contents page contribute to this clarity, and have been found to improve both locating speed (Yussen, Stright, \& Payne, 1993) and recall (Hartley \& Trueman, 1985; Wilhite, 1986) when applied in instructional texts. However, in health education such research is sellom done. Therefore, little is known about the effects of such access structures in health education brochures. In addition to broadening insights about general public education, this study specifically aimed to bridge the gap between cognitive-psychological findings and applied health education research:

An existing brochure about a healthy diet that lacked an extensive contents page and main section headings was experimentally compared with a revised version that had both. Readers" search efficiency and recall of the brochure"s content was assessed with either version of the brochure. Findings could contribute to design quidelines for effective (health-) education materials.

\section{Locating Information in a Written Document}

Guthrie and colleagues' cognitive model of text search specifies several processes involved in locating specific information in a written document (Guthrie, Britten, \& Barker, 1991 \%. In the first step of this process, a specific objective is formulated (goal formation): Then, an information category from the document is identified and selected for processing. Third; critical details within the selected category are identified and selected for processing. Fourth, depending on the goal, newly found information is integrated with prior knowledge and other information that has been located. Finally, the searcher repeats the above four operations until the full requirements of the goall are met. In this process, characteristics of the materials to be searched play a major rolle. Especially in step two and three of the model, that is, the identification and selection of a relevant category and information within that 
category, it is conceivable that text structure and design may infuence a reader's search efficiency:

The search for specific information can be made particularly easy by manipulating the salience of that information. That is, the way that textual elements are presented in a text and how they are integrated into surrounding information, can be chosen so that information stands out (Lorch, 1989). Important text elements may be presented in "access structures" such as a table of contents, topic heading, or an index, and thus be more easily located (Yussen, Stright, \& Payne, 1993, Dreher \& Brown, 1993). Such access structures enable participants to search efficiently, whereas their absence may force participants to use less accurate search strategies, such as paging and scanning through a brochure until the answer is reached, or guessing where the answer could be found based on prioir knowledge (Yussen et $a l_{\circ}$, 1993).

For locating information effectively, research with text books showed that the content should be organized in a manner compatible with the reader's expectations. (Byrnes \& Guthrie, 1992). Readers have prior knowledge about the usual structure of texts (e:g., knowing that texts contain thematically arranged chapters, tables of content, indices, etc.), and of the text's subject matter. If a brochure's design meets the readers' expectations that are based on this prior knowledge, locating specific information will be easier. Thus, including a clear table of contents with all headings ordered into main- and subsections (i.e., a text's first, second, and third levell may improvelocating efficiency.

\section{Recall of the Structure}

When a health education brochure becomes a book of reference, readers should be able to recall the document's main themes so that they know which brochure to refer to, and recall its overall structure so that they know where to find information within it: For this; they need a mental representation of the textual structure, or a relatively superficial level of understanding of the text (Kintsch, 1994). Readers who have such a "text base level"understanding of a brochure's general structure recall its macrostructure, or the main themes as indicated with section-and paragraph headings (Kintsch, 1994). When initially reading, skimming through, or llooking up specific information in a brochure, this division into main- and subsections is crucial. A recent study by Hyönä and Lorch (2004) into readers' eye-fixation patterns showed that readers' first-pass fixation time and the average look-back fixation time was notably larger towards topic headings than towards other text regions. This reflects the function of topic headings as facilitators of text processing, resulting in better memory for the topics of a text.

Increasing the salience of a text's topic structure has indeed been shown to increase the reader's topic recall (Hartley \& Trueman, 1985; Lorch \& Lorch, 1985). Specifically, the presence of signalling devices such as headings (Brooks, Dansereau, Spurlin, \& Holley 1983; Hyönä \& Lorch, 2004; Lorch, Lorch, \& Inman, 1993) and overviews (Lorch et. al., 1993) produce better memory for the topics and their arganization, as measured with free recall tasks. Thus, in the design of a health education brochure, the main structure or importance of concepts can be indicated through the use of headings and a table of contents. Because readers focus 
extra attention on these important text elements, this information is learned and retained better than other information (Reynolds \& Shirey, 1988).

\section{This Study}

To our knowledge, in the design of health education materials no one has examined the effects of textual features on the ease of locating and recalling information in brochures. The present study examined the effect of a contents page and main section headings on search efficiency and recall of the structure of a health education brochure.

The brochure that was used was an empirically tested self-help guide designed to help the reader to change toward a healthy diet (see Steenhuis, van Assema, \& Reubsaet, 2000). Especially as a self-help guide, it would be an obvious function to use it as a reference book. The presented information was based on behavioural change models (Prochaska \& DiClemente, 1984) and on research into relevant psychosocial determinants of changing diet (Brug, Glanz, \& Kok, 1997). However, the guide did not contain an extensive contents page at the beginning, nor headings at the start of its three main sections. The absence of these two kinds of access structures could hamper the reader's ability to locate specific information and to get a clear overview of the brochure. Because each section contained different kinds of information spread out over several pages, confusion about its structure could not be ruled out:

Search efficiency was defined in terms of time needed to locate search items and the amount of paging through the brochure until the answers were found. The more pages that had to be turned and scanned, the less efficient was the search. The extent to which the struicture of the brochure was remembered was measured by having participants recall the brochures main themes after first skimming through it and a sorting task of section headings after the search tasks. Both the table of contents and the main section headings were expected to add to the clarity of the brochure's structure, and hence lead to higher search efficiency and better recall of the content structure than the original brochure.

\section{Method}

\section{Participants}

Forty first-and second year psychology students from Cardiff University participated in this study for course credits. Their mean age was 19.5 years $(S D=1.24)$. They were randomly assigned to one of two conditions in a one-factorial between-participants design: 20 participants (of which 5 male) received the original brochure which had a restricted contents page and no main section headings, and 20 (of which 1 male) received the same brochure with an extensive contents page and main section headings.

\section{Materials}

Brochures. An existing brochure about a healthy diet was used (Steenhuis et.al., 2000), of which two versions were tested, the original and a revised version. Both these versions were identical in their general features. Thus, the brochures were A4-size, 32 pages long of which 25 contained text and pictures in different sizes, some in collour but mostly black-and- 
white. They started with one page of explanation about the brochure's subject, followed by half a page explaining how to use the guide. The content consisted of three main sections, called 'Fat' (11 pages),'Fruit and Vegetables' (6 pages), and 'To Maintain' ( 8 pages). Bioth the sections on fat and on fruit and vegetables started with a test on the current eating habits of the reader, followed by some explanations of why it is bad or good, and then some advice to change behaviour step by step. Scattered throughout both sections were short paragraphs about subjects related to health, fat, fruit and vegetables. The final section gave advice on how one can adhere to healthy(er) eating habits in various situations, an agenda page to keep track of one's eating habits, some low-fat recipes and a calorie list of various products. The three main sections (the first level of information in the brochure) were separated by a full page illustration of fruit and vegetables; the first two in colour and the third in black and white. On the second and third (i.e, sub- and sub-sub-) level of both brochure versions, there were 20 and 25 headings, respectively. Second level headings were for example 'Fat test', 'Why less fat?', and 'Eating less fat step by step'; on the thind level more detailed information was put, such as "Guidelines," Saturated and unsaturated fat," and "Cholesterol":

Original version. The main difference between the two versions of the brochure was in the presentation of its access structures. The original guide was set up so that readers could start reading and then, based on their specific needs, read relevant sections. Hence, a 'signpost' section on the second page of the original brochure only explained how to use the brochure; along with some of its main sections and corresponding page numbers (the test, 'why' and 'step-by-step'- sections, and 'to maintain') (see appendix 1). In total, only eight sections were mentioned here: In addition, to guide readers to relevant information; on ten occasions throughout the brochure text references were made to other possibly relevant information. The full page illustration that separated the three sections did not mention the names of the sections they preceded.

Revised version. In the revised version a "table of contents" with 48 entries was designed following general principles of perceptual grouping, which emanate from Gestalt-principles of "precedence," symmetry", and 'enclosure' (see for instance, Winn, 1994). That is, with spacing of headings and indentations of headings that share the same level, the design attempted to create visually evident groupings of sections, thus enhancing the ease of scanning the contents page (see appendix 2). The three levels in the brochure text were indicated typographically. This was done in at least two ways simultaneously, making the structure of the brochure visually sallient and thus easily recognizable. For example, the three main. section titles were highlighted with bold capital letters, which stood out from the remaining lower case normal lettering of the sub-headings. To emphasize that there were three main sections, the three groups of headings of each section were separated by a white line, creating three 'blocks' of text. Dotted lines that linked the page numbers to their headings, added to the visual perception of these 'blocks'. To highlight the three levels of headings in the brochure, the headings on each lower level were indented one tab and made one typesize smaller. This way, all headings that were on the same level were on the same indentation on the page and the same, unique size. A third feature that distinguished the two lowest levels of headings was the indentation of the page numbers on the right side of the page. So, 
with typographical cueing the table of contents was structurally arranged, to enable readers to perceive and remember the information hierarchy of the brochure Lastly, the entire table of contents was fitted on one page, to ensure a full overview of the contents in one glance.

Thus, the contents page that was added to the revised brochure on a blank page just before the "signpost-page" contained all headings on the first three levels of the brochure's structure. in addition to this, big headings were put on the three separating pages of each section of the original brochure, indicating the main structure of the brochure on the first level. Except for these two added features, both brochure versions were identical.

\section{Procedure}

Participants were tested individually in a single session of approximately 40 minutes. First, as a practice trial for the experimental search tasks, three search tasks were given with the university phone book. They were administered verbally and on laminated cards as a reminder of the search target; with the request to find the phone number as fast as possible. After a number was found and pointed to by the participant, the booklet was closed ready for the next question.

Then, participants were given one version of the brochure and were asked to skim through it until they had an overview of its content. Following this, participants were asked to recall the main sections of the brochure. After that, 14 search items were given with the request to find the information as quickly as possible in a way that they would do it normally. As participants searched through the brochure, the experimenter registered their paging and time by means of a click on the mouse button on each turn of a page. Subsequently, participants had to put the brochure away and were asked to sort the section cards into the main sections and subsections as they remembered it from the brochure.

Finally, a questionnaire was filled out, asking about the tasks, the brochure and the contents page. Specifically, participants were asked how they initially skimmed through the brochure, what features they paid attention to during the search tasks, and if they had any comments on the brochure. Participants in the revised brochure group received two extra 7-point Likert scale questions about their use and the clarity of the table of contents.

\section{Dependent Measures}

Recall. Right after the initial paging-through, participants' memory of the brochure's main structure, i.e., the three main sections, was measured with an open question. For each section they recalled correctly, participants recelved one point.

Search efficiency. Participants received search items such as 'Where in the brochure does the section about fruit and vegetables start?', Where does it give tips on how to maintain eating changes, when you cook the food yourself?', and 'Where is it explained what to do, to prevent eating fatty snacks between meals?'The time needed to locate specific information and the number of pages turned before finding the answer was measured.

Card sorting task. After the search tasks, participants were asked to sort 14 first-and second level section heading cards $(5$ from the Fat, 4 from the Fruit \& Vegetables, and 5 from the To Maintain sectiony in the order they had seen in the brochure. The quality of this 
sorting task was assessed with four measures, each of which was assessed independently of the participant's scores on the other three measures. First, the number of main sections participants had put on the table was counted and labelled as correct, 'under, or "above' the correct number of three sections, irrespective of whether the specific title of each section was correct. Second, if participants gave these three main sections their correct title ("Fat". 'Fruit and Vegetables, and 'To Maintain') they could receive up to three points, regardless of whether they had put down more than three main sections.

Third, a separate measure was aimed at identifying explicit errors in participants' recall of the sub-division of subjects within main sections. Thus, this measure indicated the number of intrusions of sub-headings into wrong main sections, irrespective of the total number of main sections that participants had indicated: 50 , possible incorrect partitions of a group of headings into two were regarded as belonging together in counting the number of: intrusions in that grouping.

Fourth, irrespective of the three earlier scores, the extent to which the order of subsections in each of the three main sections followed the ordering of subsections in the brochure was assessed. Thus, the 'order of subsections'-measure comprised three different scores (one for each main section, each independent of the actual number of main sections the participant had indicated and of the number of intrusions of subsections into incorrect main sections.

\section{Data Analysis}

As participants' initial recall of the three main sections could range from 0 to 3 , a nonparametric Chi-square comparison seemed appropriate. Furthermore, univariate ANOVA's were performed on the search times (in seconds) and the number of pages turned of the original and revised group on the 14 search items: Also, Chi-square analyses compared correct and incorrect scores of both groups on the first three measures taken from card sorting task. This dichotomous scale was chosen because it was deemed as best suitable with respect to the research questions, that is, correct versus incorrect recall of materials which typically stiould be rather easy to recall. The three orders of subsections were correlated with the correct order and subsequently compared in ANOVA's.

\section{Results}

\section{Memory for Content}

A Chi-square analysis on the number of participants recalling one, two or all three main subjects correctly ight after having skimmed through their brochure, showed that the revised brochure group outperformed the original brochure group. That is, in the revised condition 14 and 6 participants recalled three and two subjects, respectively, versus 6,13 and 1 participants in the original condition recalling three, two and one subject $\left(\chi^{2}(N=40\right.$, 2) $=6.78, p<.05$ ). On average, the revised brochure group estimated the number of main sections as 2.70, compared to the original brochure group's estimation of 2.25. Thus, most participants, especially those in the original brochure group tended to underestimate the number of main sections. 


\section{Search Behaviour and Efficiency}

A univariate ANOVA on the total search times on the 14 items revealed no significant difference between both groups (original: $M=270.11,50=76.72$ and revised: $M=236.00$, $S D=78.17), F(1,38)=1.94$, ns. Typically, the revised brochure group initially looked through the A4-size contents page to decide on which page they had to look. On the other hand, participants with the original brochure initially tried to use the limited signpost page but in many cases did not find the search target there. Subsequently, they started to page through the brochure, scanning each page for relevant headings. As the brochure was relatively thin, both strategies may have taken comparable total times in locating the search tasks. As the contents pages of both brochures differed in the amount of information they contained, their use could take different amounts of time. This was indeed the case, as the time taken to look at the contents page i.e., the first looking times for each search task in the timing data, were longer for the revised brochure group $(M=6.95, S D=2.20)$ than for the original brochure group $(M=2.17, S D=0.76)$. The time taken to locate search items after having used the contents page was significantly shorter for the revised brochure group $(M=119.29,5 D=$ $57.18)$ than the original brochure group $(M=222.52, S D=69.32), F(1,38)=26.40 ; p<.01$.

A univariate ANOVA on the total number of pages turned showed a significant difference between the groups (original: $M=100.75, S D=16.76$ and revised: $M=60.90, S D=$ $10.32), F(1,38)=82.02 ; p<.01$. The revised brochure group turned $39 \%$ fewer pages than the original group to get to the answer. Paging-frequency was lower for the revised condition for each of the 14 questions. Statistical tests showed that the effect of condition was significant for 11 of the 14 items. The three search items which did not produce significant differences in number of pages turned (items 5, 6, and 14), also did not differ in locating speed.

\section{Card Sorting Task}

With regard to the first measure of the card sorting task, i.e., the number of main sections. as indicated by participants, nobody mentioned fewer than three main sections. Everyone in both groups mentioned the correct number or more sections. However, in the revised brochure group, only three participants overestimated the number of main sections by one, whereas in the original brochure group 15 participants made an overestimation, ranging from one up to six sections too many. A Chi-square on the number of correct (exactly three sections mentioned) and incorrect answers (more than three mentioned) showed that this difference was significant, $\chi^{2}(N=40,1)=14.55, p<.01$.

Similarly, the revised brochure group reported the correct three section titles more often than the original brochure group (14 versus 5 participants), $\chi^{2}(N=40,1)=8.12, p<.01$. With regard to the third measure, in the revised brochure group fewer participants made intrusions, i.e., put section headings in wrong main sections than in the original brochure group ( 2 versus 6 , respectively), but this differences did not reach significance, $\chi^{2}(N=40,2)=$ 3.17 , ns.

Finally, concerning the order of subsections as recalled by participants, the mean correlations for the sections on 'Fat,"'Fruit and Vegetables', and "To Maintain' were slightly higher in the revised brochure group (mean $r=.27, .91$, and .80 , respectively) than in the 
original brochure group (mean $r=.09,89$, and .72 , respectively). However, none of these differences reached significance, $F(1,38)=1.36, n s, F(1,38)=0.07 ; n s$, and $F(1,38)=0.80 ; n s$, respectively.

\section{Rating of Table of Contents}

At two instances, namely right after skimming through and after doing the search items, participants were asked if they had any comments, or ff there was anything in the brochure they particularly liked or disliked. On the first question, four participants in the original brochure group commented that they wanted a table of contents, and two commented that the three main sections could be split up more clearly. After the search items, five additional participants in the original brochure group made a comment about it, three saying they would have liked a table of contents, and two commenting on the 'signpost"-section, saying that was too limited for finding information easily. Four participants in the revised brochure group said they found the table of contents very useful for finding information easily, and two remarked that the three main sections stood out very well with the big headings.

Furthermore, participants were asked what features of the brochure they had paid attention to when initially skimming through $\mathrm{it}_{\mathrm{t}}$ and how they went about looking for the information in the search tasks. Table 1 gives an overview of the items mentioned with each question. As can be seen in the table, participants in the revised brochure group used the table of contents almost always when trying to locate the information in the search tasks. This use was supported by the revised brochure participants themselves, who indicated their use of the table of contents with an average of 6.65 on a 7-point Likert scale. They rated the clarity of the table of contents with a $6.25(S D=0.55)$ on a similar scale.

Table 1. Number of participants in each group $(N=20)$ who mentioned attending to or using these brochure features while skimming through to get an overview, and while looking for specific information in the search tasks, respectively.

\section{Initial skimming:}

Table of contents (revised) / signpost (original)

Original

8

20

7
Revised

14

18

8

\section{How search items:}

Used table of contents (revised) / signpost (original) Guessed relevant main section, looked for heading Just paged through, scanned for relevant heading

\section{Original}

9

14

9
Revised

20

2

1 


\section{Discuission}

The alim of this study was to asses the additive value of the presence of a table of contents and main section headings in an extensive public information brochure on its clarity and usability. On several measures, these 'access structures' did seem to make a difference: participants were more efficient in locating information in the brochure in terms of turning over pages and had a better understanding of the brochure's structure. Specifically, participants who had the brochure with a table of contents had less difficulty, l.e., turned fewer pages to find the answers to the questions, than participants with the original brochure. Also, after skimming through the brochure once, the participants with the revised brochure more often mentioned the correct three main sections and thus had a better overview of the main structure than the participants who had seen the original brochure. So, although the public health education brochure contained several pages on each of the three main subjects, flagging these subjects with main section headings still contributed to readiers" understanding of this.

With regard to search speed, the presence of a table of contents was not found to shorten overall search times, as was expected based on other cognitive-psychological research. However, typically, in the field of cognitive psychology various kinds of information formats have been the focus of search speed research, comparing tables, directories, and prose (Guthrie et..al., 1991; O'Donnell, 1993), printed versus computerized text (McGoldrick, Martin, Bergering; \& Symons, 1992), long textbooks (Dreher \& Brown, 1993; Yussen, Stright, \& Payne 1993), or differently organized texts (Byrnes \& Guthrie, 1992). That in itself makes a comparison between their results and the findings in this study, difficult. In addition, two important differences between this and other studies, regarding the participants and materials used, may account for not finding different search times here. First, Hartley and Trueman (1985) examined effects of headings with children aged 11 to 14 , with varying reading abilities. They showed that thigh ability readers can find information significantly faster than middle-and low ability ones. Here, participants were university students $s_{i}$ who can be regarded as high ability readers. Finding differences between two samples of high-abillty participants who are relatively fast to start with is difficult. Second, most studies into effects of materials on search speed with students, have used textbooks (Bymes \& Guthrie, 1992; Dreher \& Brown, 1993; Yussen, Stright, \& Payne, 1993). As a book of reference, our brochure is relatively thin with its 32 pages. Thus, paging and quickly scanning headings while looking for the information would get any reader to the answer rather quickly and make possible differences between groups in total search times rather small.

Taken together, this explains why participants who had the extra access structures did not benefit much from these in the total time taken to find the answers; as was expected beforehand. However, this turned out to be largely due to their relatively long times spent looking at the table of contents. When looking times at the first (contents) page were extracted from the search times, the search times proved shorter with the revised brochure compared to the original brochure. Together with the lower paging frequency of this 
group, this points towards the use of a selective search-strategy (Klusewitz \& Lorch, 2000), compared to a more exhaustive search of participants with the original brochure.

A more detailed recall of the brochure's structure after performing the search tasks was shown in the card sorting task. Here, on two of the four measures that reflected recall accuracy of the brochure's structure an advantage was shown for participants with the revised brochure. They more often realized that the brochure consisted of three main sections and accurately recalled the names of these sections than participants who had seen the original brochure. These findings are in agreement with other studies; in which the presence of headings as signalling devices of text structure improved recall of the text's content Hartley \& Trueman, 1985; Wilhite, 1986).

Although the revised brochure may have made the structure more obvilous to the reader, the fact that participants with the original brochure had to put more effort into looking for the information may have enhanced their sense and memory of its structure. The finding that both groups remembered the structure equally well may have been caused by an extra focusing of attention to the text structure by the readers who did not have a table of contents or main section headings at their disposal: Through this process, the extra attention increases and information may be learned more effectivelly (Reynolds \& Shirey, 1988). Together with the fact that participants with the original brochure had paged and scainned the pages of the brochure more than participants with the revised brochure, this may have elliminated the advantage of the latter group.

Altogether the findings show a positive, contributing value of the presence of a clear table of contents in combination with main section headings to readers' understanding of the brochure's structure and the ease with which information can be located. Particularly with regaird to the second and third step in the search process of Guthrie's model (Guthrie \& Mosenthal, 1987), namely identification and selection of a relevant category, and then of critical details within that category, participants seemed to be more effective. That is, the table of contents gave them the opportunity to quickly choose a category on the correct levell of detail in the brochure: the heading of the paragraph in which the answer could be found Without the detailed information on these second and third level headings, participants had to start with selecting a main category, for instance 'Fat', or 'Fruit and Vegetables, and start scanning there for relevant paragraph headings. This essentially entails a reiteration of step two of Guthrie's model, that is, repeatedly identifying and selecting a category until the target information can be located. Especially the identification of the main sections themselves may be difficult because they are not unambiguously signalled. This results in more cycles until the goal is met, i.e., a less efficient search process.

As other research has sthown (Bymes \& Guthrie, 1992), expectations about features of the brochure play a major role in the search process. At the start of the first search task, many participants who had the brochure without a table of contents would look at the first and then the last page(s) to find some references to help them. Some participants who had seen the eight page-indications on the signpost page tried to use that as a table of contents, but were unsuccessful on some of these occasions. Subsequently, they started paging through the brochure from the start or relied on their memories of where certain sections were and 
scanned the headings in bold, ignoring the signpost-page. Research has shown that readers with an efficient strategy of category selection search more accurately than readers with exhaustive or erratic strategies (Guthrie et al. 1991). This is illustrated in this study, the table of contents in the revised brochure clearly enabled an efficient search, whereas the absence of such an access structure in the original brochure forced participants to use a less efficient search strategy. That the access structures in the original brochure were spontaneously mentioned as unsatisfactory by several participants, adds to the importance of readers" expectations in locating information.

Finally, although carried out with a brochure about healthy dieting findings of this study may generalize across public information design, irrespective of the specific subject matter concerned. Implementing a clear and complete contents page and main headings may improve readers' ability to work with any extensive brochure. In the specific field of public health education, which usually focuses on content-issues, this kind of experimental research illustrates a new approach towards brochure design. Of course, insight into determinants of health-related behaviours is crucial (see, e.g., Bartholomew, Parcel, Kok, \& Gottlieb, 2001). However, ignoring the more direct effects of the material's design features on the reading process may cause a sub-optimal transmission of its content. In general, less skilled readers are expected to benefit even more than highly skilled readers from the presence of these signals (Sanchez, Lorch, \& Lorch, 2001). Specifically, given the differences reported between high-and low-skilled readers in finding information (Hartley \& Trueman, 1985) in a brochure without clear access structures such as a table of contents and main section headings, readers with less reading-and locating skills may not be able to find the information at all, and consequently get lost in the brochure. If readers of health education materials get lost in them and do not get an overview of their main messages, the chance that they will change their behaviour according to those messages is slim. The development of the originall brochure that was used in this study is a typical example of a content-overdesign approach, where research into essential design features was neglected, resulting in a sub-optimal brochure. Cognitive psychological insights into effects of brochure design on the processing of the information (see also Kools, Ruiter, wan die Wiel, \& Kok, 2004) can contribute to more effective communication and eventually a better chance of behavioural change. 
Appendix 1. The table of contents of the original brochure.

\section{SIGHPOST FOR THIS GUIDE}

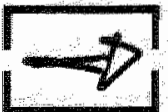

The frst part of this guide is about fat. vou can first check your own eating habits by

filing out the fat test. After that you can, depending on your score, look further into this guide, for instance, when from the test it is apparent that you eat too much fat, you could read the part which explains why it is important not to eat too muth fat for readers who subsequently really want to try to eat less fat, this guide gives some practlical tips that can help. This guide abso explains how you can malntain your healthy eating hathits in the future. This may allso interest people who aiready have a healthy diet.

Fat test: page 6

Why fess rat? page 10

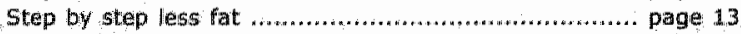

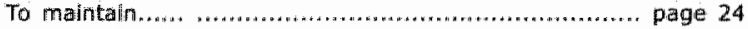

The second part of this guide is about fruit and wegetables. There you can stant filling out the frutit \& vegetables test. After that, you can read further, depending on your score "For instance about the importantance of eating enough frut and vegetables, and how you can do this in an easy way with the help of some practical tips. Also, you can read the part which explains how you can maintain your healthy eating habits in the future.

Fruit \& Vegetables test page 18

Why more frut and vegetables? page 20

Step by step more vegetables.

page 21

Step by step more frult

To maintain 
Appendix 2. The table of contents as designed and applied in the revised brochure version.

\section{CONTENTS}

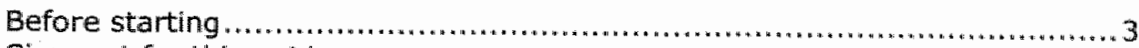

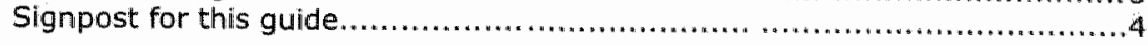

\section{FAT IN FOOD}

Fat test: how much fat do you eat?

The quideline for fat $\ldots \ldots \ldots \ldots \ldots \ldots \ldots \ldots \ldots \ldots \ldots \ldots \ldots \ldots \ldots \ldots$

Need more energy? .............................................. 9

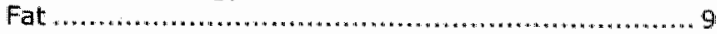

Saturated and unsaturated .................................. 9

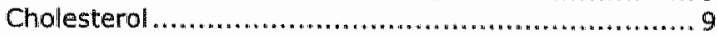

Why less fat? .................................................................... 10

Fat and heart disease and strakes ........................ 10

Fat and cancer .................................................. 10

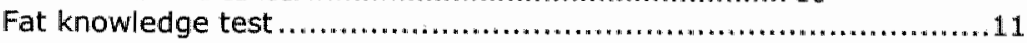

Eating less fat step by step ....................................................13

Milk and dairy products..................................... 13

Butter............................................................ 14

Cheese and sweet fillings ...................................... 14

Meat products............................................... 14

Meat / cheese with your hot meal.......................... 14

Gravy and sauces $\ldots \ldots \ldots \ldots \ldots \ldots \ldots \ldots \ldots \ldots \ldots \ldots \ldots \ldots \ldots \ldots$

Snacks........................................................... 15

What is on the packing? .........................................................

\section{FRUIT AND VEGETABLES}

Fruit and vegetables test: how much do you eat? ..........................18

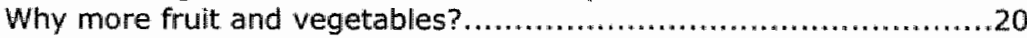

Fruit \& vegetables and cancer..............................20

Fruit \& vegetables and heart disease and stroke...... 20

Herbicldes ........................................................... 20

Vitamin pills ................................................ 20

Eating more vegetables step by step .....................................22

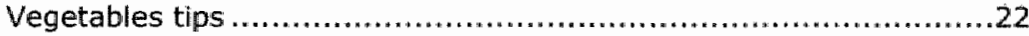

Vegetables from a can jar or freezer ....................... 22

Nitrate and nitrite..............................................22

Eating more fruit step by step.............................................. 23

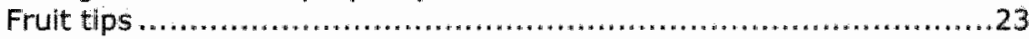

TO MAINTAIN

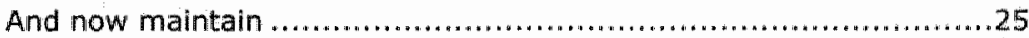

Eating together with others ..................................................25

When you do not prepare food yourself ................., 25

When you do the cooking yourself .........................25

To have an appetite.......................................................26

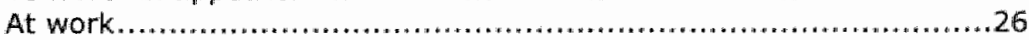

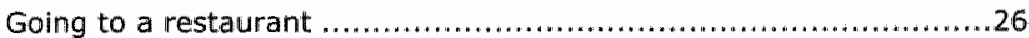

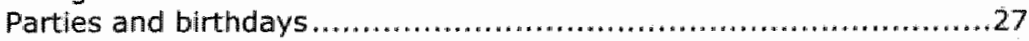

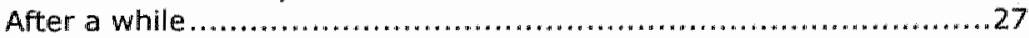

Daily menu............................................................... 28

Recipes..................................................................29

Cod with small potatoes and French beans .............. 29

Bean dish for 4 persons ........................................ 30

Vegetable pasta for 4 persons. $\ldots \ldots \ldots \ldots \ldots \ldots \ldots \ldots \ldots \ldots \ldots \ldots .31$ 
Chepter !

Chapter 2

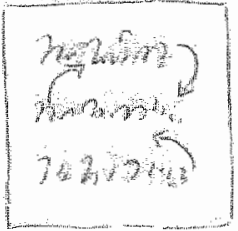

Chapter 3

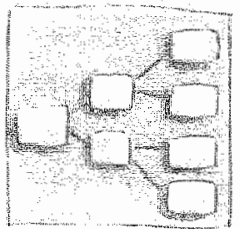

Chapter 4

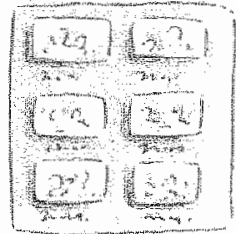

Chapter 5

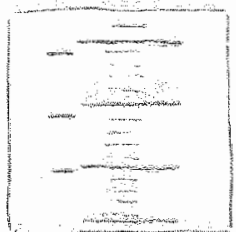

Chapter 6

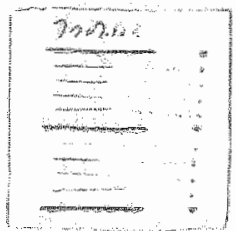

Chapter 7

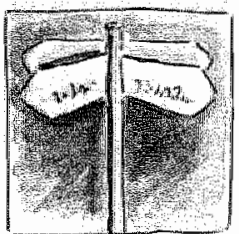

Chapter 8

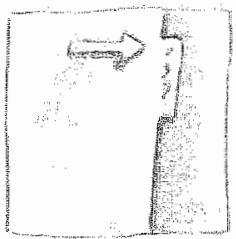

Chapter 9

Summary

Samenvatting

References
Generalintroduction

1

Increasing readers comprehension of

health education brochures: A qualiative study into how professional writers make texts coherent

The effect of graphic organizers on

subjective and objective comprehension of a heath education text

Pictures and text in instructuons for medical devices: Effects on recall and actual performance

The effects of headings in a brief health education text on locating speed and evaluation

Access structures hello readers locate and remember information in a health education brochure.

\section{The understandability of pictorials in a} health education brochure

Testing the usability of access structures in health education brochures education practice 
Pictonials

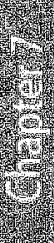


$\mathrm{H}$

ealth education brochures typically convey different kinds of information, ranging from explanations about physical causes of disorders, to tips for changing behaviours. Reader's may not read such a brochure from start to finish, but may open it with some questions in mind that they want to answer. For instance, readers of a brochure on healthy living may only want to read practical information on what to do (e.g. about negative consequences of their life-style) and skip other sections, thus disregarding the information order the writer chose. To enable this selective reading, certain kinds of information could be denoted by design features such as colour, lay-out or pictorials to help readers recognize different categories of information and so find information more efficiently: In research into the effectiveness of health education materials, little attention is paid towards such design characteristics and their effect on the usability of written information. Based on cognitive psychological research into pictorials, the goal of the present study was to compare the usability, or understandability of two pictorials in a brochure. Pictorial information in written materials in general can contribute to the understanding of their content and thereby aid readers: in the reading process (Wogaiter, Sojurner, \& Brelsford, 1997; Young \& Wogalter, 1990).Two pictorials were tested in their context, that is, in a health education brochure, to see whether such findings could contribute to health education practice.

\section{Understanding pictorials}

Research into perception, recognition, and understandability of pictorials is mostly done in the context of warnings (see, e.g., Davies, Haines, Norris, \& Wilson, 1998; Hicks, Bell, \& Wogalter, 2003; Easterby \& Hakiel, 1981) and to a lesser extent in way-finding design (Zwaga \& Boersema, 1983). Warnings often contain a pictorial, which visually explains the written message. A pictorial is typically designed to refer to the function, or goal of the object it represents in the specific context it is encountered in. For example, a simplified line-drawing of a printer that one can click on in a word processing program refers to the printer"s function of printing out a document that is currently open in that program. A well-designed pictorial can communicate a message at a glance, without languagle barriers. Similarly, a poorly designed pictorial may communicate nothing or worse, the wrong message (Wogalter, 1999).

Research into the understandability of pictorials has shown that their meanings are generally not very self-evident (Davies et al., 1998; Olmstead, 1999; Wogalter, Begley, Scancorelli, \& Brelsford, 1997; Zwaga \& Boersema, 1983). One reason for this is that many pictorials are not well designed and thus fail to convey their intended meaning (Sojourner \& Wogalter, 1998). For the understandability of pictorials, their concreteness has been established as an essential feature (Mishra, 1982; McDouglas; de Bruijn, \& Curry, 2000). Here, concreteness is defined as the extent to which pictorialls depict objects, places, or people. Hicks, Bell and Wogalter (2003) showed that ease of visualization of the pictorial's concept, its simplicity, and concreteness were all highlly and positively correlated with comprehension. They may even measure the same underlying dimension. Thus, simple but accurate drawings 
that are easily recognizable as concrete objects in the real world enable readers to instantly understand that pictorial in its textual context.

Related to this, in the design of pictorial information a distinction is made between depicting codes and directing cades in pictures (Weidenmann, 1994). Specifically, depicting codes simulate visual characteristics of real-world object perception whereas directing codes relate to actions and deviate from reall world appearance. For example, a drawing of an asthma pump would represent a depicting code; arrows that show the movement of air within the pump or thicker lines highlighting the press-area on the pump would represent directing codes in that picture. Usually, directing codes are abstract representations (e.g. arrows) applied to a concrete representation, and thus do not occur as pictorials on their own in textual materials.

To ensure that readers understand a pictorial's meaning in the way the designer intended, testing is considered very important (Davies et al., 1998; Wogalter et al., 1997; Olmstead, 1999). For choosing understandable pictorials, various tests have been developed (for examples, see Brugger, 1999, and Zwaga \& Boersema, 1983). However, a relatively simple test ${ }_{r}$ considered the "gold standard' in measuring pictorial comprehension, involves asking participants a pictorial's meaning in an openended test (Dewar, 1999). Simultaneously providing the context in which a pictorial is supposed to be encountered, for instance showing photographs of the environment of a traffic sign symbol (Wolff \& Wogalter, 1998), has been found to increase symbal comprehension (Cahill, 1975). Specifically, context reduces erroneous interpretations by providing a mental set that restricts a pictorial's possible interpretations (Biederman, Glass, \& Stacy, 1973). That is, it disambiguates a pictorial in the process of understanding its function.

\section{This study}

In the present experiment, we tested the understandability of two pictorials in a brochure about healthy dieting. On various pages, references were made to related information in the brochure. In the original brochure an attempt had been made to clarify the presence of these references with an accompanying pictorial of an arrow (see Figure 1) in the left margin of the page, next to the textual references. For several reasons, we expected this arrow to be difficult to understand. First, it was an uncommon line-drawing of an arrow, which readers probably had not encountered before and therefore it might be ambiguous or unrecognizable. Second, being typically used as a directing coide within a picture and as such combined with other pictorial elements the meaning of an arrow without an associated concrete object was expected to be difficult to interpret.

Therefore, a pictorial of a signpost (see Figure 2), was developed and its understandability tested. In addition to the fact that this drawing was common and therefore expected to be unambiguous, this signpost had a depicting sign' relation with its real world referent, namely a signpost which is encountered in every day life. Both these features were expected to make the signpost pictorial more concrete and thus easier to recognize and understand than the arrow pictorial. Keeping in mind the ecological 
validity, both pictorials were tested within the appropriate context and understanding was measured with open questions.

\section{Method}

\section{Participants}

Forty undergraduate psychology students from Cardiff University (mean age 19.5, S.D. $=1.24$ ) took part in this study for course credits. They were randomly assigned to one of two conditions: 20 (of which 5 male) received the original brochure with the arrow pictorials, and 20 (of which 1 male) received the same brochure but with the signpost pictorial instead of the arrow.

\section{Materials}

The study used a brochure about a healthy diet, which had been part of an intervention of a PhD-project and in that capacity had been developed systematically and evidence-based (Steenhuils, van Assema, \& Reubsaet, 2000). Two versions of this brochure were tested, the original and a revised version. The brochure was an A4-size, 32 pages long 'self-help guide' for changing ones diet into a healthier one. In the brochure design one had chosen not to include an extensive contents page. Instead, readers were 'sign-posted' through the brochure on 11 occasions to related sections on other pages. In the original brochure, a pictorial of an arrow in the left margin of the page indicated the presence of those reference-sections (see Figure 1).

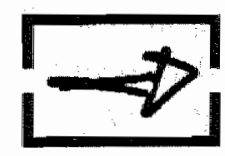

Figure 1. The arrow pictorial in the original brochure.

The revised brochure was essentially the same as the original brochure: The difference between both brochures was that the arrow pictorial was replaced by a pictorial of a signpost (see Figure 2).

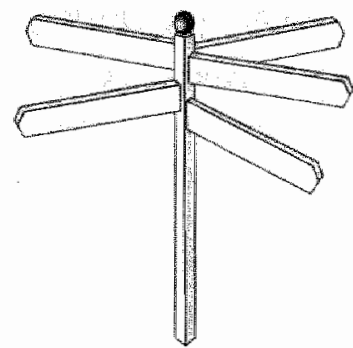

Figure 2. The signpost pictorial in the revised brochure

A short questionnaire was developed, showing the pictorial that each participant had seen. Thus, the originall brochure group saw the arrow and the revised brochure group the 
signpost. Participants were asked to indicate on a 7 -point Likent scale (ranging from'not at all clear" to "instantly wery clear') whether they found it instantly clear what this pictorial represented. Also, they were asked whether they had recognized its function throughout the brochure ('yes' or 'no'), and to explain what they thought the function was. Subsequently the other pictorial (i.e., which they had not encountered in their brochure version) was shown and through open questions participants were asked to indicate what it represented and what purpose it could serve in printed information such as the brochure they had seen. Thus, all participants saw both pictorials, one of which they had encountered before several times in the brochure:

\section{Procedure}

Participants were tested individually as this was part of a larger study exploring the effect of access structures on readers" search efficiency (Kools et al. in preparation). They were seated at a table and were handed the brochure version of the experimental condition they had been assigned to. First, they had to locate ten specific pieces of information in it, which were put in front of them on cards. These items were scattered throughout the brochure and required them to page through it. This ensured that they encountered the pictorial in its context, without explicitly being made aware of its presence. Subsequently, the questionnaire was administered.

\section{Results}

A one-way ANOVA on the question regarding the clarity of the pictorial participants had encountered in their brochure, showed that the revised brochure group found the signpost clearer $(M=5 . \pi, 5 D=1.83)$ than the original brochure group found the arrow $(M=3.7,5 D$ $=1.811, F(1,38)=5.91, p<.05$. A Chi-Square analysis on participants' recognition of the pictorial's function (i.e., understanding of the pictoriall) showed that the revised brochure group recognized the siginpost's function correctly more often (correct: 15; incorrect: 5 ) than the original group recognized the function of the arrow correctly (correct: 7 , incorrect: 13), $x^{2}$ $=6.47 ; \mathrm{df}=1 ; p<.05$ (see also Table 1).

Table 1. Number of people in each group $(\mathrm{N}=20)$ correctly identifying the function of the pilctorial.

\begin{tabular}{|l|c|c|}
\hline & Original brochure group & Revised brochure group \\
\hline Arrow & 7 & 2 \\
\hline Signpost & 19 & 15 \\
\hline
\end{tabular}

Additional analyses were done between both groups to see whether familiarity with the pictorial made a difference. Where participants indicated on an open question what the 
pictorial represented that they had not encountered in their version of the brochure (fee, original group: signpost, revised group: arrow, no differences were found in performance. That is, all participants in the original group recognized the signpost correctly, and 18 of the 20 participants in the revised group recognized the arrow correctly $\left(x^{2}=2.11, \mathrm{~d} f=1 ; p=15\right.$, m.s.). However, when guessing the purpose the pictorial could serve in a brochure only two participants in the revised group guessed the arrow's function as an indicator of references, versus 19 of the 20 participants in the original group who attributed that function to the signpost pictorial $\left(\chi^{2}=28.97\right.$; $\left.d f=1 ; p<.01\right)$. Thus, itrespective of whether the signpost had been seen before, its potential function within the brochure was understood more often than the arrow (Table 1).

Analyses within both groups confirmed that the function as 'an indicator of references to other pages with related information' was correctly attributed to the signpost more often than to the arrow, in the original brochure group $\left(\chi^{2}=15.82 ; \mathrm{df}=1 ; p<.01\right)$, and in the revised brochure group $\left(\chi^{2}=17.29 ; \mathrm{d} f=1 ; p<.01\right)$.

Functions that were ascribed to the arrow by participants in the revised group ranged from "make people turn over to next page" (mentioned by seven participants), "highlight: information, points towards important information" (mentioned by three), to "can function as a bullet-point. One participant in the revised group explicitly said she did not recognize the pictorial as an arrow at all. Even in the original group; where participants had encountered the arrow several times in the brochure and thus in the context of its function, two participants thought that the arrow"signposts important features such as "this is important", and "is like "helpful hints" or something, or 'important features'?", and one participant still did not recognize it as an arrow.

\section{Discussion}

The results supported the expectations that an existing arrow-pictorial would be less comprehensible as an indicator of references compared with a signpost-pictorial. That is, the signpost pictorial proved more recognizable than the arrow pictorial. This was supported by the fact that the pictorials' function as 'indicator of references to related information throughout the brochure' was attributed to the signpost significantly more often than to the arrow, indicating higher understandability of the signpost compared to the arrow. This difference was found between the two groups as well as within each group. So, even to the participants who had encountered the pictorial several times before in its context of the brochure, the arrow was less clear than the signpost pictorial. Comprehension of the arrow's function was remarkably low, considering other research in which context had a rather strong inflating effect on pictorial comprehension (Cahill, 1975; Wolff \& Wogalter, 1998).

Of all forty participants, nine understood the arrow's function and 34 understood the signpost's function. Compared to standards that are used in pictoriall comprehension in warnings research, only the signpost pictorial meets the $85 \%$-correct recommendation of the American National Standards Institute (ANSI Z535.3-1998), Even the more lenient $67 \%$-correct guideline of the International Organization for Standardization (ISO 3864 - 
1984) is not met by the arrow pictorial. Although with pictorials such as the ones in this study no immedlate dangers may be inwolved when they are not understood correctly, this may depend on the specific aim and context of the pictorial used. For instance, if pictorials: were used to flag contraindications on a medicine or in a health education brochure, and their function was misuniderstood this might have serious consequences. Comprehension is a necessary condition for effective health education communication (McGuire, 1972). Therefore, such comprehension-related guidelines provide health education designers with useful objective measures to strive for in designing understandable pictorials in their brochures.

Altogether, the signpost pictorial met the requirements of pictorial understanding better than the arrow pictorial. Thus, the line drawing of a signpost is a suitable implementation of a'depicting code' (Weidenmann, 1994) in the function of a real world signpost: directing people to places they want to go. in this sense, it can be regardled as having high concreteness towards depicting an object that people know (McDouglas et al., 2000), As is illustrated by the great variety of meanings which were attributed to the arrows this pictorial is so abstract and broadly applicable that by itself it may not be a good pictorial to convey meaning. Its function as it was originally meant by the designer could only be understood by readers when regarded as a directing code' in combination with the textual references next to it, and not as a 'depicting code' on its own. Evidently, to perceive this relation between the pictorial and the text, readers have to pay more and longer attention to the combination; a quick glance is not enough. In applying pictorials this way, their actual function as clear data-carriers in isolation and thus their additive (redundant) value in the comprehension of information is ignored. Thus, when several alternatives for a pictorial are available then concrete rather than abstract pictorials may be better. This study illustrates an 'encoding gap' (Hannafin, 1988) between the desigmer and the user of the health education brochure. To prevent such a difference between intended and interpreted meaning, testing pictorials in a brochure's design phase is strongly recommended.

Finally, apart from issues around the understandability of this article's pictorials, a cautioning remark should be made regarding their applicability as reference markers in a brochure. Although the present study showed that the function of signposts could be understood, it does not follow that readers will choose to adopt this form of navigation (see chapter 6 of this thesis). Health education designers should be mindful of the possibility that however understandable on their own, pictorials in the context of a particullar brochure may not be wanted by readers and so may not have the desired effect(s). Therefore it is recommended that health education designers test their pictorials' use in the brochure's context to ensure the effectiveness of their pictorials. 
Chapter

Chapter 2

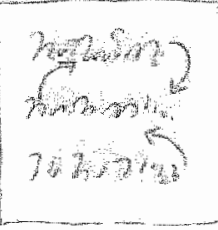

Chapter 3

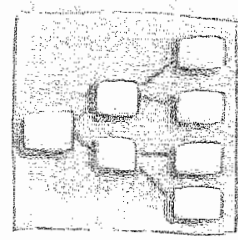

Chapter 4

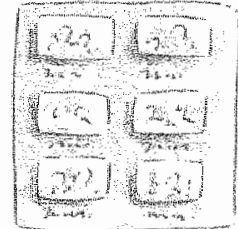

chapter 5

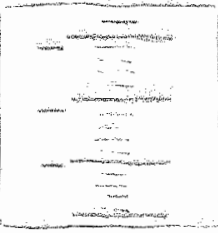

Chapteir 6

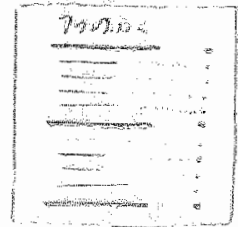

Chapter 7

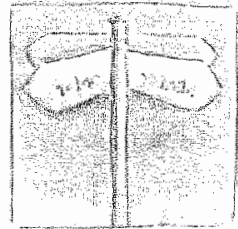

Chapter 8

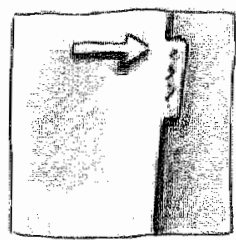

Chapters

Summary

Samenvatting

References
Generalntroduction

Increasing readers comprehension of

health education brochures: A qualtativa. study into how profes sionat whiters make texts coherent

The effert of graphic organizers on

subjective and objective comprehension of a health education text

Pictures and text in instuctions tor medical devices: Effects on recall and actual performance

The effects of headings im a brief health education text on locating speed and evaluation

Access structures help teadars locate and remember information in a health education brochure

The understandability of pictorials in a beatheducation brochure

Testing the usability of access structures in health education brochures

Ceneral discussion: Implications for heath educaton practice 
$E$ xtensive health education brochures can be especially usefull for informing people about comprehensive behavioral changes that depend on many factors. To get people to change their diet into a healthier one, for example, they should first see the necessity to do this, then be motivated to make the required changes, and finally, acquire skills to change their behavior. Inevitably, readers will vary greatly in the extent that they need certain types of information, depending for instance on the specific phase of behavioral change they are in (e.g. Prochaska \& DiClemente, 1984). For example people that are already motivated to change their diet may only wish to know how to do it. A brochure's design should enable those readers to get to specific information easily. Thus, a brochure should help readers to direct their attention towards personally relevant information. The more extensive a written information booklet is, the higher the necessity for effective navigational tools to help readers find information of their personal interest.

The aim of the present study was to examine the usability of 'navigational tools' in a health education 'self-help guide', with a focus on the ease with which people can find relevant information. For health education this is a new approach to brochure design, as such accessibility or use of written materials is hardly studied. The accessibility of written materials may be facilitated with so-called "access structures" (Waller, 1979), such as a contents page, an index, text headings, summaries, and page numbers (Hartley, 1995). In an attempt to extend this list, less conventional aids for textual access were the subject of the present study. Unlike common brochure design, the brochure on healthy food tested in this study did not contain a complete table of contents or index page to look up information. Instead, the second page comprised some section titles with page numbers and references to other sections in short reference-paragraphs throughout the brochure, which were accompanied by a pictorial of an unusual arrow in the left margin next to the text (see Figure 1a). Based on general usability-guidelines these access structures were expected to be sub-optimal for finding information, and changes were made to improve this. The usability of this kind of access structures was assessed and compared with colored tabs combined with common arrow-pictorials. Tabs are typically used in office appliances with the goal of guiding readers to preferred information parts. However, no research is available that studies the effects of such tabs-based access structures on their actual use by readers. To our knowledge, the present study is a first step in clarifying this issue. Before describing further details of the study, the cognitive ergonomics concept of usability and usability-testing will be explained and applied to the original brochure.

\section{Usability}

Cognitive ergonomics is a field in psychology in which human information processingcharacteristics are studied with the aim of improving people's interactions with their informational environment. Central in ergonomics research is the concept "usability," which has been defined by the international Standardization Organization $(15 \mathrm{O}, 1998)$ as "the extent to which users of products are able to work effectively, efficiently and with satisfoction" (p. 2).The effectiveness of a device refers to the extent to which a user can achieve specific 


\section{Figure la}

\section{WEG WIJZER VOOR DEZE GIDS}

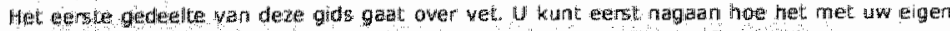

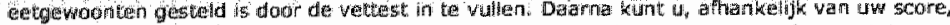

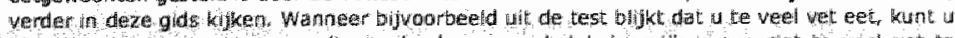

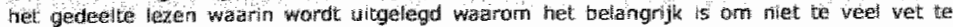

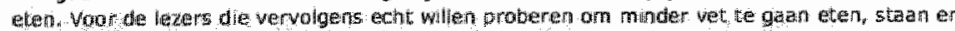

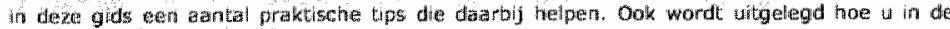

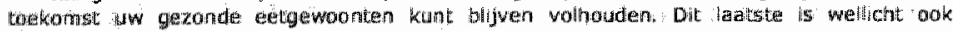

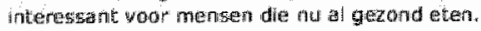

Vethesit badziode 6

wharom minder vat? Diadzjede 10

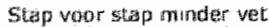
biadzijde 13

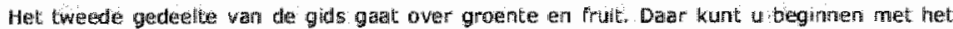

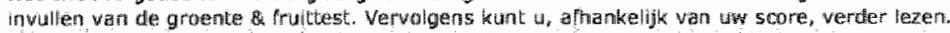
Bjwoorbeeld warom het belengrijk is woldoende gnoente en frut te eberis hoe s dat met

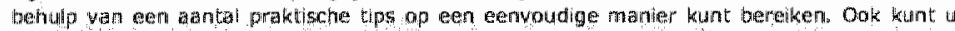

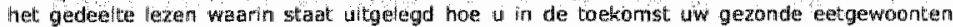
. tcurat: bijwern wothouden.

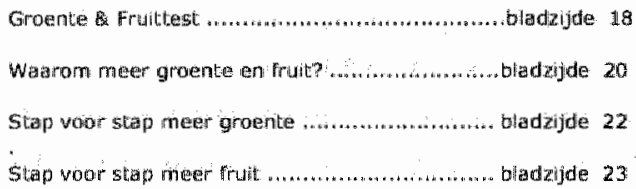

Eil nu doong

Figure 1: (a) The contents page of the original brochure and (b) the contents page of the adjusted brochure, with drawings of the tabs that were visible on the right. Note that this is the tabs-arrows black-white version of the brochure; the tabs black-white version did 


\section{WEGWTIZER VOOR DEZE IIIOS}

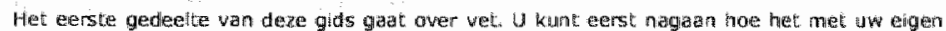

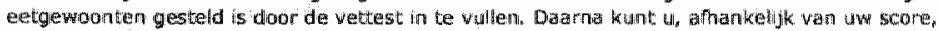

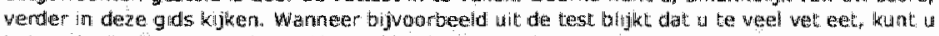

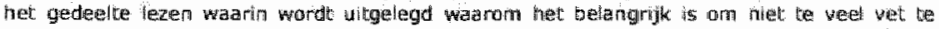

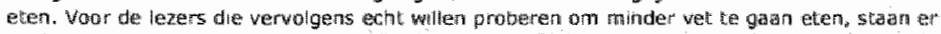

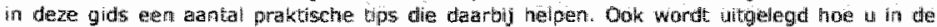

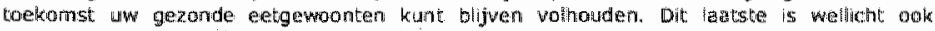
interessatio voor mensen die nili al gerond pter.

Wetters bladzijole 6

Wratam minder ver? biadzigde 10

Stary woor sta minder vet bladxigde: 13

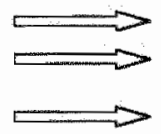

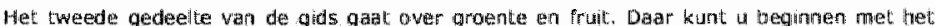

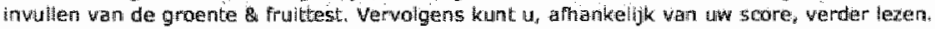

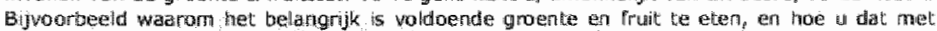
behup wan een aratal praktsche tps op en cenvoudge manier kume bereiken. Ook kunt a

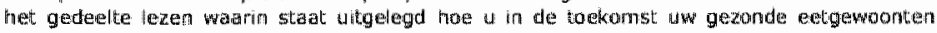
kurit bijuen volthouder.

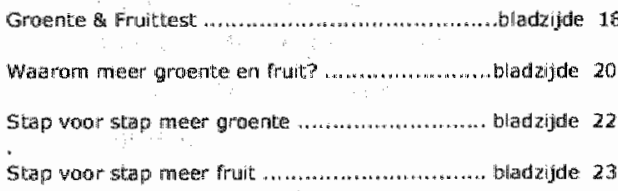

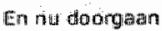

bladzijde 2

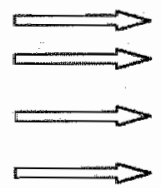

Gronentegerifu teast:

Waram meeir $g$ a f?

Stap woror stap mear

Groent:artips Frutit-tips

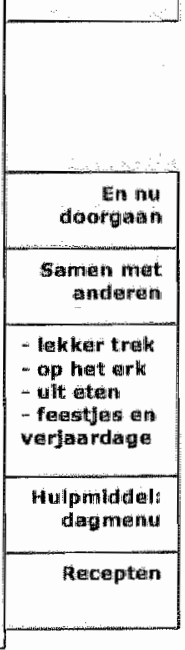

not contain the arrows, and in the tabs-arrows color version, each grouping of tabs and corresponding arrows were in a different color. The figure is meant to give an impression of the access structures; the text was left in its original, Dutch language. 
goals oi sub-goals by using it. Achieving a goal can occur more or less efficiently, depending on the user's expenditure of resources such as time or effort. User-satisfaction concerns the perceived ease of use by users. An additional effectiveness-related measure that is relevant to brochure design is its learnability, or the ease with which its contents and use are leamed (ISO, 1998).

Applied to the brochure in this study, a highly usable design would enable readers to locate information (effectiveness) with hardly any effort (efficiency), so with minimal paging and trials, and give a positive attitude towards its contents and design (satisfaction). Learning the brochure's general contents and use easily (learnability), would add to this. Thus, usability research typically comprises several dependent measures, both objective and subjective ones. The specific choice for data-gathering methods depends solely on the questions that need to be answered and on the specific design aspects of interest (McClelland, 1995).

\section{Usability Analysis of Original Brochure}

In the present study, an existing brochure about a healthy diet was used, which had been part of an evidence-based health education intervention, so its contents were based on empirical data about behavioral determinants as well as theoretical models of behavioral change (Steenhuis, van Assema, \& Reubsaet, 2000). However, as with many health education materials, no research was done to base the design decisions on or to find out if readers used the access structures the way the designer intended.

Although access structures such as indexes and contents pages have been subject of search-speed studies in educationally-oriented settings of designing textbooks (Dreher \& Brown, 1993; Yussen, Stright, \& Payne, 1993), little usability-studies have been done concerning less conventional access structures in paper-based information such as in the present brochure (see, Hartley, 2004, for an overview on access structure research). Therefore, general usability-guidelines were considered in an initial evaluation of the brochure's access structures. Based on human information-processing stages of perception, cognition, and action, Lin, Choong and Salvendy (1997, see p. 270) defined a useful list of eight criteria. In short, a design is more usable when: stimulus-response compatibility is high, it is internally and externally consistent, it is flexible to needs and wishes of various kinds of user's, it is easy to learn, minimal action and minimal working-and long-term memory load are required for using it, considerations of limits in human perceptual organization are embeddled, and a user guidance scheme is available.

An analysis of the original brochure of the present study on the criteria above revealed the need for improvement of the access structures. Specifically, the reference paragraphs of variable lengths and at variable places throughout the brochure contributed to low internal consistency. In addition, reference paragraphs throughout the text are rather unconventional (thus causing low external consistency). In another study by the authors, the arrow-pictorial that accompanied these sections had been shown to be ambiguous as to what it represented and what its purpose was in the brochure (Kools, Wright, Van de Wiel, Ruiter, \& Kok, 2005; see chapter 1 of this thesis), and thus was regarded as contributing further to a low extemal consistency. This, in turn could result in low recognition and use 
of its function as initiators to page further (low sitmulus-response compavibility). Referring readers to other sections that could be relevant for them while reading, can be regarded as an attempt to improve flexibility of use. However, a prerequisite for effectively using those references would be that the reader has read the previous text, causing low flexibility for readers who have not read anything beforehand and want to look up specific information. Given that the brochure contained a llot of information without a complete contents page on which the information hierarchy was stated, learning its general contents was expected to be rellatively difficult (low learnability of brochure content) as well as the minimal amount of action needed to find specific information elements. No explicit groupings of content or a user guidance scheme were present in the original brochure to make its use easier.

\section{The Present Study}

A combination of three changes was made in order to improve the brochure's access structures: tabs were inserted, the original brochure's arrows were replaced by conventional arrows, and color-coding was applied to the combination of arrows and tabs (see also Figure 1b). First, the most important change to the original brochure was attaching tabs with section headings to the pages for each section that was referred to in the original referenceparagraphs. To show the three main sections, tabs belonging to each section were grouped together in separate clusters.

Secondly, as pictorials should be instantly recognizable to be effective (Wogalter, 1999), a more conventional arrow was chosen to replace the unusual arrow-pictorial of the original brochure. To clarify their function, the arrows were put behind the textual references so that they did not point to the references themselves but rather, invited readers to loak to the right to see the tabs they pointed to.

Finally, the distinctiveness of the three brochure sections was made redundant by the color that each of the tab-groupings had (Christ, 1975); pink, green, and blue. In addition, the arrows that pointed towards the tabs were in corresponding colors to clarify the relation between the arrows and corresponding tab. Generally, color is known to focus attention, has strong grouping effects for objects in the same color (Keyes, 1993), and enhanced the distinctiveness of objects with different colors (Davidoff, 1987). In written information color has been found to enhance readers' memory for the information (Hall \& Sidio-Hal, 1994), help them relocate information (Wright \& Likorish, 1988; van Hout-Wolters \& Kerstjens, 1990\%, and be preferred by readers (Achterberg \& Bradley, 1991; Wright \& Likorish, 1988; van HoutWolters \& Kerstjens, 1990).

The arrows and color-coding were primarily meant for supporting the tabs. In terms of usability, the tabs were expected to have high external consistency because they are encountered in address books or office-books as aids for accessibility. The tabs were made maximally visible by extending them from the right side of the page, thus showing users where they are in the brochure. This could add to user guidance. In addition, the tabs could give users an overview of the brochure's contents, improving potential leamability. Related to this, the surveyability of the three main subjects was enhanced by grouping the tabs of each imain section together and leaving openings between each cluster of tabs thigh 
perceptual arganization). The color-coding of the tabs and arrows was meant to contribute to this, by making this grouping visually redundant.

Furthermore, the presence of the tabs was expected to decrease users' necessary memory load, as they need not remember page-numbers and names of headings when looking something up. In addition, the tabs could be grabbed individually and thus by themselves were expected to afford to turn a page with (high stimulus-response compatibility), also lowering the required minimal action by the user to find information. The tabs were expected to sustain the referencing-sections as well as function as a general table of contents for users, thus adding to the brochure's flexibility for readers with different needs.

\section{Method}

\section{Participants}

One-fiundred participants from the general population that had responded on leaflets they found at their supermarket participated in this study. They were randomly assigned to one of four conditions in a between-subjects design: the original ( 8 men, 17 women, mean age: 36.16 years), the tabs black-white ( 8 men, 17 women, mean age: 38.96 years), the tabs-arrows black-white ( 8 men, 17 women, mean age: 37.49 years), and the tabs-arrows color ( 9 men, 16 women, mean age: 36 years) brochure group. Participants were rewarded with $25,-$ gift vouchers.

\section{Materials}

The brochure. To distinguish individual effects of each design feature in the analyses, in total four versions of the brochures were designed, that were identical in their general features. All brochures were A4-size, 32 pages long of which 25 contained textual contents and pictures in different sizes, in colour and black-and-white. The remaining seven pages were either blank or contained a page-size picture of healthy foods. There were three main sections, called 'Fat" "11 pages), "Fruit and Vegetables" ( 6 pages), and "To Maintain' ( 8 pages).

Eourversions, The main difference among the four versions of the brochure was the way that the content was indicated. The original brochure was set up so that readers could start reading and then, based on their specific needs select relevant sections. Hence, a 'signpost" section on the second page of the original brochure version only explained how to use the brochure, along with three sub-sections and corresponding page numbers (that is, "test-" "why - and 'step by step-" in the 'Fat" and "Fruit and Vegetables' sections and a 'To Maintain' section) (see Figure 1 a). In addition, readers were guided to possible relevant information on ten occasions throughout the brochure text by specific references the names of headings with corresponding page-numbers). These reference-paragraphs ranged from ten to one references and were inserted based on content-considerations, so at variable places on the pages. An arrow pictorial in the left margin accompanied them.

In the second, tabs black - white version the arrow-pictorials were left out. In addition, the sections that were pointed to in the reference-paragraphs were tabulated with a total of ten tabs that stuck out of the brochure, containing various numbers of headings. They were placed immediately below each other and grabbing the tab and turning the page with 
it would open the correct page. Between the label-groups belonging to each of the three sections one-inch gaps were created (see also Figure $1 \mathrm{~b}$ ).

In addition to the tabs, in the third, tabs-arrows black-white version the original brochure's arrow-pictorial was replaced by conventional arrow line-drawings with each individual reference in the text's reference-paragraphs. In contrast to the single arrow pictorial on the left of the reference-segments in the original brochure, the adjusted arrows were put to the right of every reference to indicate that the information could be found further in the brochure (see Figure 1 b). As pictorials, they were meant to attract attention to the references and the tabs.

The fourth, tabs-arrows color-version was identical to the tabs-arrows wersion, with the addition of three colours. The four tabs in the 'Fat' section were in pink, the three'Fruit \& Vegetables" tabs in green, and the three "To Maintain' tabs in blue. Each arrow in the text that pointed towards one of the coloured tabs was in the same colour as the tab it pointed to, to enhance recognizability of the relevant section.

\section{Procedure}

Participants were tested individually while seated at a table with the experimenter, in sessions of approximately 50 minutes. The sessions were video-taped to enable analysis of participants' search behaviors afterwards. All participants signed an informed consent by which they agreed with the proposed procedures and the presence of the video-camera. Participants were asked to find ten pieces of information in the brochure that was on the table in front of them. While looking for each search item, they were asked to say what they were doing while looking for the items. This was meant as a verball back-up for the analysis of their behavior on the video-tapes. It was asked to refrain from reading entire sections of text and instead keep looking for the search item.

Then, the search items were provided one at a time in a set order, to ensure that no two items in a row were in the same section of the brochure, minimizing direct memory effects during the search. The experimenter put the cards with the search question in front of the participants and read the question out loud. Then, participants had to look up that information in a way that was natural to them. Whenever they seemed hurried they were ensured that speed was not important and that they could take as long as they wished.

After pointing to the specific location of the answer, the participant could close the booklet ready for the next item. Only if participants started to express confusion about where to find the information, the experimenter would rephrase the question to heip the participant out a bit. Special care was taken during the whole session to make participants feel at ease and experience feelings of success when they found search items. Finally, a questionnaire was administered in which their memory for the main sections in the brochure was asked as well as their evaluation of various aspects of the brochure. Lastly, the experimenter showed the participants all four brochure versions and asked which they preferred and why. 


\section{Dependent measures}

Effectiveness. From the video-recordings three visible actions were counted regarding the use of the access structures that were at participants" disposal. First; the use of the contents page was counted. Secondly, successful use of the tabs was counted. This refers to using the tabs correctly; so looking at the page behind the tab to find the information and thus opening the brochure at the correct page. Finally, the use of references from referenceparagraphs throughout text was counted: how many times participants went to a page based on a reference in a reference-paragraph.

Efficiency. It was reasoned that the more efficiently participants searched, the less they would randomly pagje, scan, or read wrong instances of text before finding the search items. Thus, random-paging frequency related to the number of times participants turned pages during their search. This only referred to paging without a specific target, so paging based on the use of the contents page or other references was not counted in this category. The frequency of visually scanning pages was assessed when participants looked through a page that did not contain the search item. This scanning behavior was visible in that participants moved their heads when looking over a page. Finally, instances of reading "wrong'pieces of text were assessed The occasions where (parts of) paragraphs were read that did not contain the search item, were counted here.

User-satisfaction. A third class of dependent measures evaluated the experienced usability or user-satisfaction with the brochures design features, with a specific focus on the access structures. This was done with a self-administered questionnaire using 7-point Likert-scales (always ranging from 1, 'not at all [evaluative word]' to 7,'very [evaluative word]"). First, participants' ease in locating the search items, participants" evaluations of the brochures general structure ('To what extent do you find the brochure's structure clear?") and its surveyability ("How surveyable did you find the brochure as a whole?') were asked. Then, specific questions asked about the usability of the access structures participants had encountered in their brochure version. So, in the original brochure group participants were asked about the arrows combined with the references, in the tab-brochure group about the tabs, and in both tabs-arrows brochures about the combination of both the tabs and arrows. First, a question asked whether participants had seen the relevant access structure and if they could explain its function (open question). Then, on the next page its actual function was stated, followed by a 7-point Likert-scale item asking to what extent they had used the access structures in their search. Six.7-point Likert-scale items asked how clear, useful, conspicuous, helpful in looking for information, and hell pfull to gain an overview of the information participants had experienced the access structures. Then, one item asked their opinions on the color-use in the brochure. Finally, with all four brochure versions in front of them, participants selected one version of the brochure they preferred and explained their choice.

Learnability. The ease with which participants learned to use the brochure was investigated with two dependent variables. First, participants' memory for the brochures main structure was assessed with one open recall question:'The brochure comprised a number of main sections. Could you state these main sections?' For each of the three main 
sections that participants mentioned one point was given. Secondly to the extent that participants did not use the access structures available from the beginning or used them in the wrong way, the extent in which they started using them correctly (i.e. contents page or the tabs) was obserwed qualitatively from the video-recordings.

\section{Analyses}

The video-data of ten participants were scored independently by two raters, resulting in a satisfactory mean inter-rater reliability score of .98 . The data of the remaining ninety participants were divided between both raters.

One-way ANOVAs with the four brochure versions as between-subjects factor were performed on the dependent variables that related to participants' search effectiveness and efficiency and on all Likert-scales of the questionnaire. As each successive brochure version involved an 'improvement" upon the earlier version and effects were thus expected to add

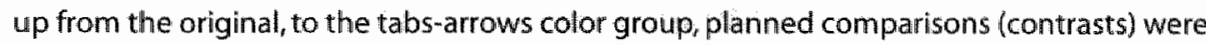
done on all main effects found. These planned comparisons always involved three contrasts: comparing the original group with the cluster of tab-groups, comparing the tabs-arrows color group with the cluster of tabs black-white and tabs-arrows black-white group, and comparing both latter groups with each other. T-tests are only reported of those contrasts. that reached significance.

With separate Chi-squares dichotomous data were compared on how many participants had noticed the arrow in their brochure and had understood its function. The answers to the open recall question of the main sections were labeled dichotomously as "correct' or incorrect' on whether the three main subjects were recalled and all groups were compared in Chi-square analyses. Finally, participants' preferences for one of the four brochure versions were counted and the reasons for their preference described. The learniling to use the access structures and the kinds of problems participants encountered while using them were qualitatively described.

\section{Results}

\section{Effectiveness}

Table 1 shows the means, standard deviations, and ranges of the effectiveness and efficiency measures. A comparison of all four groups regarding the use of the contents page showed a main effect of group, $F(3,96)=56.54 ; p<.01$. Planned comparisons showed that the original brochure group used the contents page significantly more than the other three groups, $t(96)=-8.97_{n} p<.01$. The three tabs groups did not differ from each other. On the total frequency of successful use of the tabs in the three groups with tabs brochure versions. a main effect of group was found, $F(2,72)=7.94 ; p<.01$. Planned comparisons revealed that the tabs-arrows color group had significantly more often successfully used the tabs than both other tab-groups, $t(72)=3.92 ; p<.01$. There was no significant difference between the latter two groups. With regard to the use of the references in the paragraphs throughout the brochure, no significant differences emerged from the data, $F(3,96)=1.12 ; n s$. 
Table 1. Means, standard deviations and ranges on effectiveness and efficiency measures of

\begin{tabular}{|c|c|c|c|c|}
\hline & Group & $M$ & $S D$ & range \\
\hline \multicolumn{5}{|l|}{ Effectiveness } \\
\hline \multirow[t]{4}{*}{ Use of contents page } & Original & 7.48 & 3.78 & $0-16$ \\
\hline & Tabs-bw & 0.60 & 1.63 & 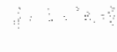 \\
\hline & Tabs-arrows bw & 0.56 & 2.00 & \\
\hline & Tabs-arrows color & 0.40 & 0.71 & \\
\hline \multirow[t]{4}{*}{ Succesful use of tabs } & Original & - & - & $0-10$ \\
\hline & Tabs-bw & 3.76 & 3.38 & \\
\hline & Tabs-arrows bw & 4.28 & 2.44 & \\
\hline & Tabs-arrows color & 6.44 & 1.29 & \\
\hline \multirow[t]{4}{*}{ Use of reference-paragraphs } & Original & 3.00 & 1.92 & $0-18$ \\
\hline & Tabs-bw & 2.88 & 3.54 & \\
\hline & Tabs-arrows bw & 1.88 & 1.83 & \\
\hline & Tabs-arrows color & 2.48 & 1.78 & \\
\hline \multicolumn{5}{|l|}{ Efficiency } \\
\hline \multirow[t]{4}{*}{ Random-paging frequency } & Original & 48.04 & 26.73 & $5-102$ \\
\hline & Tabs-bw & 23.56 & 14.30 & \\
\hline & Tabs-arrows bw & 22.68 & 15.79 & \\
\hline & Tabs-arrows color & 32.24 & 12.37 & \\
\hline \multirow[t]{4}{*}{ Visual-scanning frequency } & Original & 40.28 & 18.59 & $8-75$ \\
\hline & Tabs-bw & 23.88 & 11.03 & \\
\hline & Tabs-arrows bw & 23.92 & 13.38 & \\
\hline & Tabs-arrows color & 32.08 & 9.93 & \\
\hline \multirow[t]{4}{*}{ Reading non-target text } & Original & 6.84 & 5.37 & $0-22$ \\
\hline & Tabs-bw & 5.48 & 3.86 & \\
\hline & Tabs-arrows bw & 3.40 & 2.84 & \\
\hline & Tabs-arrows color & 5.48 & 3.49 & \\
\hline
\end{tabular}

\section{Efficiency}

A one-way ANOVA on participants' random-poging frequency showed a main effect of group, $F(3,96)=10.47 ; p<.01$ (see Table 1 for all means, SD's, and ranges). Planned comparisons showed that the original brochure brought about more random paging than the three tab- 
groups, $t(96)=-3.91, p<.01$. In addition, the tabs-arrows color group had paged more than both other tab-groups, $t(96)=279, p<01$. The tabs-arrows black-white group and the tabs black-white paged equally much.

The frequency of visually scanning pages followed the same pattern as the paging, again reaching significance, $F(3,96)=8.25 ; p<.01$. The original brochure group scanned significantly more than a combination of the three tab-groups together, $t(96)=-3.46 ; p<.01$. Also, the tabs-arrows color group sicanned more than both other tab-groups, $t(96)=-3.10, p$ $<.01$, which between themselves did not differ significantly.

A main effect of group was found on reading non-target pleces of text, $F(3,96)=3.15_{*}$ $p<.05$. Planned comparisons showed that the original brochure group read significantly more irrelevant text than the tab-groups together, $t(96)=-2.22 ; p<.05$. Also, the tabs-arrows black-white group had read less than the tabs black-white group, $t(96)=2.71 ; p<.05$. The tabs-arrows color group did not differ from both tab-groups.

\section{User satisfaction}

All groups found it relatively easy to find the information of the ten search items as indicated with scores between 5.16 (original) and 5.56 (tabs-arrows color) on a 7-point scale, $F(3,96$ ) $=0.56 ; n s$. On both questions asking how well-structured participants found their brochure version, mean scores were between 5.20 and 5.92 with an average of 5.64 for structure and 5.47 for surveyability. No significant differences were found $(F(3,96)=1.07$; ns, and $F(3,96)=$ $1.14 ;$ ins, respectively/.

The dichotomous data on whether participants had noticed the arrows and the "correct/incorrect'scores on understanding the arrow's function were analyzed for the three groups in which the brochure contained arrows (so without the tabs black-white group). Chisquare analyses showed an effect on noticing the arrows, $\chi^{2}(2, N=72)=14.41 ; p<.01$, and on understanding its function, $\chi^{2}(2, N=72)=22.33 ; p<.01$ (see Table 2). The colored arrows in the tabs-arrows color version of the brochure were noticed $(92 \%)$ and understood ( $88 \%)$ the most followed by the arrows in black and white $76 \%$ of the participants noticing and $68 \%$ understanding them correctly). The original brochure's arrows were least noticed (44\%) and understoon $(24 \%)$.

With regard to participants' evaluations of the access structures in their brochure version, ANOVAs showed effects on all items evaluating specific aspects of the four brochures' access structures (see Table 3 for mean values and significance levels). Planned comparisons showed that in general the original brochure's access structures were rated significantly worse than the other three on clarity, $t(96)=5.52 ; p<.01$, usefulness, $t(96)=$ $5.29 ; p<.01$, conspicuousness, $t(96)=5.45 ; p<.01$, helpfulness in looking for information, $t(96)=5.01 ; p<.01$, helpfulness for gaining an overview of the information, $t(96)=4.29 ; p$ $<.01$, and color use, $t(96)=3.01 ; p<.01$. In addition, the difference between the tabs black white group and the tabs-arrows black-white group was significant regarding the clarityevaluation, $t(96)=2.35 ; p<.05$, rating of conspicuousness, $t(96)=2.50 ; p<.05$, and the extent participants had found the access structure helpful in looking for information, $t(96)$ $=2.45 ; p<.05$. The tabs-arrows color group did not differ from both other tab-groups in the final planned comparison. 
Table 2. The number of participants in each group who recognized the pictorial as being an arrow and understood the arrow's function. Notice that the tabs black-white group did not have any arrows in their brochure version, and thus did not answer these questions.

\begin{tabular}{lcccc} 
& \multicolumn{2}{c}{ Noticing of arrows } & \multicolumn{2}{c}{$\begin{array}{c}\text { Understanding of arrows' } \\
\text { function }\end{array}$} \\
\cline { 2 - 5 } Version & No & Yes & No & Yes \\
\hline Original brochure & 14 & 11 & 19 & 6 \\
Tabs-arrows black-white & $(56 \%)$ & $(44 \%)$ & $(76 \%)$ & $(24 \%)$ \\
& 6 & 19 & 8 & 17 \\
Tabs-arrows color & $(24 \%)$ & $(76 \%)$ & $(32 \%)$ & $(68 \%)$ \\
\hline & 2 & 23 & 3 & 22 \\
Total $N$ & $(8 \%)$ & $(92 \%)$ & $(12 \%)$ & $(88 \%)$ \\
\hline
\end{tabular}

Participants' preferences for one of the four brochures showed a clear advantage of the colored tabs-arrows version. Ninety of the 100 participants (90\%) preferred this version, four preferred the original version, four the tabs black-white version, and two the tabs-arrows black-white brochure version. When asked the reason for their preference, participants generally found the tabs-arrows color version better surveyable in the sense that there were clearly three sections. Also, the colors were labeled as good attention-getting features and participants noticed the colors of the arrows coincided with the colors of he tabs they pointed to which was positively evaluated. However, some participants that preferred the colored version remarked that the arrows were superfluous.

\section{Learnability}

Of the 25 participants in each group, the percentage of people that had correctly recalled the three main sections, was in ascending order: the tabs-arrows black-white group (12\%), the tabs black-white group (24\%), the original group (40\%), and the tabs-arrows color group $(44 \%), x^{2}(3, N=96)=7.81 ; p<.05$. Thus, the colored tabs-arrows group recalled the main structure best, but the original group was not much worse.

A qualitative review was done of problems or incorrect use of the available access structures by participants, and whether they learned to use them. A pervasive problem of participants with the original brochure was that the eight references of the contents. page were ineffective, resulting in paging and scanning to find the information. Except for a growing acceptance of this phenomenon, little learning could take place in this. In the other three groups the tabs were more numerous and had more specific headings on them, so participants typically used them right away. However, three problems with the 
Table 3. The mean scores of each group and ANONA-test on the questionnaire items concerning their brochure's access structures, indicated on a 7 -point scale $\left(0=\operatorname{low}_{t} 7=h_{i g h}\right.$.

\begin{tabular}{|c|c|c|c|c|c|}
\hline Quest.Item & Group & $M$ & $S D$ & $F$ & significance \\
\hline \multirow{5}{*}{$\begin{array}{l}\text { Use of tabs (origünal: } \\
\text { references) } \\
\qquad\end{array}$} & Origina: & 2.56 & 218 & 26.00 & $p<01$ \\
\hline & Tabs-bw & 6.92 & .28 & 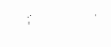 & \\
\hline & Tabs-arrows bw & 5.00 & 1.89 & & \\
\hline & Tabs-arrows color & 5.32 & 2.02 & & \\
\hline & Total & 4.95 & 2.34 & & \\
\hline \multirow[t]{5}{*}{ Clear? } & Originall & 2.44 & 2.74 & 18.91 & $p<.01$ \\
\hline & Tabs-bw & 6.24 & .72 & & \\
\hline & Tabs-arrows bw & 4.96 & 2.07 & & 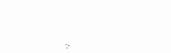 \\
\hline & Tabs-arrows color & 5.68 & 1.60 & & 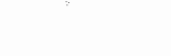 \\
\hline & Total & 4.83 & 2.40 & & \\
\hline \multirow[t]{5}{*}{ Useful? } & Original & 2.72 & 2.98 & 18.48 & $p<.01$ \\
\hline & Tabs-bw & 6.28 & .79 & & \\
\hline & Tabs-arrows bw & 5.56 & 1.81 & & \\
\hline & Tabs-arrows color & 6.12 & 1.48 & & \\
\hline & Total & 5.17 & 2.39 & & \\
\hline \multirow[t]{5}{*}{ Conspicuous? } & Original & 2.52 & 2.76 & 18.25 & $p<.01$ \\
\hline & Tabs-bw & 6.08 & 1.32 & & \\
\hline & Tabs-arrows bw & 5.00 & 1.71 & & \\
\hline & Tabs-arrows color & 5.96 & 1.65 & & \\
\hline & Total & 4.89 & 2.39 & & \\
\hline \multirow{4}{*}{$\begin{array}{l}\text { Helpful when } \\
\text { searching info? }\end{array}$} & Original & 2.84 & 3.08 & 16.99 & $p<.01$ \\
\hline & Tabs-bw & 6.48 & .82 & & \\
\hline & Tabs-arrows bw & 5.56 & 1.69 & & \\
\hline & Tabs-arrows color & 6.08 & 1.71 & & \\
\hline 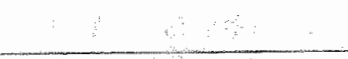 & Total & 5.24 & 2.43 & & $\therefore 8$ \\
\hline \multirow[t]{5}{*}{ Helpful for overvlew? } & Original & 2.84 & 2.95 & 10.08 & $p<011$ \\
\hline & Tabs-bw & 5.68 & 1.35 & & \\
\hline & Tabs-arrows bw & 5.28 & 1.84 & & \\
\hline & Tabs-arrows color & 5.36 & 1.78 & & \\
\hline & Total & 4.79 & 2.33 & & \\
\hline \multirow[t]{5}{*}{ Color-use? } & Original & 3.68 & 1.65 & 6.31 & $p<.01$ \\
\hline & Tabs-bw & 4.56 & 1.81 & & \\
\hline & Tabs-arrows bw & 4.28 & 1.57 & & \\
\hline & Tabs-arrows color & 5.60 & 1.32 & & \\
\hline & Total & 4.53 & 1.72 & & \\
\hline
\end{tabular}


tabs became evident: use of the wrong tab, in-exhaustive reading of tab-labels, and use of the right tab the wrong way. Almost all participants in the three tabs-groups chose the wrong tab-label sometimes. For instance, on the question "What are benefits of eating more fruit and vegetables?", some participants used the tab with the title "Fruit \& Vegetables test:" instead of the one saying 'Why more fruit and vegetables?", illustrating a misinterpretation by participants regarding the information represented. Furthermore, many participants seemed not to read all the tab labels but rather skimmed through them sometimes leading them to overlook the right tab. For instance, several participants overlooked the last tab label in searching for the recipes, leading to search inefficiency.

Finally, many participants used the tabs in the wrong way, so instead of grabbing the tab itself and turning over the page with the tab to open the page behind that, they put their finger on the tab and opened the page the tab was attached to, ending up on the page before the target page. Mostly, participants did not realize this mistake, i.e., that the label they had opened was not in a heading on that page. Only some participants that started out doing this quickly realized the mistake and subsequently used the tabs correctly, but mostly (and even for this last category of participants) the problem seemed quite pervasive. Hardly any learning seemed to occur in this process, as many times participants did not seem to realize their mistake.

\section{Discussion}

This study investigated the usability of access structures with three successive changes to an original health education brochure, t.e, adding tabs, replacing an arrow pictorial, and adding color-coding to both these features. Each change will be elaborated below, after which the brochure versions will be compared regarding their effectiveness, efficiency, and users" satisfaction. Finally, conclusions for usable health education brochure design are drawn.

Overall, the presence of tabs increased the brochure's usability, as the original brochure with only allimited contents page was less usable in several respects than the tab-brochure versions. As expected, participants with the original brochure used the contents page more often than participants who also had tabs at their disposal. With the tabs-brochure versions the tabs were used to find information. Also as expected, with the original brochure these searches were less efficient and participants were less satisfied with the contents page with reference-paragraphs than participants with the improved access structures. Similar to earlier findings (Kools et al., Submitted), the arrow of the original brochure was ineffective in terms of noticing and understanding its function, compared to the more conventional arrow-design.

In two respects the use of colors added positively to the tabs. That is, the colored tabs with arrows proved more effective in the searches than both black-white tabs-versions of the brochure. Adding colors to the arrows in combination with the tabs improved the effectiveness of the tabs in the sense that participants grabbed the right tab more often and reached the page with the search item right away, affording minimal action to find information. Also, this version was generally preferred over the other three versions. This 
finding is consistent with other studies in which consumers showed a strong preference for a colorful format (e.g, Achterberg \& Bradley, 1991). However, the search for information in the colored tabs-arrows version was not more efficient in terms of paging and scanning, than with both black and white tab-versions of the brochure. This was also reflected in the estimated ease in finding information, which was similarly high in all groups. Regarding the additive value of the presence of the conventional arrow with the tabs compared to having only tabs, a slight advantage was established. That is, participants with (black and white) arrows in their brochure read less non-target pieces of text and were more satisfied with their access structures, compared to participants that had no arrows with the tabs.

Thus, as expected, the tabs rendered the contents page ineffective: the more extensive tabs largely took over the role of the limited contents page. However, the tabs did not seem to have any influence on the effectiveness of the reference-paragraphs throughout the brochure: these were hardly used with all four kinds of access structures. The presence of ambiguous or more common arrows did not make any difference in the extent that their accompanying references were used. Subjectively, however, participants found the brochure clearer in several respects when common arrows were present and when color-coding was applied. So although the references throughout the text were hardly used, flagging their presence and linking them visually with the main access structure may have enhanced a sense of clarity of the brochure's structure.

Regarding search efficiency, the above relative ineffectiveness of the original access structure is substantiated by the relative frequent paging, scanming and reading participants engaged in before finding the information in this brochure. It is noteworthy that although search in the brochures with tabs was generally more efficient than in the original brochure, search in the colored version was evenly or less efficient tham in both black and white tab versions. As mistakes in choosing and using the tabs were noticed with all tabulated brochures ${ }_{i}$ the colors may have contributed to these mistakes in two ways. First the presence of the colors may have encouraged users to choose a (wrong) tab too fast and not read all the tab-labels available.tn addition, when opening or having paged to the right page, the calors of the tabs that were still visible to the right may have distracted users somewhat from having a good look at the page to locate the relevant heading. Both effects may have heighteried the amount of paging and scamning with the colored tabs brochure compared to both black and white versions.

The more successful use of the tabs with the colored version than with both black and white versions as reported above may indicate that at some point, participants with this version realized their mistakes more often and subsequently used the tabs the right way. However, this can only be a tentative conclusion regarding the learnability of the tabuse. The learnability of the brochure's main structure was relatively high with the original brochure, which may be the result of the less efficlent searches that caused users to see more of its contents than with the other three brochure versions. A similar effect may explain the relatively high recall in the colored tabs-arrows brochure compared to both black and white tab versions. Also, the addition of the three colors may have contributed slightly to the rememberability of the three sections. This argrees with what participants stated about the 
clarity of having three sections when explaining their preference for this brochure version. In that respect, the colors accommodated participants perceptual limitations, by making the three groups of subjects visually stanid out. The spatial separation of the three tab-groupings by itself was apparently insufficient in flagging the main sections for both tabs black-white groups. Similar conclusions can be drawn for the arrows that pointed towards the tabs.

Important to note is that, although indeed proven superior to the original, the usability. of the tabs in this study was not as optimall as expected in terms of stimulus-response compatibility. It seems that although people may be familiar with tabs and their application, their specific use to open a page for finding information varied. In addition, it was surprising that participants mostly did not even notice that the heading they should have reached with the tab actually was not located on that page. Thus, the user-guidance, always showing users were they are in the brochure and thus telling them when they go wrong, was not inherent in the corresponding tab-labels and text-headings. The persistence of this errior may have been caused by the fact that regardless how they used the tabs, participants always encountered text. It could be that when applying tabs in a brochure more conventionally, so in the form of subject divider cards without any text on that separating page, would more clearly afford to turn over the page. This application of tabs could have higher external consistency than the current application. Moreover, any mistakes made in that use would be more clearly recognizable, as opening the booklet on the page in front of the tab would get users to a blank page.

To conclude, this study is an example of how a usability-approach to existing health education materials may provide guidelines for improving the effectiveness, efficiency, and satisfaction with which members of its target group use a brochure. Here, it was found that, compared to only showing main sections in a contents page and pointing readers to specific sub-sections when deemed necessary, giving users insight into the entire contents with tabs as access structure improved the brochure's usability. While supporting and even making the original referencing-system more conspicuous to users; the tabs also allowed for immediate access to sections without having to see the references throughout the text. Generally, attaching tabs to brochure pages to flag its contents may help readers find information in a brochure easily. Especially with extensive written health education materials, which readers may wish to use more than once, such accessibility should be a point of consideration. In addition, in the present study color-coding contributed to the effectiveness of the access structure, gave a sense of overview, and users generally evaluated the materials as more pleasurable. Thus, when inaking a distinction between various subjects is deemed important, using colors to highlight different contents should be considered when designing brochure materialls. Finally, this study illustrates that when using pictorials to flag content, careful thought should go into their recognizability and placement. In this study, by carefully considering its essential function, a well-intended but unclear arrow pictorial was easily improved.

Altogether, an important practical implication of this study for health education designers is that they should test their designs, especially if uncommon features are included, to assess their effects on the usability of the materials. Using the usability- 
characteristics described in this study as guidelines may be a starting point for practitioners when designing usable health education materials. A second step in the process may be the evaluation of the materials with user trials, to ensure usable design and detect potential unexpected shortcomings. Extensive testing with multiple groups, such as the present study, may not be necessary. That is research showed that performing user trials with only four or five people may reveal up to $80 \%$ of all potential usability problems with a design (Virzi, 1992). Thus, also with relatively little costs, unsuccessful and costly health education design may be prevented. Therefore, such testing is strongly recommended. 


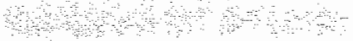

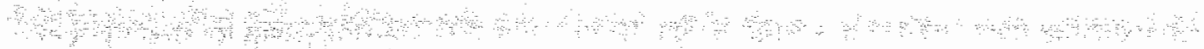

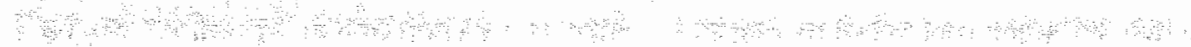

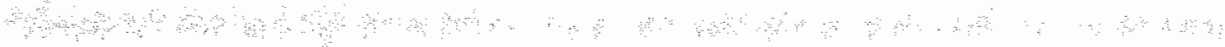
ARto

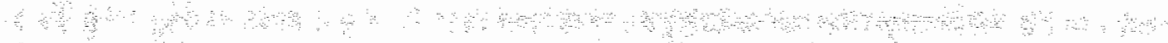

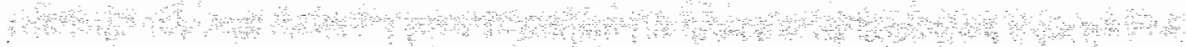

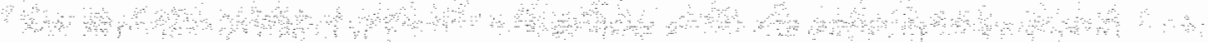

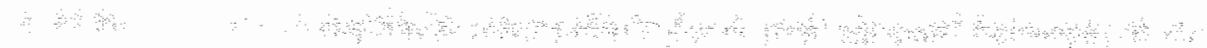


Chapter

Chapter 2

Chapter 3

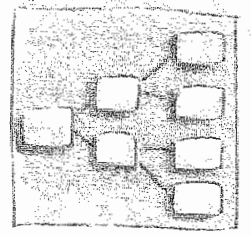

Chapter a

Chapter 5

Chapter 6

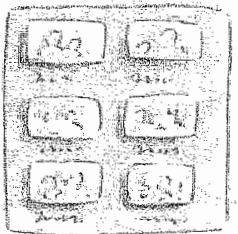

Pictures and text in instructions for medical devices. Effects on recall and actual performance

The effect of graphic organizers on

subjective and objective comprehension of a health education text education text on locating speed and evaluation and remember information in a heath education brochure

Chapter 7

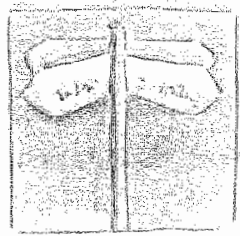

The understandability of pictorlats in theath education brochure

Chaper 8

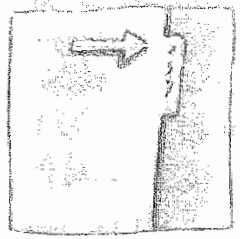

Testing the usabilty of access structures

109 in health education brochures

General discussion: Implications for health education practice 
an insights from cognitive psychology in attention and comprehension processes make the design of written health education materials more effective? That was the central question behind the studies described in this thesis. Overall, it can be concluded that the answer to this question is yes. Ou research findings showed that applying cognitivepsychological insights to the design of heath education materials may contribute to readers' attention-allocation and understanding of the materials. In addition, the research methods that were applied may be used by health educators in the form of pretests when designing written materials.

The current research project was meant to contribute to health education practice by providing guidelines for designing written materials. In this light, seven studies were done in which cognitive-psychological insights were applied to health education materials. Fypically, cognitive-psychological research into instructional design is aimed at relatively complicated instructional materials, such as textual explanations of physics, technical-or geographical phenomena. Adding to the generalizability of the theory and design principles, in this thesis those insights were applied to another kind, i.e., health education information. An overview of the main findings of the studies is given below. Short descriptions of relevant theoretical background are provided with each study, which may help health education practitioners when designing their own materials. In an attempt to translate that information to health education practice, main guidelines for the design of written health education materials are provided with each study. Readers with a more detailed interest in such implications are referred to the specific chapters that also provide examples of materials' design.

Subsequently, a protocol is described that suggests how to go about designing written materials and when and how to use the insights from the current studies. This protocol may be used by itself, but may also fit into a more comprehensive planning model for health education interventions, which is described as well. As is inevitable with research, the present thesis ralises more questions than it answers. Limitations of the studies and suggestions for further research are described in the final section.

\section{Overview and Guidelines}

\section{Text coherence}

As is explained in chapter 2 , one of the key conditions for effective health education, according to information processing theories, is the comprehension of the arguments that are made (McGuire, 1985). Information in a brochure, for instance about the causes and consequences of a disease, should be well understood by the readers in order to motivate them to perform suitable preventive actions ( $c$ f. Rogers, 1983). In cognitive psychological theories on comprehension of written information, textual coherence has been found to be of crucial importance to comprehension (van Dijk \& Kintsch, 1983; Kintsch, 1988), especially when readers have little prior knowledge about the text subject (MCNamara, Kintsch, Songer, \& Kintsch, 1996), In an attempt to contribute to health education research that has endorsed the need for meadable materialls for all literacy levels (Doak \& Doak, 1980; Davis, Michielutte, Askov, Williams, \& Weiss, 1998), the qualitative study described in chapter 2 
focused on techniques (writing principles) that health education text writers use to increase text coherence Based on nine coherence principles that hawe emanated from cognitive psychological research (Britton \& Gulgoz, 1991; Clark \& Hawland, 1977; Noordman \& Vonk 1998; Kintsch \& van Dijk, 1978), we explored how and to what extent health education text writers establish coherence in their texts.

Considerable variation was found among text writers regarding which principiles they used and to what extent they applied them. Although the impontance of a clear macro structure was endorsed by most text writers, some mainly focused on the macro level when rewriting, whereas others especially made changes on the micro level of the text. Also, when making a specific kind of change, great variation existed in the frequency with which this was done, as well as to what extent they were explicitly stated by the text writers. Especially the principles of sentence connectives, given-new order, explicit actors, and causality were hardly mentioned or used. Altogether, whether, how, and where specific changes were made to the text appeared to be very unpredictable. An explicit awareness of these principles when writing and rewriting texts may ensure a more consistent use and thus more coherent health education texts.

\section{Guidelines}

For textual coherence on the macro level, in an iterative writing process writers may pay extra attention to make sure their texts comprise the following features:

- headings are used to flag content, and

- the first and last sentences in paragraphs should explain how the information relates to previous and upcoming information, respectively.

For coherence on the text's micro level, seven principles should be kept in mind while (re)) writing a text:

- repeat the linking word from the previous sentence to maintain argument overlap,

- only use demonstrative pronouns if they have only one possible referent to avoid ambiguity,

- add descriptive elaborations to difficult or unusual words,

- use sentence connectives to explicate relations between sentences,

- maintain a given-new" order of information within sentences,

- explicitly state the actor in each sertence and

- pay special attention to explicating causality possibly by using the above principles.

Additional writing principles that writers used in the study are consistent with what is generally proposed in health education articles (Davis et al, 1998; Doak, Doak, \& Meade, 1996) and are consistent with the cognitive psychological view on text comprehension. Thus, the following principles may be used as additional guidelines for (re-)writing:

\section{Guidelines}

- sentences should not be too longr

- the active voice should be used instead of the passive woice,

- the main verb should be at the front of the sentence instead of the back. 
- add concrete, highly imaginable examples when possible, and

- delete irrelevant or distracting information.

\section{Design characteristics}

One problem that text writers expressed was that they had little influence on the ultimate design, or lay-out of the materials; and that those choices seemed rather arbitrary. This was confirmed in informal interviews with health education editors, who could give little justifications for the use of design characteristics in printed materials. Rather keeping to standardized formats to enhance recognition of their organization, seemed their primary concern (Vandyck, 2004). Because there seemed a lot to be gaimed in optimizing message design, the subsequent studies of this thesis focused on design characteristics of written materials that in cognitive psychology have been found to aid comprehension and attention-allacation in readers. Based on critical inspections of three different types of health education materials (i.e., asthma brochure, personal diet letter, and healthy diet self help guide), potential problems for readers information-processing were identified Next, design characteristics were chosen that could improve these health education materials, which were then experimentally tested.

\section{Graphic organizers}

First the effects of graphic organizers (Barron, 1969) on text comprehension were tested in chapter 3. Graphic organizers are depictions of relations among concepts in the text, and are knownaids for text comprehension in instructional design (Dee-Lucas \& Larkin, 1995; Guri-Rozenblit, 1989; Robinson \& Kiewra; 1995). In addition, research into knowledge representation has shown that people represent knowledge partly in a hierarchical way (Chi, Hutchinson, \& Robin, 1989; Kintsch \& van Dijk, 1978; Mannes \& Kintsch, 1987). This may account for findings that hierarchical overviews facilitate comprehension of the thematic structure of a text and the organization of information in the reader's memory (Lorch, Lorch, \& Inman, 1993).

Cognitively, readers may encode text on a text base level and on a situation model level (van Dijk \& Kintsch, 1983). Text base comprehension refers to a relatively superficial form of understanding: the semantic and rhetorical structures of the text are in the reader's longterm memory. Based on this mental text base representation, readers will be able to recall portions of the text rather literally, without necessarily having a thorough understanding of its content. In contrast, readers who have formed a situation model representation of a text have elaborated on the text information by actively integrating this with their prior knowledge (Kintsch, 1993). This results in multiple connections, (hence:'deep' understanding) between text-concepts and already existing concepts in their knowledge base. Based on this more extensive representation of the information in the text, readers will be able to generalize the acquired knowledge to other situations and thus answer questions of which the answers are not stated literally in the text. Such situation model understanding shoulld be the goal in health education. 
Chapter 3 describes the study in which the effects of graphic organizers on readers' understanding was measured on four levels of comprehension (Hofman \& van Oostendorp. 1999): text base understanding of the macro and micro level relations in the text, and situation model understanding on both text levels. Furthermore, in health education comprehension of materials is typically evaluated by asking readers if they have understood the information, whereas in such situations an flusion of knowing has been reported in psychological research (Glenberg, Wilkinson, \& Epstein, 1982). Therefore, the comparison of objective as well as subjective comprehension measures was of interest here. The main findings of the study showed that readers' comprehension indeed improved with the graphic organizers in the text on all four (objectively measured) comprehension levels, so on the text base micro text base macro-, stuation model micro- and situation model macro level Not only were participants more able to recall specific and more global information better, but they also showed superior performance when explaining processes and applying this knowledge to different situations. On the other hand, subjective comprehension measures failed to show any effect of graphic organizers.

\section{Guidellines}

- Especially when readers need to understand and use the knowledge acquired from a health education text, which has a hierarchical structure, heafth education designers should consider explaining relations among concepts that readers will encounter in the text with graphic organizers and inserting those above each new text section. These organizers should show the hierarchical relations among concepts, and temporal and causal relations may be explicated with arrows from cause to effect.

- The use of objective (open) comprehension questions instead of or in addition to subjective assessments should be considered, as only the former give a true' account of comprehension of the information. In addition participants answers to such questions may provide valuable insights into what exactly is unclear or which pieces of text are difficult. This may provide clues about which parts of the text are difficult and thus should be improved, for instance by additionalgraphical support.

\section{Illustrations}

Next to the relatively abstract graphic organizers tested above, more concrete graphic depictions or "organizers' may help readers understand written information as well. Graphical depictions that have a certain level of abstraction are called 'pictorials;'symbols', or 'icons", which may be used to flag different kinds of information within one document. These were subject of the study described in chapter 7 , of which the implications are described later. Other, more concrete graphical depictions that are used for increasing the understandability of textual contents are ireferred to as 'images, pictures; or "illustrations' In chapter 4 , the effect of pictures was tested on understanding procedural instructions for two asthma devices, the inhaler chamber and peak flow meter. 
Pictures have long been established to improve (text) comprehension in instructional design (Levie \& Lentz, 1982; Filippatou, 1992). Through different cognitive processing routes, text and pictures enable readers to construct both verbally-based (propositional") and visually-based mental models, which are integrated in their working memory to foster comprehension (Mayer. 1997; Schnotz \& Bannert, 1999). Two additional considerations are important for health education designers when combining text with pictures. First, the presence of redundant information in another form may provide the reader with opportunities to resolve possible ambiguities in either the text or the pictures. Second, readers may differ in their ability to extract and use information presented verbally or pictorially and providing both enables flexibility of selecting the optimal form for their needs (Stone \& Glock 1981 ).

Also, in procedural instructions a combination of text and pictures generally leads to superior comprehension and performance compared to text alone (Ganier, Gombert, \& Foyal, 2000). With text-only procedural instructions, readers perform 'macro-switches' between the text and the device to match textual and visual information before planning the actions described: However, when pictures accompany the text, the reader can perform "microswitches' between the text and relevant visual elements inside the document. This could take up less working memory resources, because more precise information is given about what to do (in the text) and where to do it (in the picture) (Ganier 2004 ) before switching to the device to perform the actions.

In the study described in chapter 4 , simple line-drawings were added to the instructional steps of both devices, containing 'directing codes' (Weidenmann, 1994) (arrows and exaggerations) to direct cognitive processes as comparing, generating inferences, and imagining motion (Hegarty, 1992). The text was presented as captions below each picture (Bernard;1990) As expected, especially the inhaler chamber, which was deemed inherently more ambiguous than the peak flow meter in terms of 'affordances' and 'constraints' (Norman, 1988), benefited from the presence of the pictures. Participants who had seen pictures with the inhaler chamber text recalled more information and more instructional steps, and were better able to follow the instructions correctly right away with fewer doubts and in a shorter time than participants with only text. With the more self-evident peak flow meter ;ess gain was established from adding pictures to the text. The pictures only contributed to a better recall of the order of instructional steps and to participants' confidence about their actions while using the device. Also, the kindls of mistakes that were observed when participants used the text-only instructions could not all be foreseen. Obvilously, the original instructions in the asthma brochure had not been tested with novice users before printing; otherwise this would have urged the designers to add pictures.

\section{Guidelines}

- Procedural information that need to be acted upon, should present a combination of pictures in the form of simple line-drawings and text. Especiolly actions that are unfamiliar and thus difficult to visualize need pictures to help readers understand what to do. Generally, 
comprehension of any information may be helped with such line-drawings, for instance when visualizing (causall) processes in the body.

- A carefulanalysis of devices may help determine which kinds of materials need visual support the most, or possibly, some extra text.

- Subsequent testing of instructions with novice users by observing the actions people perform is crucial for identifying potential remaining problems, based on which design-adjustments can be made.

\section{Access structures}

Accessibility, so the extent in which readers are able to find information they are looking for in written materials, was the central issue of adjustments tested in the remaining studies of this thes is In cognitive-psychological literature, looking for information within a document is called reading to locate':"a type of strategic reading in which the reader engages in selective reading in order to locate specific, goal-related information" (Dreher, 1993, p. 130) To locate information effectively, some overview of its content and its ordering is necessary $y_{i}$ either in the materials or in the mind of the reader. The presence of 'access structures' (Waller, 1979), such as a contents page, an index, text headings, summaries, and page numbers may help guide readers attention to central themes and thus contribute to a document's accessibility. These access structures have been found to improve both locating speed (Yussen; Stright, \& Payne, 1993) and recall (Hartley \& Trueman, 1985; Wilhite, 1986) when applied in instructional texts and were tested here in health education materials.

In terms of a model describing text-search (Guthrie, Britten, \& Barker, 1991), when readers are looking for specific information, they go through several steps. First, a specific objective (goal) is formulated. Second, an information category is selected from the document and third, critical details within the selected category are identified and selected for processing. Fourth, depending on the goal, newly found Information is integrated with prior knowledge and other information that has been located, and finally, the searcher repeats the above four operations until the full requirements of the goal are met (Guthrie, Britten, \& Barker, 1991). Especially in step two and three of the model, when people identify and select a relevant category and information within that category, the text structure and design may infuence a reader's search efficiency. Research with text books for instance, showed that the content should be organized in a manner compatible with the reader's expectations (Byrnes \& Guthrie, 1992). That is, readers have prior knowledge about the usual structure of texts le.g, knowing that texts contain thematically arranged chapters, a table of contents, indices, etci $)_{1}$ and of the text's subject matter. If a brochure's design meets the readers' expectations that are based on this prior knowledge, locating specific information will be easier.

Various access structures were studied there: headings in the healthy diet letter described in chapter 5 and a contents page with main section headings, pictorials flagging access structures, and colored tabs with pictorials in the healthy-diet self-help guide in chapters 6,7 , and 8 . It should be noted that pictorials by themselves are not typical access. 
structures. However, because they had been applied as such in the original brochure, here they were classified accordingly.

\section{Headings}

For the fourth study, described in chapter 5 , a literature-search on the role of headings in the accessibility of written materials provided little cules regarding an optimal frequency of headings or text segmentation. However, for effectively reaching the public, the way that a text is hierarchically structured and how this structure is explicated may be crucial (see also chapter 3): readers should get an overview of the materials and find information easily. To this end, signaling devices or 'access structures' (Waller, 1982 ) such as headings are generally) used to identify the subject matter for readers and thus clarify the structure of the text (Hartley, 2004). Such explicit text structure may help focus a readers' attention on particular parts of the text (Jonassen \& Kirschner, 1982) and thus also to locate information that they may look for. In other words, titles and headings that signal a text's overall or 'macro' structure (Kintsch, 1994) may effectively help readers to access the text and find relevant information on the local or "micro level. Such awareness was also shown by the health education text writers in the qualitative study, but the frequency of headings they preferred varied considerably (Kools, Ruiter, Van de Wiel, \& Kok, 2004; see also chapter 2).

One text-structuring method, namely the Information Mapping (IMAP) method (Horn, 1982; Horn, 1993), offers very strict and explicit guidelines how information should be segmented and labeled with headings for better accessibility. This results in each page starting with a title followed by highly segmented text with relatively many headings in the left text margin. When comparing this format to the original, more common text with fewer headings on several levels, no clear advantages were found for a certain number of headings and thus text segmentation on how fast participants could locate specific information in a health education letter. Thus; it seems that the use of mamy headings (and the corresponding high segmentation of text) does not necessarily make a text easier accessible in terms of finding information more quickly compared to conventional uise of headings. Compared to a version of the text without headings, it was found that as long as there are headings available, readers are able to choose the appropriate label and find information. Subjectively; on two questions the presence of many headings and high segmentation was rated more positively compared to thaving no headings at all. This may prompt health education designers to apply this kind of structuring in their texts.

However, before any recommendations can safely be made further research is necessary into readers' comprehension of such segmented text. Because text headings may serve as importance indicators as well as cues for recall, the way a text's macro-structure is signaled may determine readers' comprehension of the text-subjects and relations among those. A text's 'argument overlap', which is necessary for readers to link related concepts and thus form an understanding (Kintsch \& wan Dijk, 1978), may be reduced when a text is highly segmented, possibly causing breakdowns in readers" comprehension of the information. Also, readers" understanding of different kinds of super-and sub-ordinate relations may differ with different hierarchical relations among headings in a text. Thus, pending further 
research into effects on text comprehension mainly general or tentative guidelines can be given about the use of headings to health education designers:

\section{Guidelines}

- Use headings throughout a text to flag the main subject of separate paragraphs.

- Asking people in the target group what kinds of questions they might have about the relevant health subject, may help designers fit the text's macro structure and wordings in headings to its readers, thus improving its accessibility:

\section{Contents page and main headings}

In the study described in chapter 6 , the combination of an extensive table of contents and three main section headings improved the brochure's accessibility and helped participants recall its structure better. That is, with both features, participants showed a better initial recall of the brochure's main sections, had less difficulty, i.e, turned fewer pages to find answers to questions, and recalled its structure better in a sorting card task; than participants with the original brochure. A closer look at participants' search times showed that if present, the contents page was indeed used to find answers, which resulted in more efficient search strategies as reflected in search times. Readers were thus able to use a more selective search strategy, compared to an exhaustive strategy (Klusewitz \& Lorch, 2000) that was used when no contents page and main headings were present.

\section{Guidelines}

- Always insert a table of contents in health education multi-page brachures, showing all headings of the document.

- Such a table of contents should make the material"s hierarchical structure clear, with mainand sub-headings flagged typographically, and subjects-clusters grouped together.

Even when the main sections in a health education document are separated and thus indicated with white pages, readers may need more redundancy in flagging such sections, to understand a brochure's main structure:

- Any main subject change should be signalled explicitly with a heading, and if possibly be made redundant, for instance with big lettering and white spacing.

\section{Pictorials}

Based on cognitive psychological research that has shown that pictorials' meanings are generally not very self-evident (Davies, Haines, Norris; \& Wilson, 1998; OImstead, 1999; Wogalter, Sojourner, \& Brelsford, $1997 ;$; waga \& Boersema, 1983), chapter 7 describes a study into the understandability of the arrow-pictorial that signaled the brochure's access structures. For understanding pictorials, their concreteness (i.e, ithe extent to which pictorials depict objects; places, or people) has been established as an essential feature (Hicks, Bell, \& Wogalter, 2003; Mishra, 1982; MCDouglas, de Bruijn, \& Curry, 2000). Simple but accurate drawings that are easily recognizable as concrete objects in the real world enable readers to instantly understand the pictorial in its textual context. 
Because a pictorial itself as well as its context is always different, testing is considered very important to ensure that readers understand a pictorial's meaning in the way the designer intended (Davies et al, 1998; Wogalter, Begley, Scancorelli, \& Brelsford, 1997; Oimstead, 1999). This can be done relatively simply by asking participants a pictorial's meaning in an open-ended test (Dewar. 1999 ). Simultaneously providing the context in which a pictorial is supposed to be encountered (Wolff \& Woglalter; 1998) reduces erroneous interpretations by providing a mental set that restricts a pictorial's possible interpretations (Biederman, Glass, \& Stacy, 1973, Cahill, 1975).

In the study presented in chapter 7 , a pictorial that represented a line-drawing of an everyday-life signpost meant to flag reference-paragraphs throughout the brochure proved more recognizable than the original brochure's arrow pictorial. Also, answers to an open comprehension question showed that the pictorials" actual function was attributed to the signpost significantly more often $(85 \%)$ than to the arrow $(22.5 \%)$, indicating higher understanding of the signpost compared to the arrow. This difference was found between the two groups as well as within each group, so even when having encountered the pictorial of the arrow several times before in the context of the brochure, it was found to be less clear than the signpost. In cognitive-rgonomics terms, whereas the signpost pictorial met the $85 \%$-correct recommendation of the American National Standards Institute (ANSI Z535.3-1998) for pictorial comprehension, the arrow did not even meet the more lenient $67 \%$-correct guideline of the international Organization for Standardization (ISO 3.8641984). Although with pictorials such as the ones in this study no immediate dangers may be involved when they are not understood correctly, health educators should keep in mind that this may be different when the aim and context of the health information change. For instance, if pictorials were used to flag contraindications on a medicine-container or in a health education brochure and their function is misunderstood this might have serious consequences.

\section{Guidelines}

- Only use pictorials to flag (certain kinds of) information when concrete, relevant depictions can be designed to accompany the text.

- To ensure recognition of the representation and an understanding of its function in the materials, assessing users" comprehension with open ended questions is necessary.

- Especially when correct comprehension of the pictorial and its information is crucial for potential health-related behovior of users, a minimum of $85 \%$ understanding it correctly should be aimed for. When consequences of misunderstanding are not potentially harmful this way, a $67 \%$ comprehension-score may suffice.

\section{Tabs and color-coding}

Chapter 8 describes a study into another kind of access structure, namely colored tabs with common arrow-pictorials in the reference-paragraphs, which were meant to contribute to the original brochures access structures. Here, a moire complete usability-study was performed compared to the study in chapter 6, with measures extracted from observations of users with the brochure. As search time was found in earlier studies not to be a sensitive 
measure with relatively short written materials, this measure was dropped and the emphasis shifted towards how participants used the brochure.

Usability is central in ergonomics research and has been defined as the extent to which users of products are able to work effectively, efficiently and with satisfaction" (ISO, 1998 , see $p$. 21. Applied to the brochure in this study, a highly usable design would enable readers to locate information (effectiveness) with hardly any effort (efficiency), so with minimal paging and trials, and bring about positive attitudes towards its contents and design (satisfaction). Learning the brochure's general contents and usage without difficulty (learnability), would further add to its usability. Thus, usability research typically comprises several dependent measures, both objective and subjective ones. The specific choice for data-gathering methods depends solely on the questions that need to be answered and on the specific design aspects of interest (McClelland, 1995). Related to human informationprocessing stages of perception, cognition, and action a list of eight usability-criteria can be defined (Lin, Choong, \& Salvendy, 1997): a design is more usable when stimulus-response compatibility is high, it is internally and externally consistent, it is flexible to needs and wishes of various kinds of users, it is easy to learn, minimal action and minimal working-and longterm memory load are required for using it, considerations of limits in human perceptual organization are embedded, and a user guidance scheme is available. An analysis of the original brochure on these criteria proved its usability sub-optimal and tabs, common arrowpictorials, and color-coding were applied to improve this.

The presence of tabs was found to improve the accessibility of the brochure compared to the original access structures. With the original brochure searches for information were less efficient and satisfaction with the contents page with reference-paragraphs was lower than with the tabs access structures. Color-coding added to the effectiveness of the tabs and this version was also preferred over the black-and white versions of the brochure. The conventional arrows added to the tabs in that participants with (black and white) arrows in their brochure read less inon-target pieces of text and were more satisfied with their access structures than participants that had no arrows with the tabs. In addition, the more common arrows combined with the tabs were better understood than the original arrow-pictorials, providing another improved alternative for this pictorial. Although the tabs effectively took over the function of the limited original contents page, mistakes were still made in using them diminishing their effectiveness. Thus, next to an improved usability of the brochure, adjustments should still be made to further improve the tabs' stimulus-response compatibility and thus their effectiveness in use.

\section{Guidelines}

- The (interrelated) usability-criteria described above may be a starting point to base design decisions on for usable design:

- Stimulus-response compatibility: if reader should perfiorm specific actions with a brochure this should be made self-evident from design features. For instance, important "to do"-lists that should be saved may have tearing-lines, use as a reference- 
guide on multiple occasions may be afforded by using high quallity, thick paper, selective use may be stimulated by tabs that afford grabbing them to turn over pages. - External and internal consistency: design features (e.g. tablie of contents, colors, structure indicators) should be chosen in line with readers" expectations regarding those features, and once chosen, consistently used in the same way throughout the materialis.

- Flexibility: materials should meet to needs and wishes of various kinds of users. Those who read from start to finish as well as those who wish to look up certain information. Redundancy in design may also contribute to this, because different readers may pay attention to different features.

- Learnability: readers should need minimal extra explanations for understanding a brochure's contents and use of access structures. The design-features studied in this thesis all may contribute to learnability.

- Minimal action should be necessary for readers to find information within a booklet. For instance, the labeled tabs tested in chapter 8 , were meant to cause minimal paging by users to reach separate sections.

- Minimal working-and long-term memory load of readers should be necessary for understanding and using it, which means for instance that text should be maximally coherent, and accessibility features should not require memorization in use.

- Limits in human perceptual organization may be considered and applied in design, such as Gestalt-like principles of visual grouping of elements that need to be connected in comprehension as well. Careful weighing of design choices is important so that visual limitations are not taxed and only important information and relations among information-parts stands out (i.e., it should not become a 'circus' with many typographic and collor cues on one page).

- User guidance:readers should always be aware of the materials overall structure and where in this structure they are, to enable understanding and provide feedback to users when they are on the wrong page when looking for certain information.

- Especially with extensive written health education materials, which readers may wish to use more than once, their accessibility should be carefully considered.

- Attaching tabs to brochure pages to flag its contents may help readers find information in a brochure easily.

- The clarity of a brochure's access structures and general lay-out may be promoted by using different colors: using colors to highlight different contents should be considered when designing brochure materials.

- When using pictorials to flag content, careful thought and testing should go into their understandability and placement.

- Most importantly, especially if uncommon features are included, health educators should test their designs to assess their effects on the usability of the materials. Observing users laoking for information gives valuable information on the design features that are used, the ease with which information is located, and the kind's of mistakes that are made. Answers to recall-and 
questionnaire items may complete the picture of what users grasp and how they evaluate several design features of interest.

\section{Protocol for improving and testing message design}

Altogether, the present thesis shows how a critical look at human information-processing and the effects that design features have on this, may improve health education materials. With readers' attention and comprehension of the materials as important precursors of yielding and behavioral change (McGuire, 1985), applying such cognitive-ergonomical principles should be an essential part of systematic intervention development. A useful framework that may guide this process is intervention Mapping (IM), a protocol for the designing theory-and evidence based health promotion programs (Bartholomew, Parcell, $K_{0 k} \&$ Gottlieb, 2001). In this section, the current insights are integrated into the elaborate intervention mapping protocol.

\section{Intervention Mapping}

Intervention Mapping states that the process of intervention design can be divided into five steps. First, proximal program objectives should be specified. Proximal program objectives are the most immediate objectives that need to be achieved in order to accomplish the behavioral program outcomes. Specifying important and changeable determinants of the required health promoting behaviors is one of the sub-steps at this first stage. Second, theoretical methods and practical strategies should be selected. Methods are specific techniques to influence behavior, which are derived from theories and empirical findings. These are translated into strategies or practical actions that are undertaken to make the methods effective. Because effects of methods always depend on interactions between the target group and situational circumstances, requirements for the methods ${ }^{\prime}$ effectiveness (parameters) are important to keep in mind when choosing them. The third step is producing program components and materials. To create a program, three tasks have to be undertaken: strategies need to be translated into a program plan, taking into account the context in which the program will be used, program material should be designed, and at the concept stage materials should be pre-tested with members from the target population and implementers, and finally the materials are produced. Fourthly, program adoption and implementation strategies are planned. The fifth step is to develop an evaluation plan that described how the effectiveness of the program is tested and whether decisions were correctly made and performed throughout the process of IM. The steps of IM are followed in an iterative way, meaning that health education developers go back and forth between stages throughout the design of an intervention.

\section{Present guidelines in $I M$}

Especially for step two and thiree of $I M$, i.e., selecting theory-based intervention methods and strategles, and producing program components and materials, the present guidelines add to and specify the IM-recommendations. Specifically, when knowledge and understanding 
on the individual level have been established in M-step 1 as important determinants of behavioral change and in IM-step 2 written materials are chosen as strategy to bring this across, readers' attention-allocation and comprehension should be considered. To ensure this, Table 1 gives a brief overview of how the theoreticall and empirical findings of this thesis can be translated into specific methods. In addition; a protocol for this design process is suggested below. This can be regarded as a supplement to step 2 and 3 of the IM-protocol,

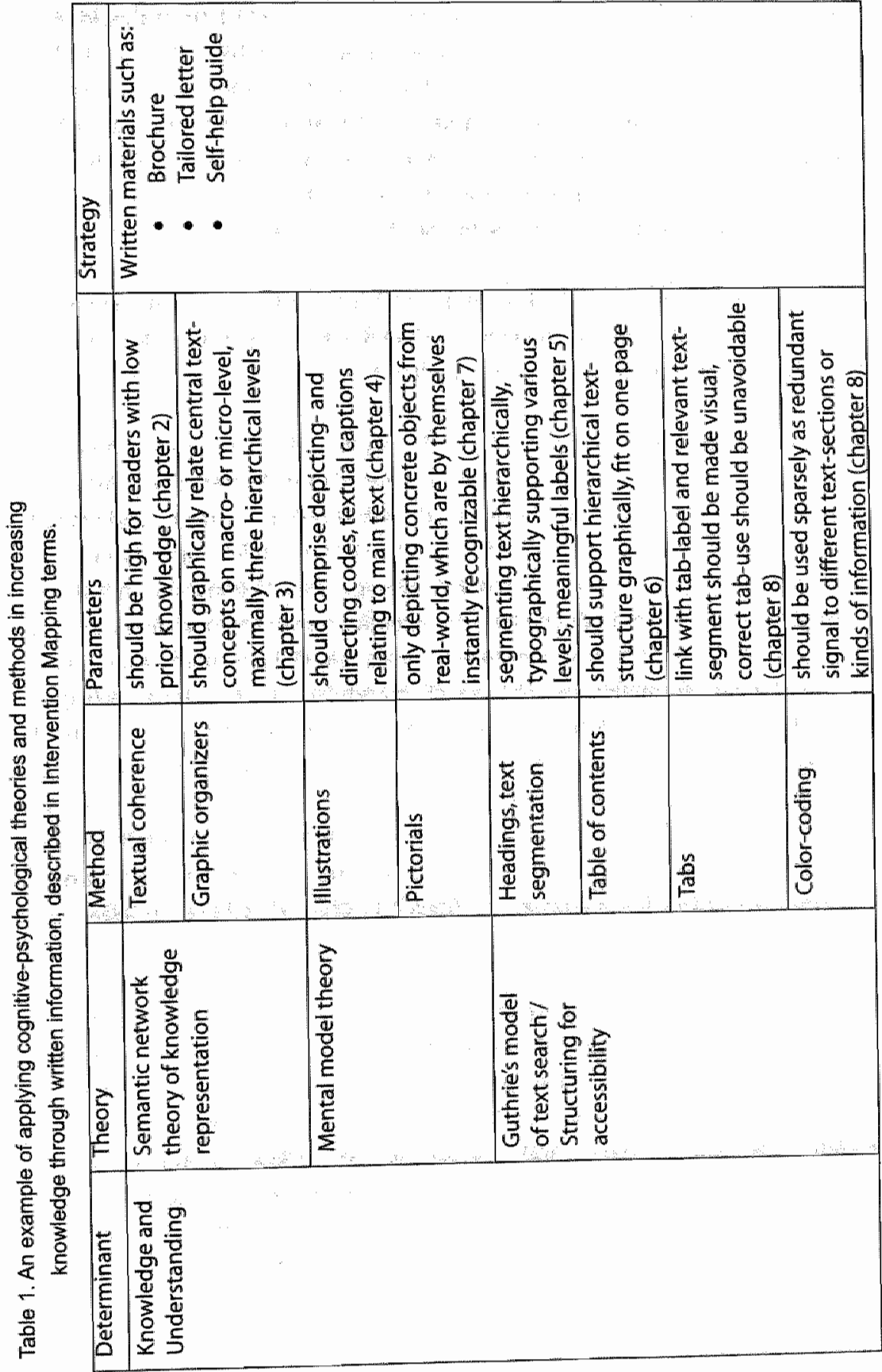


in which practitioners go back and forth between choosing, designing and testing their materials.

\section{Five-step design protocoll}

With regard to the choice for specific design characteristics and their concrete appearance in written materials, a similar approach as taken in the current studies is recommended. It is important to keep in mind that design is an iterative process, in which users should be considered and involved. The protocol below may be followed after the contents of health education materials have been chosen (i.e., when desired health promoting behaviors have been specified). Concerning contents-considerations that are driven by behavioral determinants, practitioners are referred to the intervention Mapping protocol (Barthollomew et al., 2001\%, which provides ample guidance for imaking such decisions. When thinking about the specific design of the messages, the following protocol may be used:

- STEP 1: Health educators should think about the different kinds of information present in their brochure: which information-elements should get most attention, be merely understood, remembered, or acted upon by readers?

Such critical analysis of the text strongly relates to the contents that have been chosen, and what designers expect of their readers after having read the information. For instance, explanations of processes in the body that cause a disease should primarily be understood correctly, medication-use should be performed correctly, factors that lead up to symptoms should be remembered and possibly understood at a deeper level to generalize across different situations. Explicit criteria should be generated this way in terms of the kinds of questions readers should be able to answer, to which extent knowledge of the structure should be gained, what information should be recalled, and so on. These criteria will help in the subsequent design stages when choices need to be made and pretest-outcomes should be interpreted.

- STEP 2: Relevart theoretical insights and empirical findings regarding informationprocessing (i.e., visual perception, memory, comprehension, decision making) such as described in the overview presented above should be gathered and used to select methods to apply in the materials.

As previously indicated, Table 1 summarizes the design characteristics of this thesis that may be considered at this stage. It should be noted that this list is by no means exhaustive; next to the background described in the beginning of this chapter, additional guidelines may be found in the literature. For choosing design features, health education specialists should work together with text writers and designers, aiming at a 'joint consultation', based on a common aim and with open sharing of relevant information (Nijhuis \& Boersema, 1998). Because each specialist may have specific knowledge regarding effects of design features of their expertise, such cooperation heightens the chance that all possibilities for 
design come up for discussion. When understanding content is important, for instance when encountering new information about a health issue, textual coherence is crucial for grasping relations among important concepts, in addition, graphic or visual support may be especially helpful when (unfamiliar) processes are explained. Such features could aid memory for the text as well although when memorization itself is important (for instance of a list of influence-factors, or a sequence of steps to follow), more basic highlighting of such information may suffice.

- STEP 3: Keeping potential problems for readers in mind, health education specialists, text writers, and graphic designers should work together in generating a first draft of the materials.

Realizing which characteristics are typical for members of the target group, that is, their abilities; prior knowledge and the questions they have around the health issue may help to pinpoint potential difficulties for readers with the materials. In collaboration with other specialists, sharing and discussing such knowledge and insights with each other is crucial for justifying suggestions and weighing up different design-options.

- STEP 4: Critical analysis should be performed of the kinds of design features chosen, for instance for a brochure text, keeping in mind understandability of the information and accessibility of the materiais. This may lead to preliminary adjustments to the materials.

Critical analysis of textual coherence and design features may give insight into areas that may be especially problematic for readers, with regard to understanding contents as well as using the Imaterials. Health educators should analyze the materials with both these end results in mind:ignoring the effects of the material's design features on the reading process may cause a sub-optimal transmission of its content. In doing this, members of the target group with minimal cognitive skillis or memory-capacities should be kept in mind. That is, less skilled readers are expected to benefit even more than highly skilled readers from the presence of various signals (Sanchez, Lorch \& Lorch, 2001). Specifically, given the differences reported between high-and low-skilled readers in finding information (Hartley \& Trueman, 1985), in a brochure without clear access structures, less-skilled readers may not be able to find the information at all, and consequently get lost. If readers of health education materials get lost in them and do not get an overview of their main messages, the chance that they will change their behaviour according to those messages is slim. Thus, with extensive brochure materials that readers may not read entirely upon first use, knowing how and where to find specific information may be crucial for finding answers to questions easily. The kinds of insights such as described in the previous section may play a key role in this: multiple design features applied in one health education brochure may ensure a proper understanding in all (kinds of) readers: 
- STEP S: Testing effects of the materfals* contents and design on understanding, accessibility, and possibly general usability with members of the target group.

After having inserted design characteristics to improve the materials on these aspects, the effectiveness should be measured in an ecologically valid way. Although design-specialists may feel strongly about their choices in design, such intuitions may prove deceptive in fact, this confidence in personal skills had been identified as one of the major reasons that pilot-testing with health education materials is not performed and design is not optimal (Gal \& Prigat, 2004), To ensure usable design and detect potential unexpected shortcomings; (pilot or pre-) testing with early versions of the materials with the intended target group is essential. This testing should involve understandability of contents and accessibility of the materialls, i.e, 'outcome'- as well as 'performance" measures. (Adams, 1999). Three kinds of comparisons may be considered in such testing. Fist, early versions of a brochure may be iteratively compared to 'improved' versions in relatively simple two-group experiments. 5 econd, careful consideration of various design options in steps 4 may not have lead to a choice of one over the other, or there may be disagreement among people involved. Both choices (e.g.y kinds of drawings, number of pictures, etc.) may then be developed and compared to each other in a test. Finally, one design may have been agreed upon in step 4. Rather than developing a "lesser" version to compare this to, the draft may be tested in light of the criteria developed in step 1, so the minimal requirements regarding understanding and use of the document. Generally, at this testing-stage, the research methods used in this thesis may be useful.

Regarding comprehension, the most valid way of assessing what readers do and do not understand is asking them with open comprehension questions to explain or apply what they have read. These objective comprehension measures give a true account of the materials' effects on users; something that may not be as straightforward with the more commonly used subjective questions. That is, what readers think of a brochure and what peally is effective with regard to their information-processing may be two different things, as illustrated in this thesis . For instance, graphic organizers were not found to make a difference on subjective estimates of understanding, whereas on the objective measures they did make a difference. Also; participants preferred a highly segmented text with relatively many headings, although on objective search efficienicy these features madie no difference.

Readers attention-allocation and use of health education materials may be tested by observing users with the materials. This may also give valuable insights into which idesign characteristics need further improvement. With observations, each individual situation requires health educators to consider what exactly they want to know about the brochure. The decisions made in step 1 of the process may help in forming a coding scheme of which behaviors should be tallied or logged. Additional subjective evaluations of accessibility and usability may complement the observation data. Subjective measures indicate usersatisfaction with the materials, which may be important to enhance positive evaluation and motivation to read. But again, on their own they may give an incomplete and even biased view. 
Experimental comparisons with 20 to 25 participants per group are required to enable reliable conclusions regarding design effects. It is important to keep in mind here that even small-time differences that are found between such groups may reflect differences in cognitive demands of readers, these differences and their consequences may become much larger in the real world (Wright, 1999). Thus, such testing is strongly recommended In case this is not possible because of time- or cost considerations, we still recommend doing tests with users to optimize brochure design, albeit with a smaller sample. Such pre-testing would then be of a more qualitative nature, assessing from participants' answers to comprehension questions exactly which text- or visual elements are misunderstood. Having participants look up information while thinking aloud, difficuities in use of the materials may be established as well as potential misinterpretations. Research showed that performing user trials with only four or five people may reveal up to $80 \%$ of all potential usability problems with a design (Virzi, 1992). Thus, also with relatively little costs, unsuccessful and costly health education design may be prevented.

\section{Limitations and further research}

The studies described in this thesis were primarily inspired by design characteristics. of three existing health education materials. Individual design characteristics were applied in those materials to assess their contributing value to readers' processing of the information. Although the studies may contribute to health education with regard to design characteristics and testing methods, the studies that lead to these insights were not without limitations, restricting their external validity to some extent. Major limitations will be discussed below and translated into suggestions for further research.

First, an important limitation is that not in all studies participants were drawn from the general, target-population. Thus, the findings with members of a student-population regarding graphic organizers, headings, contents page, and pictorial $s_{r}$ may not be representative for the target population of the health education materials tested. Although basic cognitive theory about people's information processing applies to everyone, students may typically be more experienced users of written materials. This may cause them to use different strategies than people who read and study less (see. e.g., Sanchez, et al., 2001). Nonetheless, the finding that even with such experienced readers, the design-characteristics tested had effects on comprehension and use, strengthens our conviction of the potential value of these features. Novice or less experienced readers may be expected to benefit even more from clear message design than people with higher meta-cognitive skills (Garner, 1987). However, research with members of the generall public is necessary to assess the strength of these effects.

Second, an important general assumption was that attention and comprehension of health education materials are two necessary prerequisites for behavioral change. With an exclusive focus on effects on those two levels, further steps in the process i.e., yielding, retention, and behavior (McGuire, 1985) were not taken into account. Therefore, it remains unclear to what extent improved attention-allocation and comprehension regarding the 
health education materials will ullimately affect behavioral change. A necessary next step would be to study in addition to attention and comprehension participants' yielding and retention, and ultimately behavioral change in the context of changes to the materials design.

Thirdly, because changes to existing materials were tested mostly separately, an obvious next question concerns the combination of changes and their effects on readers processing of the information It remains unclear whether the effects found on comprehension, recall, and usability will add up when combining them in one (different) brochure, or whether they cancel each other out to some extent. A comprehensive study should combine al relevant design characteristics, and in addition to attention- and comprehension components, measure the remaining steps in behavioral change:

Fourthly, a field study could help answer another kind of question that was left out in the present thesis, namely: "How can design features influence what people do and do not attend to or read of a health education brochure?"Starting point in all studies was that readers were inherently interested in the information and would thus read everything, or they had to look up answers to questions given to them by the experimenter. An entirely different issue is whether certain design elements can motivate readers to read more text than they normally would, or can help them find information on the level they choose: themselves. A more natural situation than the lab would be necessary to gain answers to these kinds of questions.

Finally, another limitation of the current studies may be that effects of participants prior knowledge were not studied. As explained in the general introduction, prior knowledge that participants had was controlled for by selection or random assignment. This is because in cognitive psychology, prior knowledge has been found to make a difference for the amount of textual coherence necessary for good understanding in readers. That is, without prior knowledge of a subject, readers benefit from high coherence. However, readers who have prior knowledge on a text subject have been found to benefit from lower coherence and less explicit structuring, because they are then urged to make inferences themselves (McNamara et al, 1996). Especially for deeper levels of understanding, which may be necessary for using and applying the knowledge to everyday situations other than described in the text, lower levels of coherence may enhance understanding. For health education design, this may be important to take into account, as members of the target group may quickly gain knowledge about the health subject they are involved in. It would be important to study to what extent prior knowledge makes a difference for the processing of written health education materials. Although health education practitioners should always adjust their design towards readers with minimall knowledge or cognitive abilities, they should be aware that prior knowledge may change effects, If this is found to be of influence and materials should be different for readers with different knowledge, tailoring information to individual needs not only with regard to contents as is currently done (e.g. Bental, Cawsey, \& Jones, 1999; Brug, Steenhuis, Van Assema, \& de Vries, 1996), but also to individuals" prior knowledge may be a next step towards more effective health education communication. 


\section{Conclusion}

This thesis illustrates how taking another approach towards health education design may generate helpful tools that can be used in practice to (further) improve materials. Both regarding the introduction of specific design elements and methods for testing, a cognitivepsychological viewpoint on material-development has been shown to contribute to effective use and comprehension.

With regard health education research, the present studies fit into a growing awareness that design characteristics of written materials can increase their understandability (see, e.g., Gal \& Prigat, 2004) and that research and testing are important (Dickimson, Raynor, \& Duman, 2001; Gal \& Prigat, 2004; Paul, Redman, \& Sanson-Fisher, 2003). However , health education studies thus far mainly compared combinations of several changes at the same time (Michielutte, Bahnson, Dignan, \& Schrieder, 1992; Paul et alis 2003). Although in practice it may make little difference which exact feature contributed the most to an improved understanding after having designed the materials, we argue that knowledge about individual effects is important when choices for design characteristics have to be made and alternatives should be weighed (for instance because of costs involved). This thesis is a first attempt to learn more about such individual effects. In addition, health education studies oftem use readability formulas for evaluation (Ley, 1988; Michielutte et al., 1992; Payne, Large, Jarrett, \& Turner, 2000) despite their shortcomings in measuring actual understanding in readers (see, e.g., Bailin \& Grafstein, 2001; Duffy, 1985). In a recent publication, Clerehan and her colleagues (Cleheran, Buchbinder, \& Moodie, 2005) also criticized this flawed testing and moved on to a linguistic analysis of written patient information to improve texts. Such an approach is very much in line with what we propose here for health educators to do.

For health education practice as well as for research, thinking in terms of human information-processing and realizing the mechanisms behind comprehension of text and graphics may help generate good ideas for material's design and detect potential shortcomings in an early design stage. In everyday situation, all kinds of factors may hamper the comprehensibility and usability of written materials: goal conflicts among people involved, organizational pressure, wrong assumptions about users and contexts compensating for bad design, overestimations of readers' skills, and lack of pillot-testing (Gal \& Prigat, 2004). Taking into account and applying evidence-based principles such as described in this thesis may take away some of these obstacles and give health educators a more solid backing in the design process. 
Chapter ?

Chapter 2

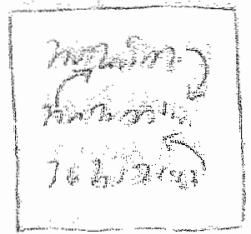

Chapter 3

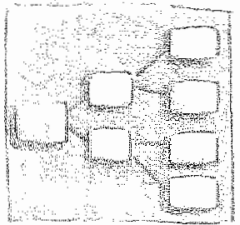

Chaprer 4

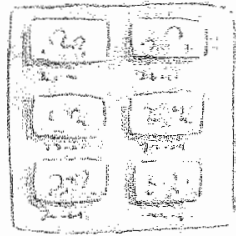

Chapter 5

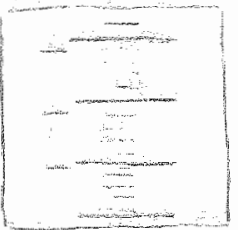

Chapter 6

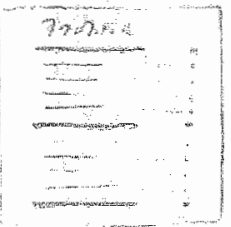

Chaptert

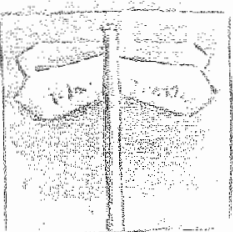

Chapter 8

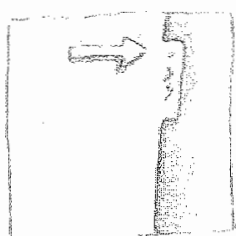

Chapter 9

Summary

Samenvating

References
Genaral introduction

i

Increasmg readers comprehension or

health education brochures. A qualtative

study into how protessional writers make texts coherent

subjective and objective comprehension

of a heath education text

51

Pictures and text in instuctions fo medical devices Efects on recall and actual performance

The efrects of headings in a brief health

67 education text on locating speed and evaluation

Access structures help readers locate and remember information in a health education brochure

The understandability of pictorias in a hedth eduction brochure

Testing the wablity of access structures in heath education brochures

General discusson Implications for heath education practice 
he research in this thesis aimed to test whether health education material design could benefit from cognitive psychology, so that the information is processed more effectively by its readers. Thus far, health education developers especially focused on the contents of health education materials, hereby largely disregarding potential effects of the materials" design on readers. Three existing healtheducation materials serwed as the starting point of the studies: a brochure about asthma, a personal letter about healthier eating habits, and a brochure about healthy dieting. With readers' comprehension and attention-allocation as central areas of interest, design characteristics that have proven effective in cognitivepsychological research were implemented in the health education documents and tested against their original versions. Close examination of the three materials previously developed by health education specialists provided a broad range of design characteristics that could be improved in order to promote their understandability. In total, seven studies were done, regarding textual coherence, graphic support; such as graphic organizers. illustrations, and pictorials, and access structures, such as headings, a contents page, and tabs.

Following Chapter 1, which provides a general introduction, Chapter 2 describes a qualitative study, aimed at gaining insight into the extent to which professional health education text writers apply writing principles derived from cognitive psychological theory. Seventeen professional text writers of health education materials participated in this study, consisting of a rewriting task combined with a think-aloud procedure and a semistructured interview. The verbal data were explored carefully in light of nine text coherence principles that have proven effective in cognitive psychological research to increase text comprehension. Two principles referred to a text's macro level, namely the use of headings and macro signals, and seven related to the micro level of a text, namely argument overlap, ambiguous pronouns, descriptive elaborations, sentence connectives, given-new order, explicit actor; and explicit causality. Findings indicated that text writers vary in their ideas and use of these coherence principles to make a text comprehensible. Although there was consensus about the importance of a clear macro structure, the extent and the way in which the macro structure was changed, varied greatly. On the micro level of the text, similar variation existed regarding whether, how many, and where in the text the writers madie coherence changes, rendering ultimate coherence improvement unpredictable. In addition, the process of rewriting revealed an implicit rather than an explicit awareness in text writers of the effects of various coherence principles in text. It was concluded that the health education profession could benefit greatly from knowledge about cognitive text processing and cognitive coherence principles for realizing effective comprehension of written health education messages.

Chapter 3 describes an experiment in which graphic organizers were developed and systematically inserted into the asthma brochure text, to examine their effects on readers' comprehension of the text. Subjective and objective comprehension measures were taken and compared with each other, to assess their contributing value in measuring comprehension. Graphic organizers are graphical depictions of relations among concepts 
In a text. In a simple two-group between subjects design, participants read a brochure text about asthma with or without these organizers. Subsequently, they received open comprehension questions on four levels: text base macro, text base micro, situation model macro and situation model micro questions. Subjective comprehension assessment was done with closed Likert-scale items. It was found that graphic organizers had positive effects on all four levels of objective comprehension. However, on the subjective comprehension measure, the groups with and without graphic organizers did not differ from each other. It is concluded that health education tex ts could benefit from relatively simple techniques to increase comprehension in readers. Furthermore, in developing health education materials comprehension should be measured more objectively to gain a reliable insight into possible effects:

A second study regarding the asthma brochure is described in Chapter 4 . The original brochure contained two text-only instructions on how to use medical devices, the 'inhaler chamber" and 'peak flow meter'. Based on cognitive-psychological theory on comprehension, both instructions were expected to be suboptimal for understanding. In addition, this effect was expected to be stronger with the inhaler chamber than with the peak flow meter as the latter device was deemed inherently clearer in terms of affordances and constraints. Based on theory into text-picture understanding, both instructions were systematically illustrated with seven line-drawings In two separate between-subject designs, participants' recall, and the quality of their performance with the instruction and device was assessed with five measures extracted from video-recordings. Results showed that especially with the inhaler chamber instruction, the illustrations improved participants' recall and performance on several sub-measures. Also as expected for the peak flow meter instruction these effects were not as strong as with the inhaler chamber. This was in line with our analysis that the inhaler chamber itself was a more ambiguous device and the actions to perform with it involved less common movements of users than the peak flow meter. It was concluded that simple illustrations may contribute to a better understanding of instructions and testing this objectively is necessary to know the extent of the effects.

Chapter 5 focuses on the accessibility of an informative personal letter about healthy eating habits. Although headings are generally known to signal textual content and thus aid accessibility of written documents, it remains unclear how many headings should be used for optimal document use. To examine whether the number of headings and the accompanying segmentation of text would have differential effects on the accessibility of a written health education document, the number of headings was varied systematically. A text-structuring approach called the Information-Mapping method, which typically uses many headings and thus high text-segmentation, on two hierarchical text-levels; was applied to the original health education letter. As this method also entailed changing the order of information somewhat, another text version was designed to control for this: In total, four text versions were designed to control for individual changes: the original letter, $a$ highly segmented imap-version that had been designed by the Dutch imap-centre (IMAPimn), another imap-version designed by the researchers, which adhered to the original informational sequence (IMAP-control), and a control text without any headings. In a 
between-subjects design, effects on search speed and opinions on the text structure were assessed. Results showed that the general presence of headings in a text indeed contributed to an easier access in the search tasks; all three texts with headings resulted in faster search times than the no-headings control version. No differences in search speed were found among the three headings-versions of the text, implying that varying numbers of headings makes no difference for accessibility. It seems that as long as there are headings present, readers are able to locate information relatively easy irrespective of the number of headings and the extent of text-segmentation.

In Chapter 6 the effects of access structures such as a table of contents and main section headings in a brochure on its usability were studied. Both changes were expected to improve the original healthy-diet brochure that lacked a clear table of contents and main section headings. The revised brochure version was compared to the original in a two-group between subjects design. Four different dependent measures were gathered. First, participants' recall of the main sections was assessed right after skimming through the brochure and second, search efficiency was measured by having participants search for 14 items in it. Then, more detailed recall was measured with a card sorting task. Finally, a questionnaire assessed subjective evaluations of the brochure. The revised brochure group showed a better notion of the main brochure structure than the original brochure group on the initial recall-question. Regarding search time, both groups searched equally long. A closer examination of the search-data revealed that this was caused by different strategies used: the original brochure group spent most time paging through the brochure, whereas the revised brochure group spent more time looking at the contents page and then paged to the page selected. After having looked at the contents page, the revised group was faster in finding the search items than the original group. $\mathrm{AlsO}_{\text {n }}$ this group turmed fewer pages during search than the original brochure group, On the card-sorting memory-task, the original brochure group still had a weaker notion of the brochure's main text structure, as shown in an overestimation of the number of main sections and assigning wrong main section titles, compared to participants with the revised brochure. Participants' subjective evaluations of the materials supported the additive value of the presence of both the table of contents and main section headings. Thus, the addition of both access structures improved the brochure's usability compared to the original brochure.

In the study described in Chapter 7 , cognitive psychological findings about concreteness of pictorials and 'depicting' and 'directing codes' in pictorial understanding were applied to the same healthy-diet brochure. The arrow pictorial used in the original brochure was deemed abstract and its function as a reference-indicator incomprehensible. In accordance with cognitive-psychological literature another pictorial (a drawing of a signpost) was developed. In a two-group between-subjects design both pictorials were shown to participants with and without their brocthure-context. As expected, recognition of what the pictorials represented and understanding of their function as indicators of references to other pages was better for the signpost than for the arrow. In addition, the percentage of people that correctly interpreted the function of the arrow pictorial did not meet international standards of understandability, which the signpost did. It was concluded 
that the use of design guidelines and subsequent testing of pictorial information with future readers can contribute to more understandable health education communication.

Chapter 8 describes a cognitive-ergonomic study on the usability of the access structures that the original healthy-diet brochure had. The brochure started with only a few references to main sections and referred readers to other information with referenceparagraphs scattered throughout the brochure text, which were accompanied by an uncommon arrow pictorial. In an attempt to increase the brochure's accessibility, tabs were added, the pictorial was replaced with common arrow-pictorialls behind the references, and color coding was applied In a between-subjects design, the original brochure and three step-wise "improved" versions were compared with regard to their usability. Participants were videotaped while looking up search items and dependent measures relating to search effectiveness, efficiency, and learnability were extracted. In addition, a questionnaire assessed user-satisfaction. Results showed that search effectiveness was highest with the colored tabs-arrows version of the brochure and also the subjective evaluations were in favor of this version. The tabs effectively took over the limited contents page of the original brochure. In line with these findings, a general inferiority of the original brochure's access structure was found on search efficiency, as participants with this version paged, scanned and read more than with any of the tabs-versions of the brochure. Also, subjective evaluation of the pictorials showed that the arrow-pictorial of this original brochure was inferior to the more common arrow-design. The addition of colors to the tabs and arrows contributed to a more usable brochure design, although errors were still madle and learning to use the tabs correctly was still not optimal. Thus, a usability-approach to uncommon brochure-design may give valuable insights for designers of health education materials.

Finally, in Chapter 9 the findings of the studies are discussed, with the aim of providing thealth education practitioners theoretical knowledge and practical guidelines for designing written materials. It is concluded that the current cognitive-psychological approach towards health education design may generate helpful tools that can be used in practice to (further) improve materials. Such tools pertain both to specific design elements that may help readers understand and use the materials as well as methods for testing early versions of materials. An iterative five-step design protocol is suggested, in which at various stages, practitioners may use those insights. Further research is suggested into reader's-and design characteristics to ascertain the specific parameters, or preconditions under which the guidelines suggested are effective. 
Chapter 1

Chapter?

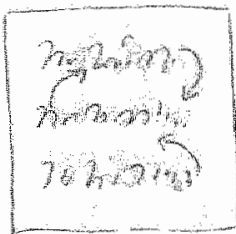

Chapter 3

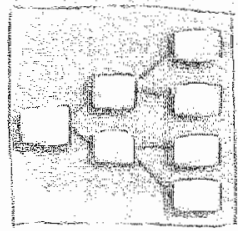

Chapter 4

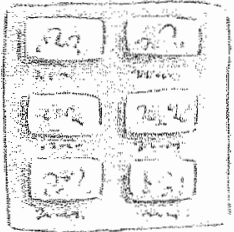

Chapter 5

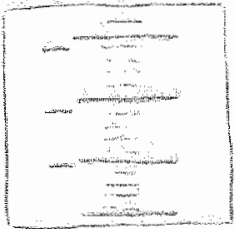

Chapter 6

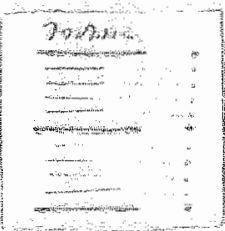

Giapter 7

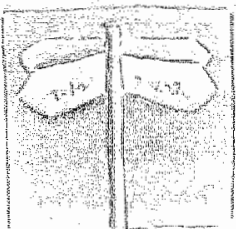

Chapter 8

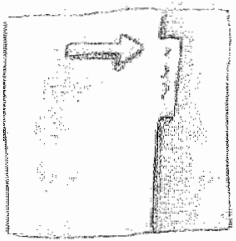

Chapter 9

Summary

Samenvatting

References
General hntroduction

hcreasing readers comptehension of

heath educaton brochures. A qualitative study into how professional whiters male texts coherent

The effect of graphic organizers on

subjective and objective comprehension of a heath education text

Pictures and text in instructions for medical devices: Effects on recall and actual performance

The effects of headings in a briaf health education text on locating sperd and evaluation

Access structures help readers locate and remember infomation in a health eduction brochure

The understandability of pictoriats in a health education brochure

Testing the usability of access structures in heath education brochures

General discussion Implications for health education practice 
$\mathrm{H}_{\mathrm{e}}$

et onderzoek in dit proefschrift had als doel om na te gaan of het ontwerp van gezondheidswoorlichtingsmateriaal profijt kan hebben wan inzichten uit de connitieve psychologie, zodat informatie effectiever verwerkt wordt door lezers. Tot dusver richtten gezondheidsvoorlichters zich vooral op de inhoud van hun materialen, waarbij ze nauwelijks systematische aandacht besteedden aan potentiêle effecten van de wormgeving op lezers. Drie bestaande gezondheidsvoorlichtingsmaterialen dienden als uitgangspunt voor de studies: een brochure over astma, een persoonlijke brief over gezondere eetgewoonten, en een brochume over gezonde voeding. Een kritische kijk naar de drie materialen die door gezondheidsvoorlichtingspecialisten ontwilkeld waren, gaf een groot aantal verschillende vormgevingskenmerken dat verbeterd kon worden am de toegankelijkheid en begrijpelijkheid van de materialen te verhogen. In totaal werden zeven studies uitgevoerd, met betrekking tot tekstuele coherentie, grafische ondersteuning zoals 'graphic organizers'; illustraties en pictogrammen, en toegangsstructuren zoals kopjes, een inhoudsopgave en tabbladen. De algemene procedure die daarbij gevolgd werd, was dat ontwerpkenmerken afkomstig uit de cognitieve psychologisch geïmplementeerd werden in die materialen en vergeleken met de originele versies op metingen van aandacht en begrip.

Na de algemene introductie in Hoofdstuk 1, wordt in Hoofalstuk 2 een kwalitatieve studie beschreven die als doel had inzicht te krijgen in de schriffprincipes die professionelie tekstschrijvers van gezondheidswoorlichtingsmaterialen toepassen, en in welke mate die overeenkomen met cognitief-psychologische theorieën. Zeventien tekstschrijvers namen deel aan deze studie, die bestond uit een herschrijftaak in combinatie met een hardop-denk protocol en een semi-gestructureerd interview. De verbale data werden geanalyseerd en vergeleken met negen coherentieprincipes die in cognitief-psychologisch onderzoek effectief gebleken zijn in het verbeteren van tekstbegrip. Twee principes hadden betrekking op het macroniveau van tekst, namelijk het gebruik van kopjes en macrosignalen, en zeven principes relateerden aan het microniveau, namelijk argument overlap. ambigue voornaamwoorden, beschrijvende uitwerkingen, zinsverbindingen, oud-nieuw volgorde, expliciete actor, en expliciete causaliteit. Tekstschrijvers bleken te verschillen in hun ideeen en toepassing van deze coherentieprincipes om hun teksten begrijpelijk te maken. Hoewel er consensus was over het belang van een duidelike macrostructuur, varieerde de mate en manier waarop de structuur veranderd werd sterk. Op het microtekstniveau bestond aanzienlijke variatie in de mate waarin en de manier waarop de schrijvers coherentieveranderingen aanbrachten, wat ervoor zorgde dat de uiteindelijke coherentieverbetering van de tekst niet te voorspellen was. Daarnaast bleek uilt het proces van herschrijven een impliciet in plaats van een expliciet bewustzijn aanwezig te zijn bij tekstschrijvers over het effect van verschillende coherentieprincipes in de tekst. Geconcludeerd werd dat de gezondheidsvoorlichting baat kan hebben bij meer kennis over cognitieve tekstverwerkingsprocessen en coherentieprincipes om goed begrip van geschreven materialen teweeg te brengen.

In Hoofdstuk 3 wordt een experiment beschreven waarin zogenamde graphic orgamizers' ontwikkeld werden en vervolgens systematisch werden geïmplementeerd 
in de astma-brochuretekst, om het effect te bestuderen op het tekstbegrip bij lezers. 'Graphic organizers' zijn grafische voorstellingen van relaties tussen concepten in een tekst. Subjectieve en objectieve begripsscores werden verzameld en met elkaar vergeleken. In een eenvoudig twee-groepen tussem-proefpersoon experiment lazen deelnemers een brochuretekst over astma met of zonder graphic organizers. Vervolgens kregen ze objectieve begripsvragen op vier nivea us; tekstbasis macro, tekstbas is micro, situatiemodel macro en situatiemodel micro vragen. Subjectieve inschatting wan tekstbegrip werd gemeten met gesloten Likert-schaal items.Graphic organizers bleken een positief effect te hebben op alle vier iniveaus van objectief gemeten tekstbegrip. Op de maat van subjectief tekstbegrip, darentegen, versichilden beide groepen niet van elkaar. Geconcludeerd werd dat het begrip bij lezers van gezondheidswoorlichtingteksten met relatief eenvoudige technieken verbeterd kan worden.Daarnaast zou bij de ontwikkeling van gezondheidsvoorlichtingsmaterialen begrip objectief gemeten moeten worden om een betrouwbaar inzicht te krijgen in mogelijke effecten wan het materiaal op begrip.

Een tweede studie met betrekking tot de astmabrochure wordt beschreven in Hoofdstuk 4. De originele brochure bevatte twee instructies die enkel uit tekst bestonden, voor het gebruik van de zogenaamde 'inhalatiekamer" en de "piekstroommeter' die enikel uit tekst bestonden. Vanuit cognitief-psychologische theorieën over begrip werd verwacht dat beide instructies niet optimaal ontworpen waren. Daarnaast werd verwacht dat dit meer het geval was bij de inhalatiekamer dan bij de piekstroommeter, omdat de laatste als inherent duidelijker werd beoordeeld in termen van functionele eigenschappen en beperkingen, Op basis van theorie over begrip van tekst en plaatjes werden beide instructies systematisch geillustreerd met zeven lijntekeningen. In twee aparte tussen-proefpersonen experimenten werd de herinnering van deelnemers gemeten. Daarnaast werd aan de hand van vijf gedragsmaten de kwaliteit van hun handelingen met de instructie met behulp van video-opnames geanalyseerd: De resultaten toonden aan dat de plaatjes vooral bij de inhalatiekamer-instructie de herinnering en uitwoering van deelnemers verbeterden. Zoals verwacht waren deze effecten niet zo sterk bij de piekstroommeter. Dit kwam overeen met de analyse dat de inhalatiekamer vanuit zichzelf een meer ambigu apparat was en dat de benadigde handelingen minder gangbare bewegingen inhielden voor gebruikers dan de piekstroommeter. Gecondudeerd werd dat eenvoudige illustraties kunnen bijdragen aan een beter begrip van instructies, en dat dit objectief getest moet worden om de grootte van deze effecten in te kunnen schatten.

In Hoofdstuk 5 gaat het om de toegankelijkheid van een informatieve persoonlijke brief over gezonde eetgewoonten. Hoewel algemeen bekend is dat kopjes tekstinhoud aanduiden en dus de toegankelijkheid van geschreven documenten verhogen, is nog onduidelijk hoeveel kopjes gebruikt zouden moeten worden voor optimaal gebruik van geschreven informatie. Om te kijken of het aantal kopjes en de bijgehorende segmentatie van tekst verschillende effecten kunnen hebben op de toegankelijkheid van een geschreven gezondheidsvoorlichtingdocument, werd het aantal kopjes systematisch gevarieerd. Een tekst-structureringsbenadering genaamd de Information-Mapping-methode, die herkenbaar is door haar vele kopjes en dus tekstsegmentatie op twee hiërarchische tekstniveaus, werd 
toegepast op de originele persoonlijke brief. Omdat deze methode ook de volgorde van de informatie enigszins verandert, werd nog een extra tekstverste ontworpen om hiervoor te controleren. In totaal werden vier tekstversies ontworpen om effecten van verschillende veranderingen te kunnen isoleren: de originele brief, een sterk gesegmenteerde imap-versie die was ontworpen door het Nederlandse imap-centrum (IMAP-imn), nog een imap-versie met de originele informatievolgorde, ontworpen door de onderzoekers (IMAP-controle), en een controletekst zonder kopjes. In een tussen-proefpersonen experiment werden effecten van de vier versies op zoeksnelheid en evaluaties van de tekststructuur met elkaar vergeieken. De resultaten gaven aan dat enkel de aanwezigheid van kopjes inderdaad bijdroeg aan een makkelijkere toegang in de zoektaken: alle drie de teksten met kopjes resulteerden in kortere zoektijden dan de controletekst zonder kopjes. Er werden geen verschillen gevonden in zoeksnelheid tussen de drie teksten met kopjes, wat impliceert dat verschillen in het aantal kopjes geen verschil maakt voor de toegankelijkheid van een tekst. Het lijkt erop dat zolang er kopjes aanwezig zijn, lezers goed in staat zijn om informatie te lokaliseren, ongeacht het aantal kopjes en de mate van tekstsegmentatie.

Hoofdstuk 6 beschrijft een studie naar het effect van toegangsstructuren zoals een inhoudsopgave en hoofdstuktitels op het gebruiksgemak van een brochure. Van beide veranderingen werd verwacht dat ze de originele brochure zouden verbeteren, aangezien die geen inhoudsopgave en hoofdstuktitels bevatte. De herziene brochureversie werd vergeleken met de originele in een twee-groepen tussen-proefpersoon experiment met vier afhankelijke maten. Allereerst werd de herinnering vam deelnemers gemeten voor de drie hoofdonderdelen gemeten direct nadat de deelnemers door de brochure hadiden gebladerd hadden. Daarma werd zoekefficiëntie gemeten door deelnemers 14 zoekitems op te laten zoeken in de brochure. Vervolgens werd meer gedetallleerde herinnering gemeten met een kaartsorteertaak. Tenslotte werd de brochure subjectief geëvalueerd met een vragenlijst. De groep met de herziene brochure toonde een betere notie van de hoofdstructuur van de brochure dan de originele brochure groep op de eerste herinneringsvraag. Met bettrekking tot de zoektijden, zochten beide groepen even lang in de brochure. Een nadere analyse vari de zoekdata toonde aan dat dit veroorzaakt werd door verschillen in de gebruikte strategieen: de originele brochure groep besteedde de meeste tijd aan bladeren door de brochure, terwijl deeinemers met de herziene brochure meer tijd besteedden aan het bekijken van de inhoudsopgave, en dan naar de gekozen pagina bladerden. Nadat ze naar de inhoudsopgave hadden gekeken was de groep met de herziene brochure sneller in het vinden van de zoekitems dan de originele-brochure groep. Ook sloegen ze minder bladzijden om tijdens het zoeken dan de originele brochure groep. Op de kaartsorteer-geheugentaak had de originele-brochure groep nog steeds een slechtere notie van de hoofdstructuur van de brochure vergeleken met de deelnemers met de herziene brochure, wat bleek uit een overschatting van het aantal hoofdonderdelen en het kiezen van verkeerde hoofdstuk-titels. De subjectieve evaluatie van de materialen door deelnemers ondersteunde de gevonden toegevoegde waarde van de aanwezigheid van de inhoudsopgave zowel als de hoofdstuktitels. De toevoeging van beide toegangsstructuren verbeterde het gebruiksgemak van de brochure in vergelijking tot de originele versie. 
In de studie die beschreven wordt in Hoofdstuk 7, werden in dezelfde brochure over gezonde voeding cogniitief-psychologische bevindingen over zowel concreetheid van pictogrammen als afbeeldende en sturende'codes' bij het begrijpen ervan, toegepast Het pictogram van een pijt uit de originele brochure werd in een eerste analyse beoordeeld als abstract, en zijn functie als verwijzer naar referenties onbegrijpelijk. In overeenstemming met cognitief-psychologische literatuur werd een ander pictogram (een lijntekening van een wegwijzer) ontwikkeld. In teen twee-groepen experiment werden beide pictogrammen aan deelnemers getoond met en zonder de brochurecontext. Zoals verwacht, was herkenining van wat de pictogrammen voorstelden en begrip van hun functie als verwijzer naar andere pagina's beter voor de wegwijzer dan voor de pijl. Het percentage mensen dat de functie van de pijl correct interpreteerde voldeed niet aam internationale standaarden voor begrijpelijkheid van pictogrammen, wat de wegwijzer wel deed. Geconcludeerd werd dat het gebruik wan richtlijnen en daaropwolgend testen van picturale informatie met toekomstige lezers, bij kan dragen aan meer begrijpelijke gezondheidsvoorlichtingcommuni catie.

Hoofdstuk 8 beschrijft een cognitief-ergonomische studie van gebruilksgemak ("usability") van de toegangsstructuren in de originele brochure over gezonde voeding. De brochure begon met slechts een aantal referenties naar hoofdonderdelen en verwees lezers naar andere informatie met referentieparagrafen verspreid over de brochuretekst, die vergezeld werden door een ongewoon pijl-pictogram. In een poging om de toegankelijkheid van de brochure te verhogen, werden tabbladen toegevoegd, de pictogrammen vervangen door meer gangbare pijl-pictogrammen achter de referenties en werd kleurcodering toegepast. In een tussen-proefpersoon experiment werd de originele brochure vergelleken met drie stapsgewijs verbeterde versies met betrekking tot hun gebruiksgemak. Deelnemers werden opgenomen op video ter wijl ze zoekitems opzochten en waaruit afhankelijke maten met betrekking tot effectiviteit, efficièntie, en leerbaarheid werden geëxtraheerd. Daarnaast werd tevredenheid gemeten met een vragenlijst. De resultaten lieten zien dat effectiviteit het hoogst was met de gekleurde tabbladen-metpijlen versie van de brochure. Ook de subjectieve evaluaties waren in het voordeel van deze versie. De tabbladen namen de beperkte inhoudspagina van de originele brochure over. In overeenstemming met deze bevindingen werd een algemene inferioriteit gevonden van de toegangsstructuren in de originele brochure op zoekefficientie, aangezien deelnemers met deze versie meer bladerden, scanden en lazen dan met de versies met de tabbladen. Daarnaast gaven subjectieve evaluaties aan dat het pij-pictogram van de originele brochure slechter was dan het meer gangbare pijl-ontwerp. De toevoeging van kleuren aan de tabbladen en pijlen droeg bij aan een meer gebruikswriendelijk brochureontwerp, hoewel hiermee ook nog fouten gemaakt werden, en het leren gebruiken van de tabbladen nog steeds niet optimaal was. Kortom, een 'usability'-benadering bij een ongewoon ontwerp van een brochure kan waardevolle inzichten geven aan ontwerpers van gezondheidsvoorlichtin gsmaterialen.

Tot besluit worden in Hoofdstuk 9 de bevindingen van alle studies besproken met als doel om mensen in de praktijk van gezondheidsvoorlichting theoretische kennis 
en praktische richtlijnen te geven voor het ontwerpen van geschreven materialen.

Geconcludeerd wordt dat een cognitief psychologische benadering bij het ontwerpen van schriftelijke voorlichting smaterialen nuttige hulpmiddelen kan voortbrengen die gebruikt kunnen wolden in de praktijk om materialen (verder) te verbeteren Deze hulpmiddelen bestaan uit specifieke ontwerpelementen die lezers kunnen helpen de materialen te begrijpen en gebruiken, alsook uit methoden om eerste ontwerpen van materiallen te testen. Een iteratief wijf-stappen protocol wordt beschreven waran in verschillende fasen deze inzichten gebruilkt kunnen worden in de praktijk Suggesties voor verder onderzoek worden gedaan, in het bijzonder voor onderzoek naar kenmerken van lezers en ontwerp om specifieke parameters, oftewel woorwaarden, vast te stellen waaronder de voorgestelde richtlijnen effectief zijn. 
Chapter 1

Chapter 2

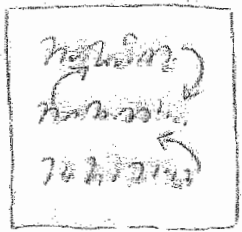

Generalmiroduction

Increastng readers compretuension of

heath education brochures: A qualitative study into how professional witers make texts coherent
Chapter 3

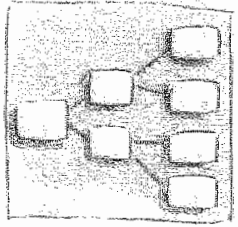

Chapter 4

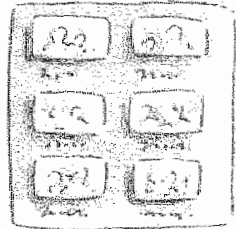

Chapter 5

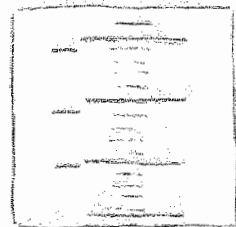

Chapter 6

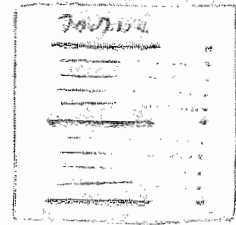

Chapter 7

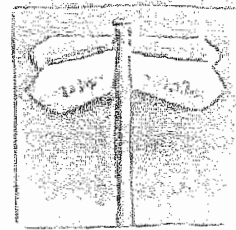

Chapter 8

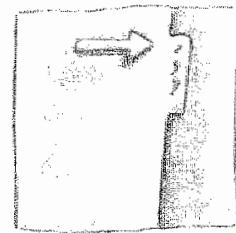

Chapter 9

Summary

Samenvatting

References subjective and objeclive comprehension of a heath education text

medical devices: Effects on recall and actual perfomance education text on locating speed and evaluation

Access structures help readers locate and remember information in a health education brochure

The understandabilly of pictorials in a 99 health education brochure

Testing the usability of access structures. in heath education brochures

General discussion: Implications for health education practice 
Achterberg, C., \& Bradlley, E. (1991). Bulletin features found most and least appealing to an extensive audience. Journal of Nutrition Education, 23,244250 .

Adams, A. (1999). Usability testing in information design. In H. J. G. Zwaga, T. Boersema \& H.C.M. Hoonhout (Eds.), Visual information for everyday use: Design and research perspectives (pp. 3-20). London:Taylor \& Francis.

Ajzen, 1. (1988) . Attitudes personality, and behavior.Chicago:Dorsey.

Albrecht, J. E., \& O'Brien, E. J. (1993). Updating a mental model: Maintaining both local and global coherence. Journal of Experimental Psychology: Learning.Memory, and Cognition, 19, 1061-1070.

Anderson, R.C. (1982). Allocation of attention during reading. In A. Flammer \& W. Kintsch (Eds.), Discourse Processing. New York: North-Holland.

ANSI (1998) American National Standard. Criteria for Safety Symbols. ANSI Z535.3-1998. Rosslym, VA: National Electronical Manufacturers Association.

Ausubel, D.P.(1968). Educational psychology: A cognitive view. New York: Holt, Rinehart, \& Winston.

Baddeley, A. (1997). Human memory: Theory and practice. Bath: Psychology Press Ltd. Baddeley, A. D. (1986). Working memory. Oxford, England: Oxford University Press.

Bailin, A., \& Grafstein, A. (2001). The linguistic assumptions underlying readlability formulae: A critique. Language and Communication, 21, 285-301.

Bandura, A. (1986). Social foundations of thought and action: A social cognitive theory. New York: Prentice Hall.

Barron, R. F. (1969). The use of vocabulary as an advance organizer. In H. L. Herber \& R.T. Vacca (Eds.), Research in reading in the content areas: First year report. Syracuse, New York: Syracuse University Reading and Language Arts Center.

Bartholomew, L. K., Parcel, G. S. Kok, G., \& Gottlieb, N. H. (2001). Intervention mapping: Designing theory-and evidence-based health promotion programs. Mountain View, California: Mayfield Publishing Company.

Beck, C.R. (1984). Visual cueing strategies: Pictorial, textual, and combinational effects. Educational Communication and Technology Journol, 32, 207-216.

Bental, D. S., Cawsey, A. \& Jones, R. (1999). Patient information systems that tailor to the individual. Patient education and counselling, 36, 171-180.

Bernard, R. M. (1990). Effects of processing instructions on the usefulness of a graphic organizer and structural cueing in text. Instructional Science, 19, 207-217.

Biederman, L., Glass, A.L., \& Stacy, E.W. (1973). Searching for objects in real world scenes. Journal of Experimental Psychology, 97, 22-27.

Bieger, G.R. \& Glock, M. D. (1986). Comprehending spatial and contextual information in picture-text instructions. Journal of Experimental Education, 54, 181-188.

Britton, B. K., Glynn, S. M, Meyer, B. J., \& Penland, M. J.(1982). Effects of text structure on use of cognitive capacity during reading. The Jounal of Experimental Psychology, 74, 51-61.

Britton, B. K., \& Gülgöz, S. (1991). Using Kintsch's computational model to improve instructional text: Effects of repairing inference calls on recall and cognitive structures. Journal of Educational Psychology, 83, 329-345. 
Brooks, L. W., Dansereau, D. F, Spurlin, J, E, \& Holley, C. D. (1983). Effects of headings on text processing. Journal of Educational Psychology, $75,292-302$.

Brug, J, Glanz, K, \& Kok, G. (1997). The relationship between self-efficacy, attitudes, intake compared to others, consumption, and stages of change related to fruit and vegetables. American Heath Promation, 12, 25-30.

Brug, J. Steenhuis, I. H. M. van Assema, P, \& de Vries, H. (1996). The impact of a computertallored nutrition intervention. Preventive Medicine, 25, 236-242.

Brugger, C. (1999) Public information symbols: a comparison of 150 testing procedures. In $\mathrm{H}$. J. G. Zwaga, T.Boersema, \& H.C.M. Hoonhout (Eds.), Visual information for everyday use: design and research perspectives. (pp. 305-313). London:Taylor \& Francis Ltd.

Buston, K. (1997). NUD*IST in action: Its use and its usefulness in a study of chronic illness in young people. Sociological Research Online, 2, 1-16.

Byrnes, J. P., \& Guthrie, J.T. (1992). Prior knowledge and textbook search. Contemporary Educational Psychology, 17, 8-29.

Cacioppo, J.T. Petty, R. E., \& Feng Kao, C. (1984). The efficient assessiment of need for cognition. Joumal of Personality Assessment, 48, 306-307.

Cahill, M.C. (1975) Interpretability of graphic symbols as a function of context and experience factors. Journal of Applied Psychology, 60, 376-380.

Carroll, J. M. (1990). The Nurenberg Funnel: Designing minimalist instruction for practical computer skill. Cambridge, MA, US: The MT Press.

Chi, M.T.H.i Hutchinson, J.E., \& Robin, A. F. (1989). How inferences about novel domain-related concepts can be constrained by structured knowledge. Merrill-Palmer Quarterly, 35 , 27-62.

Christ, R. E. (1975). Review and analysis of color coding research for visual displays. Human Factors, 17, 542-570.

Clark,H.H.\& Haviland, S.E. (1977).Comprehension and the Given-New contract.In:R.O. Freedle (Ed.). Discourse Production and Comprehension. (pp. 1-40). Norwood: Ablex.

Clark, K. L., AbuSabha, R., von Eye, A. \& Achterberg, C. (1999). Text and graphics: Manipullating nutrition brochures to maximize recall. Health Education Research, 14, 555-564.

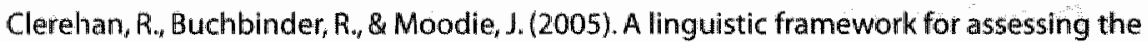
quality of witten patient information: Its use in assessing methotrexate information for meumatoid arthritis. Health Education Research, 20, 334-344.

Commander, N.E., \& Stanwyck, D. J. (1997). Illusion of knowing in adult readers: Effects of reading skill and passage length. Contemporary Educational Psychology, 22, 39-52.

Davidoff, J. (1987). The role of colour in visual displays. International Review of Ergonomics, 1 , $21-42$.

Davies, S. Haines, H., Norris, B., \&Wilson, J. R. (1998). Safety pictograms: Are they getting the message across? Applied Ergonomics, 29, 15-23.

Davis, T. C. Michielutte, R., Askov, E. N., Williams, M. V. \& Weiss, B.D. (1998). Practical assessment of adult literacy in health care. Health Education and Behavior, 25, 613-624. 
Dee-Lucas, D, \& Larkin, J.H. (1995). Learning from electronic texts. effects of interactive overviews for information access. Cognition and instruction, 13,431-468.

Dewar, R. (1999) Design and evaluation of public information symbolls. In H. . G. Zwaga, T. Boersema, \& H.C. M. Hoonhout (Eds.), Visual information for everyday use: design and research perspectives. (pp. 285-303). London: Taylor \& Francis Ltd.

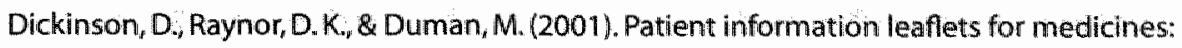
using consumer testing to determine the most effective design. Patient Education and Counseling, 43, 147-159.

Dixon,F.A., \& Glover, J. A. (1990). Another look at number signals and preview sentences. Bulletin of the Psychonomic Society, 28, 287-288.

Doak, L. G., Doak, C.C. \& Meade, C.D. (1996). Strategies to improve cancer education materials. Oncology Nursing Forum, 23, 1305-1312.

Doak, L.G., \& Doak, C.C. (1980). Patient comprehension profiles: recent findings and strategies. Patient Counseling and Health Education, 2, 101-106.

Dreher, M.J. (1993). Reading to locate information: Societal and educational perspectives. Contemporary Educational Psychology, 18, 129-138.

Dreher, M.J. \& Brown, R. F. (1993). Planning prompts and indexed terms in textbook search tasks. Journal of Educational Psychology, 85, 662-669.

Duffy, S. A. (1986). Role of expectations in sentence integration. Journal of Experimental Psychology: Learning, Memory, and Cognition, 12, 208-219.

Duffy, T.M. (1985). Readability formulas: What's the use? In T. M. Duffy \&. R. Waller (Eds.), Designing usable texts (pp. 113-143). Orlando, FL: Academic Press.

Duffy, T. M., \& Waller, R. (1985). Designing Usable Texts. London: Academic Press, Inc.

Duggan, G. B. \& Payne, S. J. (2001). Interleaving reading and acting while following procedural instructions. Journal of Experimental Psychology: Applied, 7, 297-307.

Easterby, R. S. \& Hakiel, S. R. (1981). Field testing of consumer safety signs: the comprehension of pictorially presented messages. Applied Ergonomics, 12, 143-152.

Ericsson, K. A. \& Simon, H. A. (1984). Protocol analysis: Verbal reports as data. Cambridge: MIT Press.

Familant, M. E.\& Detwailer, M.C. (1993). Iconic reference: evolving perspectives and an organizing framework. International Journal of Man-Machine Studies, 38, 705-728.

Filippatou, D. \& Pumfrey, P.D. (1996). Pictures, titles, reading accuracy and reading comprehension: A research review. Educational Reseorch, 38, 259-291.

Flower, L.S.\& Hayes, J.R. (1980). The dynamics of composing: Making plans and juggling constraints. In: Gregg, L. \& Steinberg. E. (Eds.), Cognitive processes in writing. (pp. 3150). New York: Hillsidale.

Gal, I., Prigat, A. (2004). Why organizations continue to create patient information leaflets with readability and usability problems: An explorative study. Health Education Research Advance Access, Dec 21.

Gambrell, L. B. \& Brooks Jawitz, P. (1993). Mental imagery, text illustrations, and children's story comprehension and recall. Reading Research Quarterly, 28, 264-276. 
Ganier $F(2001)$. Processing text and pictures in procedural instructions. information Design Journal: 10, 146-153.

Ganier, F. (2004). Factors affecting the processing of procedural instructions: implications for document design. IEEE Transactions of Professional Communication, 47, 15-26.

Ganier F, Gombert, J. E. \& Foyal, M. (2000). Effets du format de presentation des instructions sur l'apprentissage de procedures a l'aide de documents techniques. Le Travail Humain, 63, 121-152.

Garner, R. (1987). Metacognition and reading comprehension. Westport, CT: Ablex Publishing.

Glanz, K. Rimer, B. K., \& Marcus Lewis, F, (2002). Health behavior and health education: Theory, research, and practice. San Francisco: John Willey \& Sons.

Glenberg, A.M. \& Epstein,W. (1985). Calibration of comprehension.Journal of Experimental Psychology: Learning, Memory, and Cognition, 11, 702-718.

Glenberg, A.M., Wilkinson, A. C, \& Epstein, W. (1982). The illusion of knowing: Failure in the self-assessment of comprehension. Memary and Cognition, 10, 597-602.

Glover, J.A., Dinnel, D. L., Halpain, D. R., \& McKee,T.K. (1988). Effects of across-chapter signals on recall of text. The Journal of Experimental Psychology, 80, 3-15.

Glover, J. A., Harvey, A. Li, \& Corkill, A. J. (1988). Remembering written instructions: tab A goes into slot $C_{\text {, }}$ or does it? British Journal of Educational Psychology, 58, 191-200.

Goldman, 5. R. (1997). Learning from text: Reflections on the past and suggestions for the future. Discourse Processes, 23, 357-398.

Graesser A.C., Millis, K. K. \& Zwaan, R.A. (1997). Discourse comprehension. Annual Review of Psychology, 48, 163-189.

Guri-Rozenblit, 5. (1989). Effects of tree diagram on students' comprehension of main ideas in an expository text with multiple themes. Reading Research Quarterly, 24, 236-247.

Guthrie, J.T.; \& Mosenthal, P. (1987). Literacy as multidimensional: Locating information and reading comprehension. Educational Psychologist, 22, 279-297.

Guthrie, J.T., Britten, T., \& Barker, K. G. (1991). Roles of document structure, cognitive strategy, and awareness in searching for information. Reading Research Quarterly, 26, 300-324.

Guthrie, J.T., Weber, 5. \& Kimmerly, N. (1993). Searching documents:cognitive processes and deficits in understanding graphs tables $_{\star}$ and illustrations. Contemporary Educational Psychology, 18, 185-221.

Gyselinck, V. \& Tardieu, H. The role of illustrations in text comprehension: What, when, for whom, and why? in: van Oostendorp, H.\& Goldman, S. R. (Eds.), The construction of mental representations during reading (pp. 195-218). Mahwah, NU: Lawrence Erlbaum Associliations.

Hacker, D. J. (1998). Self-regulated comprehension during normal reading. In D.J., Hacker J. Dulosky, A. C. Greasser (Eds.), Metacognition in educational theory and practice (pp. 165-191). Mahwah, New York: Lawrence \& Erlbaum.

Hall, R.H. \& Sidio-Hall, M. A. (1994). The effect of collor enthancement on knowledge map processing Journal of Experimental Education, 62, 209-217.

Hannafin, M. J. (1988) The effects of instructional explicitness on learning and error persistence. Contemporary Educational Psychology, 13, 126-132. 
Hartley, 1 (1982). Information Mapping: A Critique. Information Design Joumal, 3, 51-58.

Hartley J. (1985). Designing instructional text. 2nd edition. London, Kogan Page.

Hartley, J. (1995). Is this chapter any use? Methods for evaluating text. In I. R. Wilson \& E. N.

Corlett (Eds.), Evaluation of human work: A practical ergonomics methodology (2nd ed.). (pp. 285-309). Philadelphia, PA, US: Tayllor \& Francis.

Hartley, J. (2004). Designing instructional and informational text. In D. H. Jonassen (Ed.).

Handbook of research on educational communication and technology (pp. 917-947).

Mahwah, Nut. Erlbaum.

Hartley, $\mathcal{L}_{\text {, \& }}$ Trueman, M. (1985). A research strategy for text designers: The role of headings.

Instructional Science, 14, 99-155.

Hayes, J. R. \& Flower, L. S. (1978), On the structure of the writing process. Topics in Language

Disorders, 7, 19-30.

Hegarty, M. (1992) Mental animation: Inferring motion from static displays of mechanical

systems. Journal of Experimental Psychology: Learning. Memory, and Cognition, 18, 1084 1102.

Helander, M. Landawer, T. K., \& Prabhu, P. (1997). Handbook of human-computer interaction:

Elsevier Science B.V.

Hicks, K. E., Bell, J. L. \& Wogalter, M. S. (2003). On the prediction of pictorial comprehension. Paper presented at the Human Factors and Ergonomics Society 47 th Annual Meeting, Denver, Colorado.

Hofman, R., \& van Oostendorp, H. (1999). Cognitive effects of a structural overview in a hypertext. British Journal of Educational Technology, 30, 129-140.

Horn, R. E. (1982). Structuring writing and text design. In D. H. Jonassen (Ed.), The techinology of text. Principles for structuring, designing, and displaying text (pp. 341-376). Englewood Cliffs, New Yersey: Educational Technology Publications.

Horn, R. E.(1992). Clarifying two controversies about information mapping's method. Educational and Training Technology international, 29, 109m117.

Horn, R. E. (1993). Structured writing at twenty-five. Performance and instruction, 32, 11117. Hyöna, l. $_{\text {\& }}$ Lorch, R. F. (2004). Effects of topic theadings on text processing: evidence from adult readers' eye fixation patterns. Learning and Instruction, 14, 131-152.

1509186 (1995) Procedures for the development and testing of public information symbols, Revision 1995. Geneva: International Organization for Standardization.

ISO 9241-11: 1998(E). Ergonomic requirements for office work with visual display terminals (VDTs)-Part 11: Guidance on usability.

Jansen, C., Korzillius, H. lePair, R., \& Roest, M. (2002). Een Information Mapping ${ }^{\text {ei }}$-telkst getest: worden de sterallures waargemaakt? Tijdschrift voor Taalbeheersing, 24, 1-13.

Johnson-Laird, P. N. (1983). Mental models: Toward a cognitive science language, inference, and consciousness. Cambridge, MA: Harvard University Press.

Jonassen, D. H. (1982). Implicit structures in text. In D. H. Jonassen (Ed.), The technology of text. Principles for structuring, designing, and displaying text (pp. 5-13). Englewood Cliffs, New Yersey: Educational Technology Publications. 
Jonassen, D. H., \& Kirschner, P.A. (1982). Explicit techniques for structuring text: in D.H. Jonassen (Ed), The technology of text. Principles for structuring, designing, and displaying text (pp. 123-136). Englewood Cliffs, New Yersey: Educational Technology Publications.

Keyes, E. (1993). Typography, color, and information structure. Technical Communication, 40, $638-654$.

Kiewra, K. A., Dubois, N.F, Christian, D. \& McShane, A. (1988). Providing study notes Relation of three types of notes for review. Jlaurnal of Educational Psychology, 80, 595-597.

Kintsch, W. (1988). The fole of knowledge in discourse comprehension: A constructionintegration model, Psychological Review, 95, 163-182.

Kintsch, W. (1993), Information accretion and reduction in text processing: Inferences. Discourse Processes, 16, 193-202.

Kintsch, W. (1994). Text comprehension, memory, and learning. American Psychologist, 49, 294303.

Kintsch, W. (1994). Text comprehension, memory, and learning. American Psycholagist, 49, 294303.

Kintsch, W. (1998). Comprehension: A paradigm for cognition. New York, NY, US: Cambridge University Press.

Kintsch, W. \& van Dijk, T.A. (1978). Toward a model of text comprehension and production. Psychological Review, 85, 363-394.

Kintsch, W. \& van Dijk $k_{i}$ T.A. (1978). Toward a model of text comprehension and production. Psychological Review, 85, 363-394.

Kintsch, W. \& van Dijk, T. A. (1978). Toward a model of text comprehension and production. Psychological Review, 85, 363-394.

Kirsch, L. S., Jungeblut, A., Jenkins, L, \& Kolstad, A. (1993). Aduit Literacy in America: A First Look at the Findings of the National Adult Literacy Survey. National Center for Education Statistics: Report NCES 1993-275.

Klusewitz, M. A., \& Lorch, R. F. (2000). Effects of headings and familiarity with a text on strategies for searching a text. Memory and Cognition, 28, 667-676.

Kools, M., Ruiter, R.A. C., van de Wiel, M.W. J., \& Kok, G. (2004). Increasing readers" comprehension of health education brochures: $A$ qualitative studly into how professional writers make texts coherent. Health Education and Behawior, 31,720-740.

Kools, M., Wright, P, Ruiter, R. A. C., Van de Wiel, M. W. J., \& Kok, G. (Submitted). The Understandability of Pictorials in a Health Education Brochure. Internal Report, Maastricht University.

Kools, M., Wright, P. Van de Wiel, M. W. J, Ruiter, R. A.C., \& Kok, G. (Submitted). Access structures help readers locate and remember information in a health education brochure. Internal Report, Maastricht University.

Kosslyn, S.M. (1994) Elements of graph design. New York: Freeman.

Kragt, $H_{1}$ (1992). Enhancing industrial performance. London:Taylor \& Francis.

Krull ${ }_{n} R_{1}$ \& Rubens, P. (1986). Effects of color highlighting on user performance with online information. Technical Communication, 33, 268-269. 
Larkin, J. H., \&.Simon, H.A. (1987). Why a diagram is (sometimes) wort th ten thousand words. Cognitive Science, $11,65-99$.

Levie, W.H.\& Lentz, R. (1982). Effects of text illustrations: A review of research. Educational Communication and Technology Journal, 30, 195-232.

Ley, $\mathrm{P} .(1988)$. Communicating with patients: Improwing communication, satisfaction and compliance London: Croom Helm.

Lin, $H$. X., Chaong, Y.Y, \& Salvendy, G. (1997). A proposed index of usability: A method for comparing the relative usability of different software systems. Behaviour and Information Technology, 16, 267-278.

Linderholm, $T_{t,}$ Everson, M. G. van den Broek, P., Mischinski, M. Crittenden, $A_{1,}$ \& Samuels, J. (2000). Effects of causal text revisions on more- and less-skilled readers? comprehension of easy and difficult texts. Cognition and Instruction, 18,525-556.

Loman, N.L. \& Mayer, R.E.(1983). Signaling techniques that increase the understandability of expository prose. Journal of Educational Psychology, $75,402 \times 412$.

Lorch, R.F.(1985). Effects on recall of signals to text organization. Bulletin of the Psychonomic Society, 23, 374-376.

Lorch, R. F. (1989) Text-signaling devices and their effects on reading and memory processes. Educational Psychology Review, 1, 209-234.

Lorch, R. F. (1989). Text-signaling devices and their effects on reading and memory processes. Educational Psychology Review, 1, 209-234.

Lorch, R. E, \&. Lorch, E. P. (1985). Topic structure representation and text recall. Journal of Educational Psychology, 77, 137-148.

Lorch, R. F., Jr., \& Lorch, E. P. (1996). Effects of headings on text recall and summarization. Contemporary Educational Psychology, 21, 261-278.

Lorch, R. F,, Jr., Lorch, E. P., Ritchey, K., McGovern, L., \& Coleman, D. (2001). Effects of headings on text summarization. Contemporary Educational Psychology, 26, 171-191.

Lorch, R. F, Lorch, E. P. \& Inman, W. E. ("993). Effects of signaling topic structure on text recall. Journal of Educational Psychology, 85, 281-290.

Lorch, R. F, Lorch, E. P. \& Matthews, P. D. (1985). On-line processing of the topic structure of a text. Journal of Memory and Language, 24, 350-36.2.

Mannes, 5. M., \& Kintsch; W. (1987). Knowledge organization and text organization. Cognition and Instruction, 4,91-115.

Mayer, R. E. (1989). Models for understanding. Review of Educational Research 59, 43-64.

Mayer, R. E. (1989). Systematic thinking fostered by illustrations in scientific text. Journal of Educational Psychology, 81, 240-246.

Mayer, R. E. (1997). Multimedia learning: Are we asking the right questions? Educational Psychologist, 32, 1-19.

Mayer, R. E, \& Sims, V.K. (1994). For whom is a picture worth a thousand words? Extensions of a dual-coding theory of multimedia learning. Journal of Educational Psychology, 86. 389-401. 
Mayer, R, E, Steinhoff, K, Bower, G. \& Mars, R. (1995). A generative theory of textbook design: Using aninotated illustrations to foster meaningful learning of science text. Educational Technology Research and Development; 43, 31-43.

MicDouglas, S. I. P. de Bruijn, O. and Curry, M. B. (2000). Exploring the effects of icon characteristics on user performance: the role of icon concreteness, complexity $y_{i}$ and distinctiveness Journal of Experimental Psychology: Applied, 6, 291-306.

McGoldrick, J, $A_{s}$ Martin, J, Bergering, $A_{0},{ }_{3}$ \& Symons, 5 (1992). Locating discrete information in text: Effects of computer presentation and menu formatting. Journal of Reading Behavior, $24,1-20$.

McGuire, W. J. (1972) Attitude Change:The Information Processing Paradigm. In C.G.Clintock (Ed.) Experimental Social Psychology. New York: Holt, Rinehart \& Winston.

McGuire, W. J. (1985). Attitudes and attitude change. In M. Lindsay \& E. Aronson (Eds.), The handbook of sacial psychology (Vol. 2, pp. 233-346). New York: Random House.

McLelland I. (1995). Product assessment and user trials. In J. R. Wilson \& E. N. Corlett (Eds.), Evaluation of human work (pp. 249-284). London:Taylor \& Francis.

McNamara, D. S., Kintsch, E., Songer, N. B., \& Kintsch, W. (1996). Are good texts always better? Interactions of text coherence, background knowledge, and levels of understanding in learning from text. Cognition and instruction, 14, 1-43.

Medin, D. L., Goldstone, R. L., \& Gentner, D. (1993). Respects of similarity. Psychological Review, $100,254-278$.

Mesters, I., Meertens, R., Kok, G. \& Parcel, G. S (1994). Effectiveness of a multidisciplinary education protocol in children with asthma (0-4 years) in primary health care. Journal of Asthma, 31, 347-359.

Michielutte, R., Bahnison, J. Dignan, M. B., \& Schrieder, E. M. (1992). The use of illustrative and narrative text style to improve readability of a health education brochure. Journal of Cancer Education, 7, 251-260.

Mishra, R. C. (1982) Perception and comprehension of some pictorial symbols as a function of familiarity and nature of depicted objects. Perceptual and Mator Skils, 55, 962.

Moore, D.W $W_{4}$ \& Readance, J.E. (1984). A quantitative and qualitative review of graphic organizer research. Journal of Educational Research, 78, 11-17.

Moreno R. \& Mayer, R. E. (1999). Cognitive principles of multimedia learning: The role of modality and contiguity. Journal of Educational Psychology, 91, 358-368.

Morrell, R. W. \& Park, D.C. (1993). The effects of age, illustrations, and task variables on the performance of procedural assembly tasks. Psychology and Aging, 8, 389-399.

Neisser, U. (1967). Cognitive Psychology. East Norwalk, CT, US: Appleton-Century-Crofts.

Nijhuis, W., \& Boersema, T. (1999). Cooperation between graphic designers and applied behavioral researchers. In H.J.G.Zwaga,T. Boersema, \& H.C.M. Hoonhout (Eds), Visual information for everyday use: Design and research perspectives. London:Taylor \& Francis.

Nisbett, R. E, \& Wilson, T.D. (1977). Telling more than we can know:Verbal reports on mental processes. Psychological Review, 84, 231-259. 
Noordman, L. G.M.; \& Vonk, W. (1998). Memory-based processing in understanding causal information. Discourse Processes, 26, 1911-212.

Norman, D. (1988). The psychopathology of everyday things, in: Norman D, Ed. The Psychology of Everyday Things. New York: Basic Books, 1-33.

O'Donnell, A. (1993). Searching for information in knowledge maps and texts. Comtemporary Educational Psychology, 18, 222-239.

Olmstead, W.T. (1999). The usability of symbols for health care facilities: the effects of culture, gender and age. In H.J.G.Zwaga ${ }$ T. Boersema, \& H. C. M. Hoonhout (Eds.), Visual information for everyday use: design and research perspectives, (pp 315-320). London: Taylor \& Francis Ltd.

Otero, J. (1998). Influence of knowledge activation and context on comprehension monitoring of science texts. in D. J. Hacker, J. Dulosky, \& A. C. Greasser (Eds.), Metacognition in educational theory and practice, (pp. 145-164). Malhwah, New York: Lawrence \& Erlbaum.

Otero, $J_{.,} \&$ Kintsch, W. (1992). Faillures to detect contradictions in a text: What readers believe versus what they read. Psychological Science $3,229-235$.

Paul, C. L. Redman, S., \& Sanson-Fisher, R.W. (2003). Print material content and design: is it relevant to effectiveness? Health Education and Research, 18, 181-190.

Payne, S., Large, S., Jarrett, N., \& Turner, P. (2000). Written information given to patients and families by palliative care units: a national survey. Lancet, $355,1792$.

Petterson, R. (2000). Atterition. Document Design, 2, 114-130.

Prochaska, J. O, \& DiClemente, C.C. (1984). The transtheoretical approach: crossing traditional boundaries of therapy. Homewood, IL: Dow Jones-Irwin.

Reynolds; R. E. \& Shirey, L.L. (1988). The role of attention in studying and learning. In C.E. Weinstein, E.T. Goetz \& P. A. Alexander (Eds.), Learning and study strategies: /ssues in assessment, instruction, and evaluation (Vol, xvii, pp. 77-100). San Diego, CA, US: Academic Press, Inc.

Reynollas, R. E., Trathen, W., Sawyer, M. L. \& Shepard, C. (1993). Causal and epiphenomenal use of the selective attention strategy in prose comprehension. Contemporary Educational Psychology, 18, 258-278.

Pice, G. E., Meyer, B. J. \& Miller, D. C. (1989). Using text structure to improve older adults' recall of important medical information. Educational Gerontology, $15,527-542$.

Robinson, R.D., \& Kiewra, K.A. (1995). Visual argument: graphic organizers are superior to outlines in improving learning from text. Journal of Educational Psychology, 87,455467.

Robinson, R. D. \& Schraw, G. (1994). Computational efficiency through visual argument: do graphic organizers communicate relations in text too effectively? Contemporary Educational Psychology, 19, 399-415.

Robinson, R:D., \& Skinner, C. H. (1996). Why graphic organizers facilitate search processes: fewer words or computationally efficient indexing? Contemporary Educational Psychology, 21, 166-180. 
Robinson, R. D, Katayama, A.D., Dubois, N.F, \& Devaney, T. (1998). Interactive effects of graphic organizers and delayed review on concept application. The Joumal of Expenimental Education, 67,1731 .

Rogers, R.W. (1983). Cognitive and physiological processes in fear appeals and attitude change: A revised theory of protection motivation. In I. T. Cacioppo \& R.E. Petty (Eds), Social psychophysiology: A sourcebook (pp. 153-176) New York: Guilford Press.

Rouet, , F, Vidal Abarca, E, Erboul A. B. \& Millogo, V. (2001). Effects of information search tasks on the comprehenision of instructional text. Discourse Processes, 31, 163-186.

Sadoski, M, Goetz, E. T \& Fritz, J B (1993). Impact of concreteness on comprehensibility, interest, and memory for text: Implications for dual coding theory and text design. Journal of Educational Pyychology, 85, 291-304.

Sanchez R. P. Lorch, E. P. \& Lorch, $\|_{s}$, R.F. (2001). Effects of headings on text processing strategles: Contemporary Educational Psychology, $26,418-428$.

Sanders, T. J., Spooren, W. P., \& Noordman L. G. (1992). Toward a taxonomy of coherence relations. Discourse Processes, 15, 1-35.

Sanders, T. J.M. \& Noordman, L. G. M. (2000). The role of coherence relations and their linguistic markers in text processing. Discourse Processes, 29, 37-60.

Schnotz, W. \& Bannert, M. (1999). Einfluesse der Visualisierungsform auf die Konstruktion mentaler Modelle beim Text- und Bildverstehen./ Influence of the type of visualization on the construction of mental models during picture and text comprehension. Zeitschrift für Experimentelle Psychologie, 46, 217-236.

Schommer, $M$, \& Surber, JR. (1986). Comprehension-monitoring failure in skilled adult readers. Journal of Educational Psychology, 78, 353-357.

Shapiro, A. M. (1999). The relevance of hierarchies to learning biology from hypertext. The Journal of the Learning Sciences, 8; 215-243.

Shepherd, S. K., Sims, L. S, Cronin, F. J., Shaw, A., \& Davis, C. A. (1989). Use of focus groups to explore consumers' preferences for content and graphic design of nutrition publications. Jownal of the American Dietetic Association, 89, 1612-1614.

Sojourner, R. J. \& Wogalter, M.S. (1998). The influence of pictorials on the comprehension and recall of pharmaceutical safety and warning information. International Journal of Cognitive Ergonomics, 2, 93-106.

Steenhuils, I. H. M., van Assema, P., \& Reubsaet, A. (2000). Eet smakelijk, eet gezond: evaluatie van een zelfhulpgids. Tijdschrift Sociale Gezondheidszorg, 78, 412-418.

Stone, D. E. \& Glock, M.D. (1981). How do young adults read directions with and without pictures? Journal of Educational Psychology, 73, 419-426.

Tabachnick, B. G. \& Fidell, L.S, (2000). Conditioning matrices: Cleaning up your act before analyzing your data: In B. G. Tabachnick \& L. S. Fidell (Eds.), Using multivariate statistics (pp.66-85). Boston: Allyn \& Bacon.

Trabasso, T, Secco, T., \& Broek, P.V.D. (1984), Causal cohesion and story coherence. In H: Mandl, N. L. Stein, T.Trabasso (Eds.), Learning and comprehension of text (pp. 83-111): Hillsdale, NJ: Erlbaum. 
Van der Meij, H. \& Carroll, J.M. (1995). Principles and heuristics for designing minimalist instruction. Technical communication, 42, 243-261.

Van Dijk, T.A. \& Kintsch, W. (1983), Observations on the status of experimental research on discourse comprehension in T. A. wan Dijk \& W. Kintsch (Eds.), Strategies of discourse comprehension (pp. 21-60). New York Academic press, inc.

Vandyck, I.J. J. (2004). Gezondheidswoorlichting vanuit gvo- en cognitief psychologisch perspectief Unpublished Master thesis, Maastricht University.

Van Hout-Wolters, B. \& Kerstjens, W. M. J. (1990). Het gebruik van kleurendruk bij zoektaken in schriftelijk studiemateriaal. Tijdschrift woor Onderwijsresearch, 15, 347-354.

Vekiri, 1. (2002). What is the value of graphical displays in learning? Educational Psychology Review, 14,261-312.

Vidal Abarca, E. (1992). Important information in expository prose: The role of awareness of textual structure and of the skill in ranking ideas in a text. In: B. van Hout-Wolters \& W. Schnotz (Eds.), Text comprehension and learning from text (pp. 35-52). Amsterdam: Swets \& Zeitlinger.

Virzi, R.A. (1992). Refining the test Phase of Usability evaluation: how many subjects is enough? Human Factors, 34, 457-468.

Wallace, D. S., West, S.W.C., Ware, A., \& Dansereau, D.F. (1998). The effect of knowledge maps that incorporate gestalt principles on learning. The Journal of Experimental Education, $67,5-16$.

Waller, R. (1979). Typographic access structures for educational texts. In P.A. Kolers, M. E. Wrolstad \& H. Bouma (Eds.), Processing of visible language (Vol. 1,pp. 175-188). New York: Plenum.

Waller, R. (1982). Text as diagram: Using typography to improve access and understanding. In D. H. Jonassen (Ed.), The technology of text. Principles for structuring, designing, and displaying text (pp. 137*166). Englewood Cliffs, New Yersey: Educational Technology Publications.

Waller, R., \&halley, P. (1987). Graphically organised prose, Leaming and Instruction, 1,369 381.

Wan, Ex, Robertson, P.,Brook, J. Bruce, 5., \& Armitaige, K. (1999). Retaining hyperlinks in printed hypermedia documents. Computer Networks, 31, 1509-1524.

Weidenmann, B. (1994) Codes of instructional pictures. In W. Schnotz \& R. W. Kulhavy (Eds.), Comprehension of graphics (pp. 29-42). Elsevier Science B.V.

Withite, S.C.(1988). Reading for a multiple-choice test: Headings as $\$ c$ hema activators. Journat of Reading Behavior, 20, 215-228.

Wilhite, S.C. (1986). The relationship of headings, questions, and locus of control to multiplechoice test performance. Journal of Reading Behavior, 18, 23-40.

Wilson, J.R. \& Corlett, E. N. (1995). Evaluation of human work: A practical ergonomics methodology. London:Taylor \& Francis.

Winn,W. (1994). Contributions of perceptual and cognitive processes to the compreherision of graphics. In W. Schnotz \& R. W. Kulhavy (Eds.), Comprehension of graphics (pp. 3-27). Amsterdam: North-Holland. 
Wogalter, M. S. (1999). Factors influencing the effectiveness of wamings. In H. J. G. Zwaga, T. Boersema \& H.C.M. Hoonhout (Eds.), Visual information for everyday use. Design and research perspectives (pp.93 110). London: Taylor \& Francis Ltd.

Wogalter, M. S B Begley, P. B., Scancorelli, L.F. and Brelsford, J.W. (1997) Effectiveness of elevator service signs: Measurement of perceived understandability, willingness to comply and behaviour. Applied Ergonomics, 28, $181-187$.

Wogalter, M. S, Sojourner, R, J, \& Brelsford, J.W. (1997). Comprehension and retention af safety pictorials. Ergonomics, $40,531-542$.

Wolff, IS. \& Wogalter, M. S. (1998). Comprehension of pictorial symbolsteffects of context and test method Human Factors, 40, 173-186.

Wright, P. (1977). Presenting technical information: A survey of research findings. Instructional Science, $6,93-134$.

Wright, P.(1988). The need for theories of NOT reading: Some psychological aspects of the human-computer interface. In B. Elsendoorn \& H.Bouma (Eds.), Working mode/s of human perception (pp. 319-340). London: Academic Press.

Wright, P. (1999). Designing healthcare advice for the public. in F.T. Durso, R. S. Nickerson, R. W. Schvaneveldt, S.T. Dumais, D. S. Lindsay \& M. T. H. Chi (Eds.), Handbook of Applied Cognition (pp. 696-460). New York: John Wiley \& Sons Ltd.

Wright, P., $_{2}$ Lickorish, A. (1988). Colour cues as location aids in lengthy texts on screen and paper. Behaviour and Information Technology, 7, 11-30.

Young, S. L. and Wogaiter, M. S. (1990) Comprehension and memory of instruction manual warnings: Conspicuous print and pictorial icons. Human Factors, 32, 637-649.

Vussen, S. R., Stright, A.D. \& Payne, B. (1993). Where is it? Searching for information in a college textbook. Contemporary Educational Psychology, 18; 240-257.

Zwaga, H.J.G.\& Boersema, T. (1983) Evaluation of a set of graphic symbols. Applied Ergonomics, 14, 43-54. 


\section{Curriculum Vitae}

Marieke was born in Breda on July 20th 1978. With her father being in the NATO-airforce she grew up in Stolzenau, Germany. After returning to the Netherlands in 1990 she graduated secondary school (Atheneum) in 1996 at the Rombouts College in Brunssum. in September 1996, Marieke started studying psychology at Maastricht University. In 1999, she spent four months in Oulu, Finland, for education. In March 2001, Marieke graduated in cognitive ergonomics and educational psychology, after which she started her PhD-studies at the Faculty of Psychology at Maastricht University. From September 2003 until April 2004 she spent six months of her PhD at Cardiff University, Wales. Since September 2005 she works as assistant professor at Maastricht University.

\section{Published:}

Kools, M. (2002). Cognitief [tekst-]begrip als leidraad voor coherente teksten. Tekstblad], september 2002, 10-15.

Kools, M. Ruiter, R. A. C., Van de Wiel, M. W. J, \& Kok, G (2004). Increasing readers comprehension of health education texts: A qualitative study into how professional writers make texts coherent. Health Education \& Behavior, 31, 720-740.

Kools, M., Van de Wiel, M.W.J., Ruiter, R. A.C., Crüts, A.r \& Kok, G. The effect of graphic organizers on subjective and objective comprehension of a health education text. Health Education \& Behavior, In press.

Koolls, M., Van de Wiel, M.W. J., Ruiter , R. A.C., \& Kok, G. Pictures and text in instructions for medical devices: Effects on recall and actual performance. Patient Education \& Counseling, In press.

Visschers, V.H. M. Ruiter, R. A. C., Kools, M. \& Meertens, R. M. (2004), The effects of warnings and an educational brochure on computer working posture: $A$ test of the $C-H I P$ model in the context of RSI-relevant behaviour. Ergonomics, 47, 1484-1498.

\section{Submitted:}

Kools, M.t Ruiter, R. A.C., Van de Wiel, M. W.J., \& Kok, G. The effects of headings in a brief health education text on locating speed and evaluation.

Kools, M., Wright, P., Van de Wiel, M.W. J., Ruiter, R. A. C., \& Kok, G. Access structures help readers locate and remember information in a health education brochure.

Kools, M., Wright, P., Ruiter, R. A.C., Van de Wiel, M. W. 1., \& Kok, G. The understandability of pictorials in a health education brochure.

Kools, M. Ruiter, R. A.C., Van de Wiel, M. W. J., \& Kok, G. Testing the usability of access structures in health education brochures. 